INSTITUTO DE PESQUISAS ENERGÉTICAS E NUCLEARES

Autarquia associada à Universidade de São Paulo

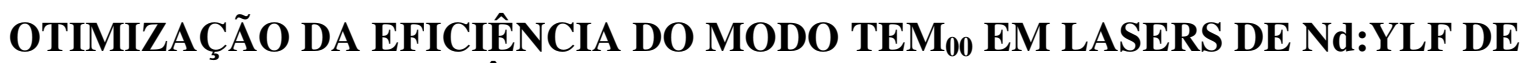
ALTA POTÊNCIA BOMBEADOS LATERALMENTE

\section{EDUARDO COLOMBO SOUSA}

Dissertação apresentada como parte dos requisitos para a obtenção do grau de Mestre em Ciências na Área de Tecnologia Nuclear - Materiais.

Orientador:

Dr. Niklaus Ursus Wetter 
INSTITUTO DE PESQUISAS ENERGÉTICAS E NUCLEARES

Autarquia associada à Universidade de São Paulo

\section{OTIMIZAÇÃO DA EFICIÊNCIA DO MODO TEM ${ }_{00}$ EM LASERS DE Nd:YLF DE} ALTA POTÊNCIA BOMBEADOS LATERALMENTE

\section{EDUARDO COLOMBO SOUSA}

Dissertação apresentada como parte dos requisitos para a obtenção do grau de Mestre em Ciências na Área de Tecnologia Nuclear - Materiais.

Orientador:

Dr. Niklaus Ursus Wetter 
À minha família pelo apoio e carinho incessantes. 
AGRADECIMENTOS

Ao Dr. Niklaus Ursus Wetter por todo o conhecimento transmitido.

Aos companheiros de laboratório Fabíola, Jonas, Marco, Alessandro, Paulo e Ilka pelo apoio em todos os momentos e à amizade conquistada.

Aos amigos da FATEC Daniel, Douglas e Rogério.

A todos os colegas bolsistas do CLA pela amizade e convívio.

À FAPESP pelo apoio financeiro e à bolsa concedida.

A toda a equipe de funcionários do CLA pela ajuda constante.

E um agradecimento especial a minha família e amigos, que sempre estiveram ao meu lado. 


\title{
OTIMIZAÇÃO DA EFICIÊNCIA DO MODO TEM To EM LASERS DE Nd:YLF DE ALTA POTÊNCIA BOMBEADOS LATERALMENTE
}

\author{
EDUARDO COLOMBO SOUSA
}

\section{RESUMO}

Para muitas aplicações de um laser, é necessário um feixe com boa qualidade no modo fundamental. Neste trabalho são investigadas as condições para se obter alta eficiência e qualidade do feixe, otimizando o acoplamento do modo fundamental com a região do meio ativo excitada pelo bombeamento, por meio da utilização de cavidades inovadoras. A maior eficiência já reportada para um laser de Nd:YLF com oscilação em $1053 \mathrm{~nm}$ sob bombeamento transversal por diodo é demonstrada usando uma cavidade compacta baseada em uma reflexão interna total na face de bombeamento, obtendo-se uma potência máxima de saída multimodo de $9,5 \mathrm{~W}$ para $21 \mathrm{~W}$ de bombeamento, o que corresponde a $45 \%$ de conversão óptica. Uma melhora significativa na qualidade do feixe é demonstrada por meio do desenvolvimento de uma cavidade com duas reflexões no meio ativo, obtendo-se uma potência máxima no modo fundamental de $6,9 \mathrm{~W}$ com fator de qualidade $\mathrm{M}^{2}$ do feixe igual a 1,16 x 1,05 nas direções horizontal e vertical, respectivamente. 


\title{
TEM $_{00}$ MODE EFFICIENCY ENHANCEMENT IN HIGH POWER DIODE-SIDE- PUMPED Nd:YLF LASERS
}

\section{EDUARDO COLOMBO SOUSA}

\begin{abstract}
For many laser applications high beam quality in fundamental mode is necessary. In this work we study the conditions that achieve high efficiency and high beam quality by optimizing the overlap between the fundamental mode and the excited region inside the active medium, using novel cavities. The highest efficiency reported so far for diode side pumped $1053 \mathrm{~nm} \mathrm{Nd:YLF}$ lasers is demonstrated using a compact cavity design based on total internal reflection at the pumped face, obtaining a maximum output power of $9,5 \mathrm{~W}$ in multimode operation for $21 \mathrm{~W}$ of pump power, which represents $45 \%$ of optical efficiency. Beam quality improvement is demonstrated using a cavity with two bounces at the active medium, achieving a maximum output power of $6,9 \mathrm{~W}$ during fundamental operation with $\mathrm{M}^{2}$ beam quality factor of $1,16 \times 1,05$ in the horizontal and vertical directions, respectively.
\end{abstract}


Página

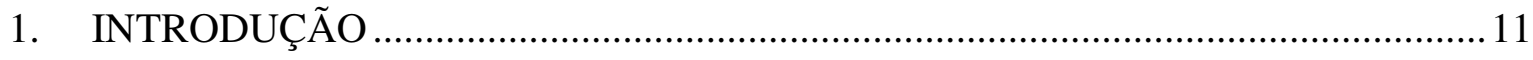

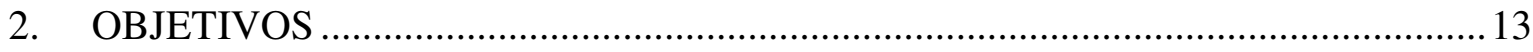

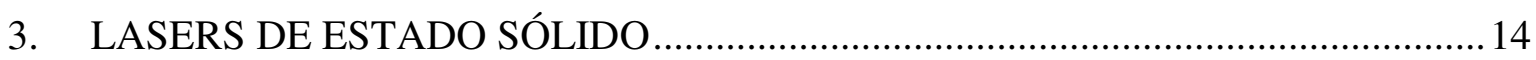

3.1 Dinâmica da população do meio ativo ................................................................ 14

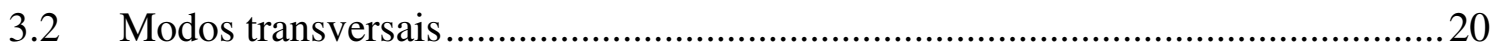

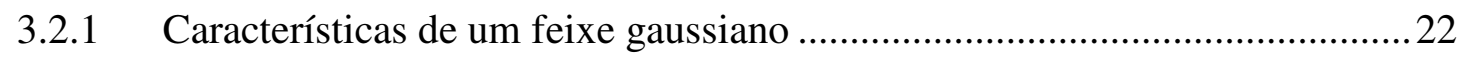

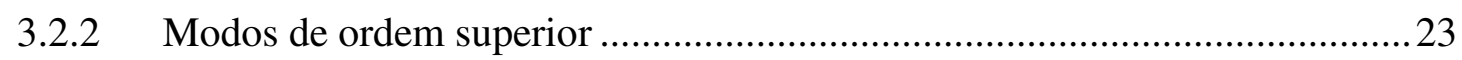

3.2.3 Distribuição de intensidade do modo TEM $_{00}$................................................2 24

3.2.4 Distribuição de intensidade do modo $\mathrm{TEM}_{10}$...............................................26

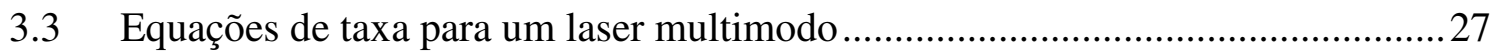

3.4 Solução analítica do limiar de oscilação para modos transversais isolados...........31

3.4.1 Limiar do modo TEM $_{00}$ sob bombeamento lateral ........................................ 31

3.4.2 Limiar do modo $\mathrm{TEM}_{10}$ sob bombeamento lateral ........................................33

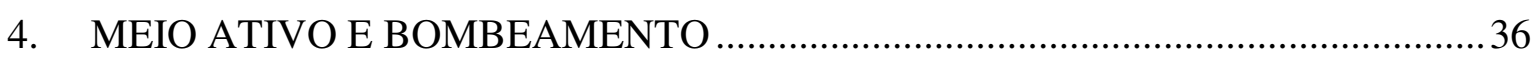

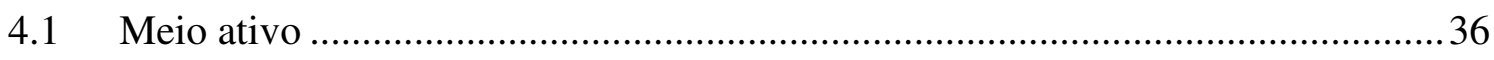

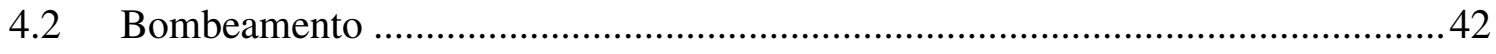

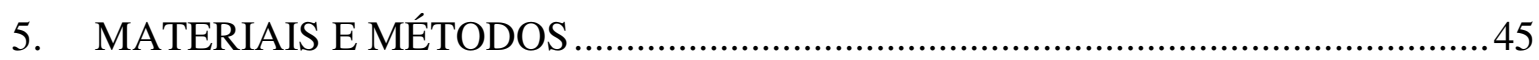

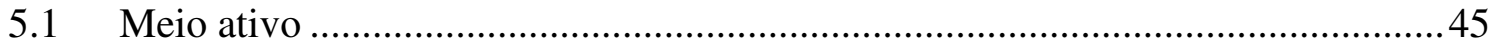

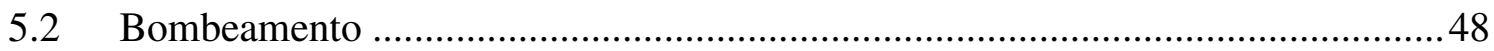

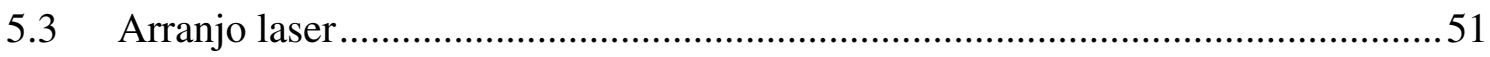

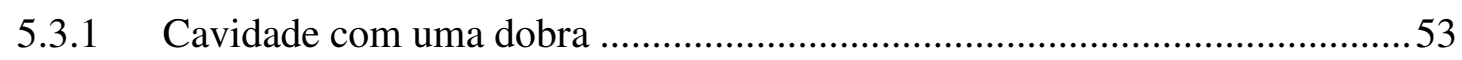

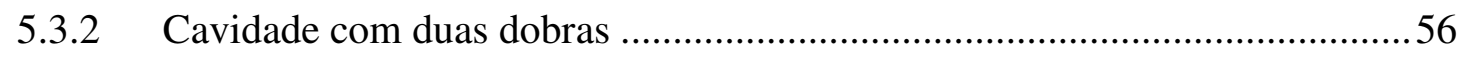

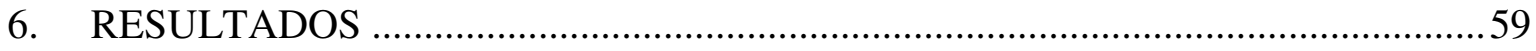

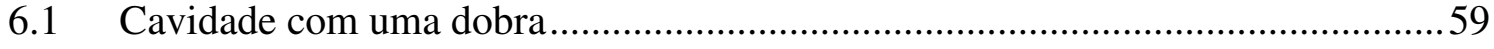

6.2 Cavidade com uma dobra e lâmina intracavidade...............................................62

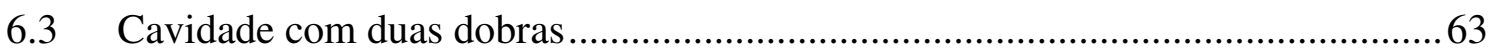

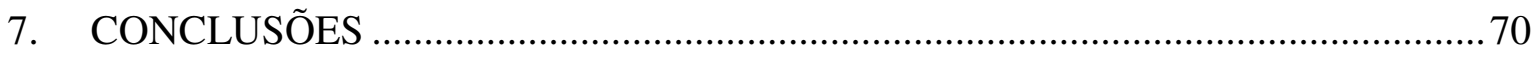

8. APÊNDICE A - Operação em regime contínuo ..................................................... 71 
9. APÊNDICE B - Cavidade com emissão em 1047nm ................................................ 74

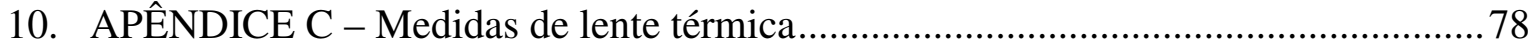

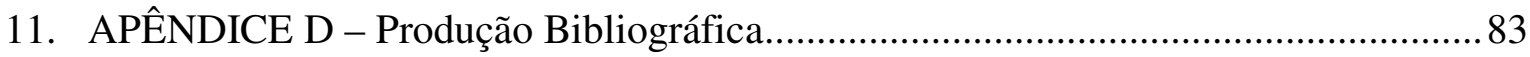

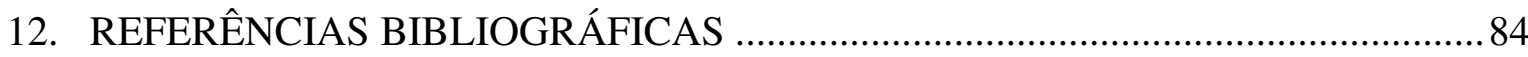




\section{LISTA DE FIGURAS}

FIGURA 1: Diagrama de níveis simplificado em um sistema de quatro níveis. 18

FIGURA 2: Configuração dos modos transversais retangulares [2].

FIGURA 3: Propagação de um feixe gaussiano.

FIGURA 4: Configuração da cavidade com reflexão interna total.

FIGURA 5: Razão entre o limiar de oscilação do modo TEM $_{00}$ e do modo TEM $_{10}$

FIGURA 6: Diagrama de níveis de energia simplificado do Nd:YLF.

FIGURA 7: Espectro de absorção do cristal de Nd:YLF dopado com 0,8mol\% de neodímio.

FIGURA 8: Processo de preparação de amostras de cristais laser - Corte (centro superior), lapidação (esquerda) e polimento (direita).

FIGURA 9: Cristal de Nd:YLF preparado com dimensões de $14 \mathrm{~mm}$ x $13 \mathrm{~mm}$ x 3,7mm...48

FIGURA 10: Espectro de emissão do diodo de 20W sob regime pulsado.

FIGURA 11: Porcentagem de potência absorvida em função da profundidade da radiação de bombeamento. .50

FIGURA 12: Seleção da polarização $\sigma$ por meio do ângulo de Brewster.

FIGURA 13: Diagrama da cavidade com uma dobra. M1 é o espelho curvo altamente refletor, M2 é o espelho plano de saída e f é a lente esférica de bombeamento.

FIGURA 14: Foto da cavidade laser com uma dobra.

FIGURA 15: Diagrama da cavidade com duas dobras. M1 é o espelho curvo altamente refletor, M2 é o espelho plano de saída, M3 é o espelho plano altamente refletor e f é a lente esférica de bombeamento.

FIGURA 16: Foto da cavidade laser com duas dobras.

FIGURA 17: Distância d entre as duas passagens do feixe intracavidade na configuração com duas dobras. 
FIGURA 18: Espectro de emissão do laser.

FIGURA 19: Potência de saída em função da potência de bombeamento da cavidade com uma dobra usando diferentes transmissões (T) do espelho de saída.

FIGURA 20: Perfil do feixe de saída na cavidade com uma dobra.

FIGURA 21: Qualidade do feixe laser na horizontal (esquerda) e na vertical (direita) para a cavidade com uma dobra.

FIGURA 22: Análise de Findlay-Clay para a cavidade com uma dobra.

FIGURA 23: Potência de saída em função da potência de bombeamento do arranjo com uma dobra usando lâmina intracavidade para obtenção do modo fundamental. 62

FIGURA 24: Qualidade do feixe laser na horizontal (esquerda) e na vertical (direita) com uma dobra e lâmina intracavidade.

FIGURA 25: Potência de saída em função da potência de bombeamento da cavidade com duas dobras na configuração com maior eficiência.

FIGURA 26: Análise de Findlay-Clay para a cavidade com duas dobras na configuração com maior eficiência.

FIGURA 27: Perfil do feixe de saída na cavidade com duas dobras na configuração com maior eficiência.

FIGURA 28: Qualidade do feixe laser para a cavidade com duas dobras na configuração com maior eficiência.

FIGURA 29: Perfil do feixe na cavidade com duas dobras no modo fundamental.

FIGURA 30: Potência de saída em função da potência de bombeamento da cavidade com duas dobras no modo fundamental.

FIGURA 31: Qualidade do feixe laser para a cavidade com duas dobras no modo fundamental.

FIGURA 32: Análise de Findlay-Clay para a cavidade com duas dobras no modo fundamental.

FIGURA 33: Secções xy do cristal na região de bombeamento. a) distribuição da intensidade de bombeamento; b) distribuição da intensidade dos modos $\mathrm{TEM}_{00}$ paralelos em reflexão interna total. 
FIGURA 34: Limiar de oscilação do modo TEM $_{10}$ em função da distância entre as duas passagens do feixe na configuração com duas dobras: simulação (linha) e resultados experimentais (pontos)

FIGURA 35: Representação do suporte para refrigeração do cristal

FIGURA 36: Potência de saída em função da potência de bombeamento do arranjo com uma dobra sob regime contínuo

FIGURA 37: Diagrama da cavidade com uma dobra e emissão em 1047nm. M1 é o espelho curvo altamente refletor, M2 é o espelho plano de saída e f é a lente esférica de bombeamento.

FIGURA 38: Espectro de absorção do cristal de Nd:YLF dopado com 1,3mol\% de neodímio.

FIGURA 39: Espectro de emissão do laser na polarização $\pi$.

FIGURA 40: Potência de saída em função da potência de bombeamento do arranjo com emissão em 1047nm

FIGURA 41: Arranjo experimental para a determinação da distância focal da lente térmica no cristal.

FIGURA 42: Diferença entre o raio do feixe de He-Ne antes e após o bombeamento ( $\mathrm{r}_{2}{ }^{\prime}-$ $\mathrm{r}_{2}$ ), em virtude da lente térmica. Os valores sobre a curva indicam a distância focal calculada. 80

FIGURA 43: Arranjo experimental para a determinação do raio de curvatura da superfície de bombeamento.

FIGURA 44: Diferença entre o raio do feixe de He-Ne antes e após o bombeamento ( $\mathrm{r}_{2}{ }^{2}-$ $\mathrm{r}_{2}$ ), em virtude da curvatura da face de bombeamento. Os valores sobre a curva indicam o raio de curvatura calculado. 


\section{INTRODUÇÃO}

A cada dia o laser se consolida como umas das principais ferramentas de alta tecnologia existentes, estando presente nos mais diversos ramos da atividade humana. Desta forma, está em constante processo de inovação, numa busca incessante por melhor desempenho. O desenvolvimento de lasers de estado sólido baseia-se na concepção de arranjos inovadores que possibilitem a obtenção de alta eficiência e alta qualidade de feixe. Em geral, o modo fundamental é o mais almejado em aplicações laser. Para a obtenção do modo fundamental com alta eficiência, um dos elementos mais importantes é a otimização da sobreposição entre o volume do feixe intracavidade e a região do meio ativo excitada pela fonte de bombeamento. Neste trabalho, é mostrado o desenvolvimento de uma cavidade inovadora, que demonstrou a maior eficiência já reportada em um laser de Nd:YLF com transição em $1053 \mathrm{~nm}$ sob bombeado transversal por diodo laser.

$\mathrm{Na}$ busca por lasers compactos e de alto desempenho, a utilização de lasers de diodo como fonte de bombeamento se justifica em vista das vantagens inerentes à melhor utilização da energia de bombeamento, acarretando na diminuição do calor depositado no meio ativo. Desta forma, além do aumento da eficiência de operação, o uso do diodo laser também diminui os efeitos térmicos decorrentes do bombeamento, permitindo a obtenção de melhor qualidade do feixe de saída. O bombeamento longitudinal é a configuração mais eficiente para a transferência de energia ao meio ativo. Contudo, sua utilização com diodos de alta potência é restringida pela necessidade de complexos arranjos para a reconfiguração do feixe de bombeamento. Além disto, para promover o acoplamento com o modo fundamental, torna-se necessário concentrar a energia de bombeamento em uma área diminuta, o que limita a potência de bombeamento devido ao risco de fratura por tensões térmicas. O cristal de Nd:YLF possibilita a obtenção de alta qualidade do feixe de saída, especialmente pela sua baixa lente térmica, contudo, possui a desvantagem de um baixo limiar de fratura. Desta forma, o uso do bombeamento transversal se torna mais propício para esta matriz, por permitir a utilização de arranjos mais simples e o aumento da potência de bombeamento depositada no meio ativo, ao custo de uma pior sobreposição com o feixe laser. 
Para a obtenção de alta eficiência sob bombeamento transversal, este trabalho mostra o desenvolvimento de uma configuração inovadora utilizando incidência em ângulo de Brewster para a reflexão interna total na face de bombeamento. Para otimizar o acoplamento com o modo fundamental é mostrada uma configuração inovadora com duas reflexões internas na face de bombeamento.

Diversas configurações, utilizando múltiplas reflexões do feixe dentro do meio ativo, já foram reportadas para lasers com bombeamento transversal por diodo. Em geral, estas configurações possuem a radiação de bombeamento bem distribuída no meio ativo. $\mathrm{O}$ laser desenvolvido neste trabalho se diferencia de outros por fazer uso de uma configuração proposta para meios de alto ganho que promove um melhor aproveitamento da alta inversão de população concentrada próxima à face de bombeamento, onde o feixe intracavidade realiza a reflexão interna total. No entanto, como o Nd:YLF possui baixa absorção, é possível introduzir uma inovação pela incidência em ângulo de Brewster, que é utilizado para minimizar a perda por reflexão sem a necessidade de utilização de filmesfinos anti-refletores. Desta forma, a configuração demonstrada neste trabalho reúne alta eficiência e simplicidade, em conjunto com as vantagens oferecidas pelo cristal de $\mathrm{Nd}$ :YLF, principalmente a baixa lente térmica observada em $1053 \mathrm{~nm}$.

O presente trabalho aborda o processo de desenvolvimento do laser em suas concepções prática e teórica. Inicialmente, é mostrada a teoria e os conceitos gerais a respeito de lasers de estado sólido e modos transversais em uma cavidade ressonante, bem como os mecanismos necessários para a otimização da qualidade do feixe de saída, expondo-se as equações de taxa para determinação dos limiares de oscilação dos modos transversais. Em seguida, é mostrado o desenvolvimento experimental durante a preparação das amostras de cristais empregadas na cavidade e a montagem do protótipo do laser de Nd:YLF bombeado transversalmente por diodo, expondo-se, ao final, os resultados encontrados. 


\section{OBJETIVOS}

O objetivo deste trabalho é a otimização da eficiência e da qualidade do feixe em lasers de Nd:YLF bombeados transversalmente por diodo, por meio da otimização do acoplamento do modo fundamental com a região do meio ativo excitada pela fonte de bombeamento, utilizando cavidades inovadoras com incidência em ângulo de Brewster para a reflexão interna total na face de bombeamento. 


\section{LASERS DE ESTADO SÓLIDO}

\subsection{Dinâmica da população do meio ativo}

Segundo os postulados da teoria quântica, sistemas atômicos e moleculares só podem existir em certos estados permitidos, caracterizados por níveis discretos de energia. Em um sistema de átomos similares em equilíbrio térmico à temperatura $\mathrm{T}$, o número relativo de partículas em dois estados de energia diferentes é dado pela relação de Boltzmann [1]

$$
\frac{\mathrm{N}_{2}}{\mathrm{~N}_{1}}=\frac{\mathrm{g}_{2}}{\mathrm{~g}_{1}} \cdot \mathrm{e}^{-\left(-\frac{\mathrm{E}_{2}-\mathrm{E}_{1}}{\mathrm{k} \cdot \mathrm{T}}\right)}
$$

onde $\mathrm{k}$ é a constante de Boltzmann $\left(\mathrm{k}=1,38 \cdot 10^{-23} \mathrm{~J} \cdot \mathrm{K}\right)$ e $\mathrm{N}_{1}$ e $\mathrm{N}_{2}$ são o número de partículas nos estados de energia $E_{1}$ e $E_{2}$, respectivamente, sendo $E_{2}>E_{1}$. Quando dois ou mais estados possuem a mesma energia, o nível é dito degenerado e todos os estados de mesma energia são igualmente populados. A degenerescência dos estados de menor e maior energia é representada por $\mathrm{g}_{1} \mathrm{e} \mathrm{g}_{2}$ respectivamente.

Desta forma, a relação de Boltzmann prevê que, em um sistema de dois níveis em equilíbrio térmico, o nível de menor energia é mais densamente populado que o nível de maior energia. No entanto, na presença de um campo eletromagnético com densidade de energia $\rho(v)$ e frequiência $v$ ressonante, os átomos podem ser excitados para o estado de maior energia por meio da absorção de fótons com a exata diferença de energia hv entre os níveis $\left(\Delta \mathrm{E}=\mathrm{E}_{2}-\mathrm{E}_{1}=\mathrm{hv}\right)$, sendo $\mathrm{h}$ a constante de Planck $\left(\mathrm{h}=6,62 \cdot 10^{-34} \mathrm{~J} \cdot \mathrm{s}\right)$.

A probabilidade de transição do estado de energia inferior para o superior em virtude do efeito do campo eletromagnético é dada por uma constante de proporcionalidade $\mathrm{B}_{12}$ (com dimensões $\mathrm{cm}^{3} /\left(\mathrm{s}^{2} \cdot \mathrm{J}\right)$ ) multiplicada pela densidade de energia da radiação aplicada. 
Assim, a taxa com que a população do nível superior aumenta devido à absorção é dada por

$$
\frac{\mathrm{dN}_{2}}{\mathrm{dt}}=\mathrm{B}_{12} \cdot \rho(v) \cdot \mathrm{N}_{1}=\mathrm{W}_{12} \cdot \mathrm{N}_{1}
$$

em que $\mathrm{W}_{12}$ é a taxa de absorção pelos átomos dada em $\mathrm{s}^{-1}$.

Um átomo no estado excitado pode retornar naturalmente ao estado de energia mais baixo por meio do processo de emissão espontânea, emitindo um fóton com energia hv igual à diferença de energia entre os níveis. A emissão espontânea é caracterizada pelo tempo de vida do estado excitado, reduzindo a população do nível superior numa taxa proporcional à constante $\mathrm{A}_{21}$ (em unidade de $\mathrm{s}^{-1}$ ), que representa a probabilidade de transição espontânea e é igual ao recíproco do tempo de vida do nível $\left(\tau_{21}\right)$.

$$
\frac{\mathrm{dN}_{2}}{\mathrm{dt}}=-\mathrm{A}_{21} \cdot \mathrm{N}_{2}=-\frac{\mathrm{N}_{2}}{\tau_{21}}
$$

Os fótons emitidos por emissão espontânea pelos diferentes átomos possuem direções aleatórias e constituem processos individuais; por isso, não possuem relação de fase, sendo incoerentes.

Um átomo num estado excitado também pode transitar para um estado de menor energia através de outro mecanismo, conhecido como emissão estimulada. Neste caso, um fóton incidente de energia hv estimula o átomo a retornar ao estado de energia mais baixo e dois fótons coerentes e de mesma energia hv emergem. A probabilidade de decaimento estimulado, em contraste à emissão espontânea, é proporcional à densidade de energia do campo incidente, bem como à constante de proporcionalidade $\mathrm{B}_{21}$. Assim, a emissão estimulada reduz a população do nível superior em uma taxa dada por

$$
\frac{\mathrm{dN}_{2}}{\mathrm{dt}}=-\mathrm{B}_{21} \cdot \rho(v) \cdot \mathrm{N}_{2}=-\mathrm{W}_{21} \cdot \mathrm{N}_{2}
$$

onde $\mathrm{W}_{21}$ é a taxa de emissão estimulada dada em $\mathrm{s}^{-1}$. 
A probabilidade total de um átomo passar do estado excitado para o estado fundamental é igual à soma da probabilidade de emissão espontânea e de emissão estimulada. Considerando que os átomos do sistema estão em equilíbrio térmico, a taxa com que os átomos são excitados ao nível de maior energia é igual à taxa total de emissão com que o átomo retorna ao estado fundamental:

$$
\frac{\text { taxa de emissão }}{\text { taxa de absorção }}=\frac{N_{2} \cdot\left[A_{21}+B_{21} \cdot \rho(v)\right]}{N_{1} \cdot B_{12} \cdot \rho(v)}=1
$$

Tem-se, então, que a densidade de energia do campo incidente pode ser dada por

$$
\rho(v)=\frac{A_{21}}{B_{21}} \cdot\left(\frac{N_{1} \cdot B_{12}}{N_{2} \cdot B_{21}}-1\right)^{-1}
$$

Utilizando-se a relação de Boltzmann, dada na equação 1, tem-se

$$
\rho(v)=\frac{A_{21}}{B_{21}} \cdot\left(\frac{g_{1} \cdot B_{12}}{g_{2} \cdot B_{21}} \cdot e^{\frac{h \cdot v}{k \cdot T}}-1\right)^{-1}
$$

Esta equação deve ser consistente com o espectro de radiação do corpo negro de Planck mostrada na equação 8.

$$
\rho(v)=\frac{8 \pi h v^{3}}{c^{3}} \cdot\left(e^{\frac{h \cdot v}{k \cdot T}}-1\right)^{-1}
$$

onde c é velocidade da luz. Comparando-se a equação 7 com a relação de Planck (8), obtêm-se as relações dos coeficientes de Einstein:

$$
\begin{aligned}
& \mathrm{B}_{21}=\frac{\mathrm{g}_{1}}{\mathrm{~g}_{2}} \cdot \mathrm{B}_{12} \\
& \frac{\mathrm{A}_{21}}{\mathrm{~B}_{21}}=\frac{8 \pi \mathrm{h} v^{3}}{\mathrm{c}^{3}}
\end{aligned}
$$


Por meio da relação 9 pode-se constatar que, quando dois níveis não possuem degenerescências, a probabilidade de emissão estimulada é igual à probabilidade de absorção. Desta forma, a equação 5 pode ser reescrita como

$$
\frac{\text { taxa de emissão }}{\text { taxa de absorção }}=\left[1+\frac{\mathrm{A}_{21}}{\mathrm{~B}_{21} \cdot \rho(v)}\right] \cdot \frac{\mathrm{N}_{2}}{\mathrm{~N}_{1}}
$$

Através da equação de Planck, a relação 10 também pode ser explicitada como

$$
\frac{A_{21}}{B_{21} \cdot \rho(v)}=e^{\frac{h \cdot v}{k \cdot T}}-1
$$

mostrando que, para átomos em equilíbrio térmico, a emissão espontânea é mais provável do que a emissão estimulada se $h v>>k T$. No entanto, a emissão estimulada pode ser preponderante se hv<<kT. Nesta condição, a equação 12 torna-se nula de forma que a relação entre as taxas de emissão e absorção fica exclusivamente dependente da população dos níveis:

$$
\frac{\text { taxa de emissão }}{\text { taxa de absorção }} \cong \frac{\mathrm{N}_{2}}{\mathrm{~N}_{1}}
$$

Observa-se, então, que em situações fora do equilíbrio térmico, se a população dos estados é invertida de forma que a população do nível superior seja maior do que a do nível inferior $\left(\mathrm{N}_{2}>\mathrm{N}_{1}\right)$, a taxa de emissão será maior que a taxa de absorção, implicando na amplificação da intensidade da radiação aplicada. Isto também pode ser constatado por meio da lei de Lambert-Beer dada em função da secção de choque de emissão estimulada $\left(\sigma_{21}\right)$ e da densidade de população (n) dos níveis, dada em unidades de $\mathrm{cm}^{-1}$.

$$
I=I_{0} \cdot e^{-\sigma_{21} \cdot\left(n_{1}-n_{2}\right) \cdot x}
$$

Conforme visto anteriormente, de acordo com a relação de Boltzmann, quando o sistema estiver em equilíbrio térmico, poucos átomos ocuparão o nível de maior energia. Como $\mathrm{n}_{1}>>\mathrm{n}_{2}$, a diferença de população $\left(\mathrm{n}_{1}-\mathrm{n}_{2}\right)$ é positiva, de forma que a Lei de 
Lambert-Beer descreve a absorção exponencial da radiação incidente ao longo do material. Porém, sendo possível ocorrer uma inversão de população, a diferença entre as populações torna-se negativa e a absorção é convertida em emissão estimulada, ocorrendo amplificação da radiação. Tal processo reduzirá a população do nível superior até que o equilíbrio se restabeleça. Para manter o processo de emissão estimulada é necessário conservar a inversão de população injetando-se energia no sistema por meio de um mecanismo de bombeamento.

A inversão de população pode ser escrita da seguinte maneira

$$
\mathrm{n}=\Delta \mathrm{n}_{21}=\left(\mathrm{n}_{2}-\frac{\mathrm{g}_{2}}{\mathrm{~g}_{1}} \cdot \mathrm{n}_{1}\right)>0
$$

A maioria dos sistemas lasers apresenta estrutura bem mais complexa que o sistema de dois níveis, em virtude da eficiência para se atingir uma inversão de população. Em geral, sistemas de quatro níveis podem ser altamente eficientes. Na figura 1, pode-se observar o diagrama simplificado dos níveis de energia em um sistema de quatro níveis.

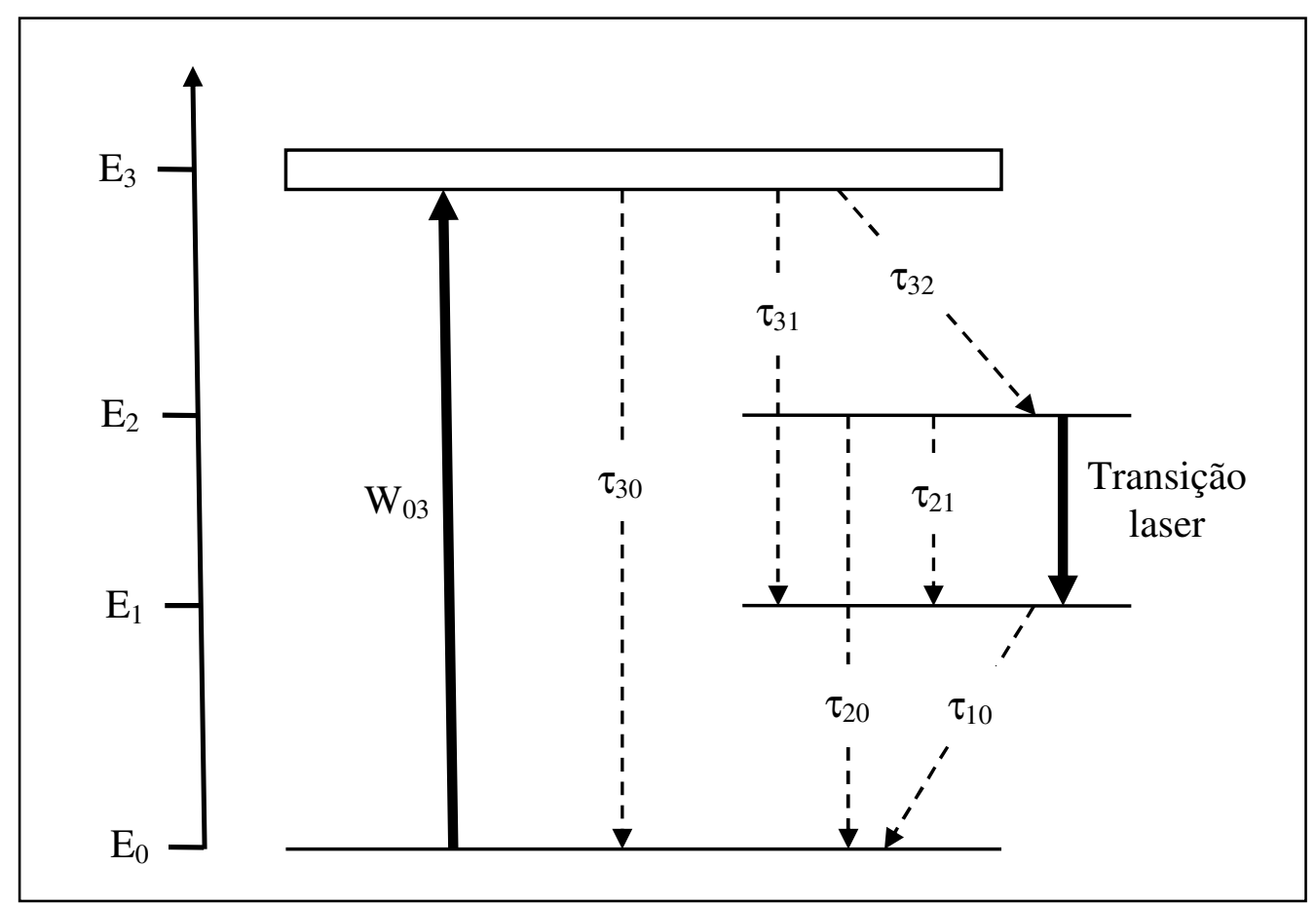

FIGURA 1: Diagrama de níveis simplificado em um sistema de quatro níveis.

Num sistema de quatro níveis, os átomos no estado fundamental $\mathrm{E}_{0}$ são excitados por um campo eletromagnético externo com energia $E_{03}=E_{3}-E_{0}$ para o nível 
$\mathrm{E}_{3}$. Os átomos excitados rapidamente decaem por emissão não-radiativa para o nível laser superior $\left(\mathrm{E}_{2}\right)$. A transição laser ocorre com o decaimento estimulado do nível $\mathrm{E}_{2}$ para $\mathrm{o}$ nível laser inferior $\mathrm{E}_{1}$ por emissão radiativa. No nível $\mathrm{E}_{1}$, os átomos decaem por emissão não-radiativa para o estado fundamental. $\mathrm{O}$ tempo de relaxação entre o nível $\mathrm{E}_{1}$ e o nível fundamental $\left(\tau_{10}\right)$ é caracterizado por ser muito rápido comparado com o tempo de vida de fluorescência $\left(\tau_{21}\right)$, ou seja, $\tau_{10}<<\tau_{21}$.

Transições não-radiativas se caracterizam por possuírem curtos tempos de vida e ocorrem entre níveis muito próximos, emitindo fônons na rede cristalina. Os fônons são os responsáveis pelo aquecimento do material hospedeiro. Em níveis com maiores diferenças de energia, a probabilidade de decaimento não-radiativo é menor, podendo ocorrer decaimento radiativo ou múltiplos processos não-radiativos. Quando um nível apresenta muitas transições proibidas, de acordo com as regras de seleção, a probabilidade de ele decair para um nível de menor energia pode diminuir, apresentando, portanto, um maior tempo de vida e sendo denominado metaestável. A existência do nível metaestável é de vital importância para ação laser por permitir a ocorrência de inversão de população.

Para ocorrer inversão de população no nível metaestável, outras condições devem ser respeitadas. Para que os elétrons excitados ao nível $\mathrm{E}_{3}$ sejam transferidos para o nível $\mathrm{E}_{2}$ ao invés de retornar ao nível fundamental, é necessário que $\tau_{30} \gg \tau_{32}$. Considerando que o tempo de vida é muito pequeno e que ocorre somente decaimento ao nível $\mathrm{E}_{2}$, pode-se negligenciar a população do nível $\mathrm{E}_{3}$, isto é, $\mathrm{n}_{3} \approx 0$. Desta forma, a equação de taxa que descreve o nível superior laser em um sistema de quatro níveis é dada pela equação 16 [2].

$$
\frac{\mathrm{dn}_{2}}{\mathrm{dt}}=\mathrm{W}_{\mathrm{p}} \cdot \mathrm{n}_{0}-\mathrm{c} \sigma_{21} \mathrm{~s} \cdot\left(\mathrm{n}_{2}-\frac{\mathrm{g}_{2}}{\mathrm{~g}_{1}} \cdot \mathrm{n}_{1}\right)-\frac{\mathrm{n}_{2}}{\tau_{21}}-\frac{\mathrm{n}_{2}}{\tau_{20}}
$$

Segundo a equação 16, a população do nível laser superior aumenta devido ao bombeamento e diminui devido à emissão estimulada e à emissão espontânea. O termo $\mathrm{W}_{\mathrm{p}} \mathrm{n}_{0}$ foi adicionado para caracterizar o efeito do bombeamento, representando o número de átomos transferidos do nível fundamental para o nível laser superior (em unidade de $\mathrm{cm}^{-3} \mathrm{~s}^{-1}$ ), onde $\mathrm{W}_{\mathrm{p}}$ é a taxa de bombeamento levando em consideração a eficiência de transferência do nível $\mathrm{n}_{3}$ para o nível $\mathrm{n}_{2}$. $\mathrm{O}$ segundo termo do lado direito da equação representa a emissão estimulada e a absorção, dado em função da inversão de população e 
da taxa de emissão $\mathrm{W}_{21}=c \sigma_{21} \mathrm{~s}$, em que $\mathrm{s}$ é a densidade de fótons por unidade de área. Também foram adicionados os termos referentes à emissão espontânea do nível laser superior para o nível laser inferior e para o nível fundamental, relacionando a população do nível com o tempo de decaimento $\tau_{21}$ e $\tau_{20}$ em cada uma destas transições respectivamente.

Da mesma forma, a população do nível laser inferior é descrita pela seguinte equação de taxa

$$
\frac{\mathrm{dn}_{1}}{\mathrm{dt}}=\mathrm{c} \sigma_{21} \mathrm{~s} \cdot\left(\mathrm{n}_{2}-\frac{\mathrm{g}_{2}}{\mathrm{~g}_{1}} \cdot \mathrm{n}_{1}\right)+\frac{\mathrm{n}_{2}}{\tau_{21}}-\frac{\mathrm{n}_{1}}{\tau_{10}}
$$

demonstrando que a população aumenta com a emissão estimulada e a emissão espontânea do nível laser superior e com a absorção, mas diminui devido a um processo de relaxação não-radiativo para o nível fundamental caracterizado pelo tempo de decaimento $\tau_{10}$.

Em um laser de quatro níveis o tempo de decaimento $\tau_{10}$ é caracterizado por ser muito rápido. Desta forma, considerando $\tau_{10} \approx 0$, segue que $n_{1}=0$. Assim, a inversão de população $\mathrm{n}$ pode ser aproximada para a densidade de átomos $\mathrm{n}_{2}$ do nível laser superior, obtendo-se da equação 16 a equação de taxa para um sistema de quatro níveis ideal:

$$
\frac{\mathrm{dn}}{\mathrm{dt}}=\mathrm{W}_{\mathrm{p}} \cdot \mathrm{n}_{0}-\mathrm{c} \sigma_{21} \mathrm{~s} \cdot \mathrm{n}-\frac{\mathrm{n}}{\tau_{\mathrm{f}}}
$$

considerando o tempo de fluorescência do nível laser superior dado por

$$
\frac{1}{\tau_{\mathrm{f}}}=\frac{1}{\tau_{21}}+\frac{1}{\tau_{20}}
$$

\subsection{Modos transversais}

Os modos são classificados conforme a variação do campo eletromagnético perpendicularmente e ao longo do eixo do ressonador. As características espectrais de um laser são determinadas principalmente pelos modos longitudinais, ao passo que as características espaciais como a divergência, o diâmetro e a distribuição de energia do feixe são determinados pelos modos transversais. Em geral, em um ressonador óptico pode haver mais de um modo, tanto transversal quanto longitudinal. 
Os modos transversais que oscilam em uma cavidade laser são designados pela sigla $\mathrm{TEM}_{\mathrm{mn}}$ para coordenadas cartesianas, em que os índices $m$ e $n$ são inteiros que indicam, para uma secção transversal arbitrária do feixe emergente, o número de linhas nodais de intensidade do feixe nas direções vertical e horizontal, respectivamente. $\mathrm{Na}$ figura 2 é possível observar exemplos de alguns modos transversais retangulares, em que a ordem do modo ( $\mathrm{m}$ ou $\mathrm{n}$ ) indica o número de regiões claras na direção x ou y.

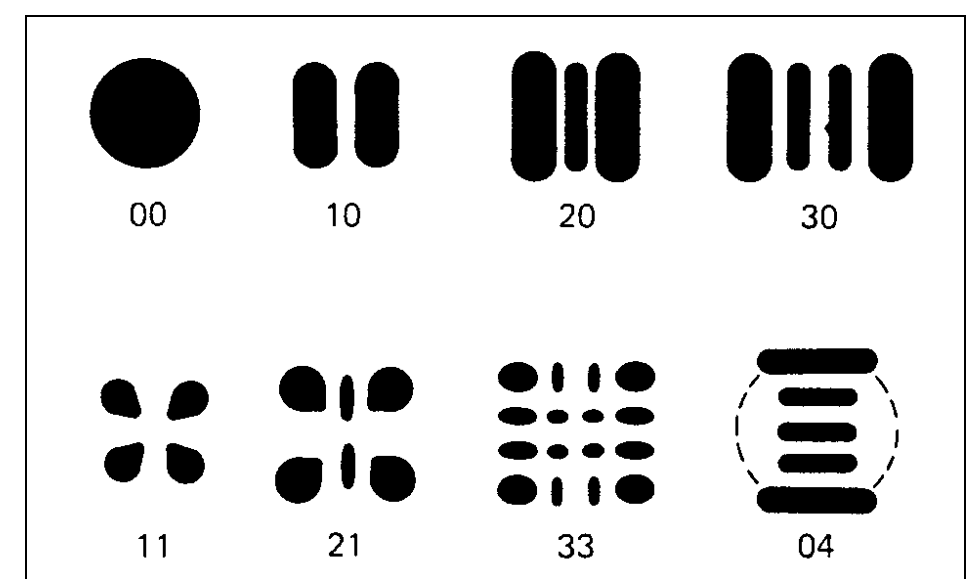

FIGURA 2: Configuração dos modos transversais retangulares [2].

Em coordenadas retangulares, a intensidade de um modo $\mathrm{TEM}_{\mathrm{mn}}$ é dada por

$$
I_{m n}(x, y, z)=I_{0} \cdot\left[H_{m}\left(\frac{\sqrt{2} \cdot x}{w(z)}\right) \cdot \exp \left(\frac{-x^{2}}{w^{2}(z)}\right)\right]^{2} \cdot\left[H_{n}\left(\frac{\sqrt{2} \cdot y}{w(z)}\right) \cdot \exp \left(\frac{-y^{2}}{w^{2}(z)}\right)\right]^{2}
$$

As funções $\mathrm{H}_{\mathrm{m}}(\mathrm{s})$ e $\mathrm{H}_{\mathrm{n}}(\mathrm{s})$ são os polinômios de Hermite de ordem m e n, ao passo que $\mathrm{w}(\mathrm{z})$ é o raio do feixe de menor ordem quando sua intensidade diminui a $1 / \mathrm{e}^{2}$ do valor máximo [3]. Sendo $s=\sqrt{2} \cdot \mathrm{x} / \mathrm{w}(\mathrm{z})$, os polinômios de Hermite são representados por

$$
\begin{aligned}
& \mathrm{H}_{\mathrm{o}}(\mathrm{s})=1 \\
& \mathrm{H}_{1}(\mathrm{~s})=2 \mathrm{~s} \\
& \mathrm{H}_{2}(\mathrm{~s})=4 \mathrm{~s}^{2}-2 \\
& \mathrm{H}_{3}(\mathrm{~s})=8 \mathrm{~s}^{3}-12 \mathrm{~s} \\
& \mathrm{H}_{4}(\mathrm{~s})=16 \mathrm{~s}^{4}-48 \mathrm{~s}^{2}+12
\end{aligned}
$$




\subsubsection{Características de um feixe gaussiano}

O modo de ordem mais baixa em uma cavidade ressonante é denominado como modo fundamental ou modo $\mathrm{TEM}_{00}$ e a sua intensidade obedece a uma distribuição gaussiana. O modo fundamental é o mais almejado em aplicações laser devido a diversas razões, dentre elas: possui alta coerência espacial; a divergência angular do feixe é mínima; e, quando focado, o diâmetro transverso do volume focal é mínimo [4]. A intensidade em um feixe gaussiano decresce radialmente com a distância r como mostrado na equação 26.

$$
I(r, z)=I_{0} \cdot \exp \left(\frac{-r^{2}}{w(z)^{2}}\right)
$$

onde $\mathrm{w}$ é o raio do feixe em que a intensidade diminui a $1 / \mathrm{e}^{2}$ do valor máximo. Desta forma, a secção transversal definida pelo raio $r=w$ contém $86,5 \%$ da energia total do feixe gaussiano.

Durante a propagação de um feixe gaussiano ao longo de um eixo na direção z (figura 3), o feixe se contrai para um diâmetro mínimo $2 \mathrm{w}_{0}$ na cintura e, então, se expande como uma hipérbole da seguinte forma:

$$
\mathrm{w}(\mathrm{z})=\mathrm{w}_{0} \cdot \sqrt{1+\left(\frac{\lambda \cdot\left(\mathrm{z}-\mathrm{z}_{0}\right)}{\pi \cdot \mathrm{w}_{0}{ }^{2}}\right)^{2}}
$$

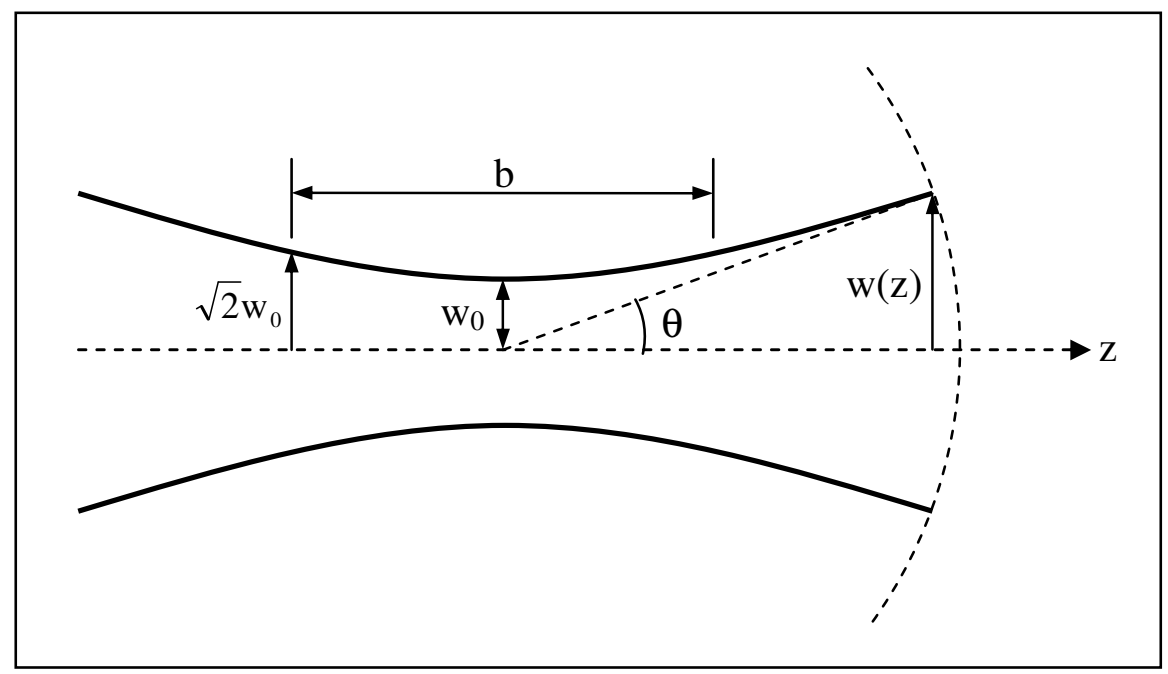

FIGURA 3: Propagação de um feixe gaussiano. 
O intervalo definido entre os dois pontos ao lado da cintura do feixe em que $\mathrm{w}(\mathrm{z})=\sqrt{2} \mathrm{w}_{0}$ é conhecido como parâmetro confocal, sendo uma região onde o diâmetro do feixe varia muito pouco, sendo freqüentemente utilizado para a caracterização do feixe gaussiano. O parâmetro confocal é dado pela expressão 28.

$$
\mathrm{b}=\frac{2 \pi \cdot \mathrm{w}_{0}^{2}}{\lambda}
$$

Fora da região definida pelo parâmetro confocal, o feixe diverge com o seguinte ângulo

$$
\theta=\lim _{z \rightarrow \infty} \frac{w(z)}{z}=\frac{\lambda}{\pi \cdot w_{0}}
$$

\subsubsection{Modos de ordem superior}

$\mathrm{O}$ modo fundamental possui o menor diâmetro e a menor divergência de feixe no ressonador, características que aumentam para modos de ordem superiores. Assim, o raio w'(z) de um feixe de ordem superior aumenta por um fator $\mathrm{M}$ em relação ao raio do modo fundamental, conforme mostrado na equação 30 .

$$
\mathrm{w}^{\prime}(\mathrm{z})=\mathrm{M} \cdot \mathrm{w}(\mathrm{z})
$$

Analogamente, a divergência de um modo de ordem superior ( $\left.\theta^{\prime}\right)$ também aumenta segundo o fator $\mathrm{M}$.

$$
\theta^{\prime}=\mathrm{M} \cdot \theta
$$

Multiplicando a divergência pelo diâmetro mínimo do feixe, obtém-se

$$
\theta^{\prime} \cdot \mathrm{w}_{0}^{\prime}(\mathrm{z})=\mathrm{M}^{2} \cdot \theta \cdot \mathrm{w}_{0}(\mathrm{z})=\mathrm{M}^{2} \cdot \frac{\lambda}{\pi}
$$


Desta forma, um feixe de ordem superior se expande na propagação ao longo da direção z conforme descrito na equação 33.

$$
\mathrm{w}^{\prime}(\mathrm{z})=\mathrm{w}_{0}^{\prime} \cdot \sqrt{1+\left(\frac{\mathrm{M}^{2} \cdot \lambda \cdot\left(\mathrm{z}-\mathrm{z}_{0}\right)}{\pi \cdot \mathrm{w}_{0}^{\prime}{ }^{2}}\right)^{2}}
$$

O parâmetro $\mathrm{M}^{2}$ é um fator de qualidade do feixe reconhecido mundialmente e compara a divergência de um feixe com distribuição arbitrária com a divergência do feixe no modo fundamental. Desta forma, o fator $\mathrm{M}^{2}$ indica o número de vezes que a divergência do feixe supera a divergência do modo fundamental. $O$ fator de qualidade no modo fundamental é idealmente igual a 1, aumentando gradativamente para modos de ordem superior. Na prática, o $\mathrm{M}^{2}$ do modo fundamental é adotado entre 1 e 1,5.

\subsubsection{Distribuição de intensidade do modo TEM To $_{00}$}

A intensidade do modo fundamental pode ser obtida substituindo, na equação genérica 20, o polinômio de Hermite para ordem zero, expresso na equação 21, obtendo-se então

$$
I_{00}=I_{0} \cdot \exp \left(\frac{-2 x^{2}}{w^{2}(z)}\right) \cdot \exp \left(\frac{-2 y^{2}}{w^{2}(z)}\right)
$$

Para a configuração da cavidade utilizada neste trabalho (figura 4) é preciso complementar esta teoria, pois, quando o feixe intracavidade realiza uma dobra no interior do meio ativo, é necessário considerar a sobreposição do feixe sobre si mesmo. Desta forma, para o modo $\mathrm{TEM}_{00}$ a distribuição da intensidade do modo passa a ser dada pela equação 35 .

$$
I_{00}=I_{0} \cdot\left\{\exp \left[\frac{-2 \cdot(x-D)^{2}}{w^{2}(z)}\right]+\exp \left[\frac{-2 \cdot(x+D)^{2}}{w^{2}(z)}\right]\right\} \cdot \exp \left(\frac{-2 y^{2}}{w^{2}(z)}\right)
$$

onde $\mathrm{D}$ é a distância do feixe à borda do cristal no centro de bombeamento. 
$\mathrm{O}$ valor de $\mathrm{I}_{0}$ pode ser obtido por meio da normalização da gaussiana em cada uma das direções, tal como é mostrado na equação 36 para a direção x.

$$
I_{0, x} \cdot \int_{0}^{\infty}\left\{\exp \left[\frac{-2 \cdot(x-D)^{2}}{w^{2}(z)}\right]+\exp \left[\frac{-2 \cdot(x+D)^{2}}{w^{2}(z)}\right]\right\} \cdot d x=1
$$

A solução da integração da gaussiana é dada por

$$
\int_{0}^{\infty} \mathrm{e}^{-\mathrm{a} \cdot \mathrm{x}^{2}} \cdot \mathrm{dx}=\frac{1}{2} \sqrt{\frac{\pi}{\mathrm{a}}}
$$

Sob incidência rasante pode-se estimar que $\mathrm{D}=0$. Portanto, aplicando esta solução à normalização do modo, obtém-se

$$
\mathrm{I}_{0, \mathrm{x}}=\sqrt{\frac{2}{\pi}} \cdot \frac{1}{\mathrm{w}(\mathrm{z})}
$$

O mesmo procedimento se aplica à normalização na direção y para o intervalo de integração de $-\infty$ a $+\infty$, de tal forma que $\mathrm{I}_{0, \mathrm{x}}=\mathrm{I}_{0, \mathrm{y}}$. Considerando o diâmetro do feixe laser $\left(\mathrm{w}_{\mathrm{L}}\right)$ constante ao longo do eixo $\mathrm{z}$, a normalização nesta direção gera um fator $\mathrm{I}_{0, \mathrm{z}}=$ $1 / l_{\text {cav }}$, onde $l_{\text {cav }}$ é o comprimento da cavidade laser. Substituindo estes dados na equação 34, chega-se à expressão de intensidade do modo TEM 00 .

$$
\mathrm{I}_{00}=\frac{2}{\mathrm{w}_{\mathrm{L}}^{2} \cdot \pi \cdot 1_{\text {cav }}} \cdot \exp \left(\frac{-2 \mathrm{x}^{2}}{\mathrm{w}_{\mathrm{L}}^{2}}\right) \cdot \exp \left(\frac{-2 \mathrm{y}^{2}}{\mathrm{w}_{\mathrm{L}}^{2}}\right)
$$
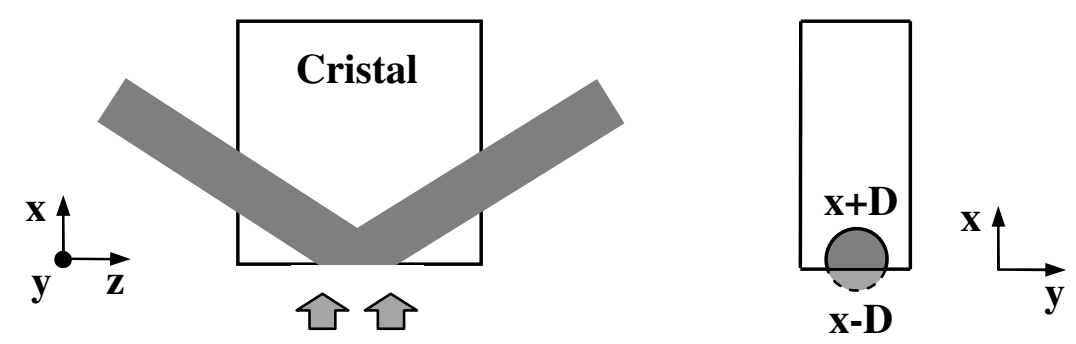

Bombeamento

FIGURA 4: Configuração da cavidade com reflexão interna total. 


\subsubsection{Distribuição de intensidade do modo TEM TE $_{10}$}

Um processo similar pode ser realizado para se determinar a distribuição de intensidade para outros modos. Desta forma, a intensidade do modo $\mathrm{TEM}_{10}$ pode ser obtida substituindo na equação 20 o polinômio de ordem 1 para a direção x e o polinômio de ordem zero para a direção y, o que resulta em

$$
I_{10}=I_{0} \cdot \frac{8 x^{2}}{w^{2}(z)} \cdot\left\{\exp \left[\frac{-2 \cdot(x-D)^{2}}{w^{2}(z)}\right]+\exp \left[\frac{-2 \cdot(x+D)^{2}}{w^{2}(z)}\right]\right\} \cdot \exp \left(\frac{-2 y^{2}}{w^{2}(z)}\right)
$$

$\mathrm{O}$ valor de $\mathrm{I}_{0}$ em x pode ser obtido por meio da normalização do modo nesta direção.

$$
\mathrm{I}_{0, \mathrm{x}} \cdot \int_{0}^{\infty} \frac{8 \mathrm{x}^{2}}{\mathrm{w}^{2}(\mathrm{z})} \cdot\left\{\exp \left[\frac{-2 \cdot(\mathrm{x}-\mathrm{D})^{2}}{\mathrm{w}^{2}(\mathrm{z})}\right]+\exp \left[\frac{-2 \cdot(\mathrm{x}+\mathrm{D})^{2}}{\mathrm{w}^{2}(\mathrm{z})}\right]\right\} \cdot \mathrm{dx}=1
$$

Sendo a solução da integral 41 dada por

$$
\int_{0}^{\infty} x^{2} \cdot e^{-a \cdot x^{2}} \cdot d x=\frac{\sqrt{\pi}}{4} \cdot a^{-3 / 2}
$$

encontra-se que $\mathrm{I}_{0, \mathrm{x}}$ é dado de acordo com a equação 43 , quando $\mathrm{D}=0$.

$$
\mathrm{I}_{0, \mathrm{x}}=\sqrt{\frac{2}{\pi}} \cdot \frac{1}{2 \mathrm{w}(\mathrm{z})}
$$

Como na direção y a ordem é zero, a normalização em y é a mesma realizada para o modo fundamental e $\mathrm{I}_{0, y}$ é dado de acordo com a equação 38 . O diâmetro do feixe laser é considerado constante ao longo do eixo $\mathrm{z}$, sendo $\mathrm{w}_{\mathrm{L}} \mathrm{o}$ raio do feixe no modo fundamental. Desta forma, substituindo os resultados na equação 40, obtém-se a distribuição de intensidade do modo TEM 10 .

$$
\mathrm{I}_{10}=\frac{8}{\mathrm{w}_{\mathrm{L}}^{4} \cdot \pi \cdot 1_{\mathrm{cav}}} \cdot \mathrm{x}^{2} \cdot \exp \left(\frac{-2 \mathrm{x}^{2}}{\mathrm{w}_{\mathrm{L}}^{2}}\right) \cdot \exp \left(\frac{-2 \mathrm{y}^{2}}{\mathrm{w}_{\mathrm{L}}^{2}}\right)
$$




\subsection{Equações de taxa para um laser multimodo}

A equação de taxa que descreve a inversão de população em um laser ideal de quatro níveis, mostrada na equação 18 , pode ser reescrita no estado estacionário levando em consideração a distribuição espacial do feixe laser e do feixe de bombeamento. Para tanto, a equação é dada em função da taxa de bombeamento $\mathrm{r}(\mathrm{x}, \mathrm{y}, \mathrm{z})$ (em unidade de $\left.\mathrm{cm}^{-3} \mathrm{~s}^{-1}\right)$ e da densidade de fótons do i-ésimo modo transversal $\mathrm{s}_{\mathrm{i}}(\mathrm{x}, \mathrm{y}, \mathrm{z})[5,6]$.

$$
\frac{\mathrm{dn}(\mathrm{x}, \mathrm{y}, \mathrm{z})}{\mathrm{dt}}=\mathrm{r}(\mathrm{x}, \mathrm{y}, \mathrm{z})-\mathrm{c} \cdot \sigma_{21} \cdot \mathrm{n}(\mathrm{x}, \mathrm{y}, \mathrm{z}) \cdot \sum \mathrm{s}_{\mathrm{i}}(\mathrm{x}, \mathrm{y}, \mathrm{z})-\frac{\mathrm{n}(\mathrm{x}, \mathrm{y}, \mathrm{z})}{\tau_{\mathrm{f}}}=0
$$

Resolvendo a equação 45 para a densidade de fótons tem-se

$$
\mathrm{n}(\mathrm{x}, \mathrm{y}, \mathrm{z})=\frac{\tau_{\mathrm{f}} \cdot \mathrm{r}(\mathrm{x}, \mathrm{y}, \mathrm{z})}{1+\sum \mathrm{s}_{\mathrm{i}}(\mathrm{x}, \mathrm{y}, \mathrm{z}) / \mathrm{I}_{0}}
$$

em que $\mathrm{I}_{0}$ é definido como

$$
\mathrm{I}_{0}=\frac{1}{\mathrm{c} \cdot \sigma_{21} \cdot \tau_{\mathrm{f}}}
$$

A equação que descreve a densidade de fótons é dada em função do decaimento estimulado subtraído das perdas.

$$
\frac{\mathrm{d} \mathrm{S}_{\mathrm{i}}}{\mathrm{dt}}=\iiint_{\text {cavidade }} \mathrm{c} \cdot \sigma_{21} \cdot \mathrm{n}(\mathrm{x}, \mathrm{y}, \mathrm{z}) \cdot \mathrm{s}_{\mathrm{i}}(\mathrm{x}, \mathrm{y}, \mathrm{z}) \cdot \mathrm{dV}-\gamma_{\mathrm{i}} \cdot \mathrm{S}_{\mathrm{i}}=0
$$

sendo $\mathrm{S}_{\mathrm{i}}$ o número total de fótons do modo laser composto por i modos transversais

$$
\mathrm{S}_{\mathrm{i}}=\iiint_{\text {cavidade }} \mathrm{s}_{\mathrm{i}}(\mathrm{x}, \mathrm{y}, \mathrm{z}) \cdot \mathrm{dV}
$$


A taxa de perdas de fótons do modo $\left(\gamma_{\mathrm{i}}\right)$ é caracterizada pela perda por duplo passo $\left(\mathrm{L}_{\mathrm{i}}\right)$, que inclui a transmissão dos espelhos, em uma cavidade de comprimento $l_{\text {cav }}$.

$$
\gamma_{\mathrm{i}}=\frac{\mathrm{c}}{2 \mathrm{l}_{\mathrm{cav}}} \cdot \mathrm{L}_{\mathrm{i}}=\frac{1}{\tau_{\mathrm{f}}}
$$

Substituindo, na expressão 48, a densidade de inversão de população obtida em 46, obtém-se a relação entre a intensidade dos modos e a taxa de bombeamento, considerando as distribuições espaciais do feixe laser e do feixe de bombeamento. Relação que demonstra o comportamento de um modo i na presença de outros modos $\mathrm{j}$.

$$
\iiint_{\text {cavidade }} \frac{\mathrm{s}_{0, \mathrm{i}}(\mathrm{x}, \mathrm{y}, \mathrm{z}) \cdot \mathrm{r}_{0}(\mathrm{x}, \mathrm{y}, \mathrm{z})}{1+\sum_{\mathrm{j}} \mathrm{S}_{\mathrm{j}} \cdot \mathrm{s}_{0, \mathrm{j}}(\mathrm{x}, \mathrm{y}, \mathrm{z}) / \mathrm{I}_{0}} \cdot \mathrm{dV}=\frac{\mathrm{I}_{0} \cdot \gamma_{\mathrm{i}}}{\mathrm{R}}
$$

A densidade de fótons e a taxa de bombeamento podem ser expressas por

$$
\begin{aligned}
\mathrm{s}_{\mathrm{i}}(\mathrm{x}, \mathrm{y}, \mathrm{z}) & =\mathrm{S}_{\mathrm{i}} \cdot \mathrm{s}_{0, \mathrm{i}}(\mathrm{x}, \mathrm{y}, \mathrm{z}) \\
\mathrm{r}(\mathrm{x}, \mathrm{y}, \mathrm{z}) & =\mathrm{R} \cdot \mathrm{r}_{0}(\mathrm{x}, \mathrm{y}, \mathrm{z})
\end{aligned}
$$

onde $\mathrm{s}_{0, \mathrm{i}}$ e $\mathrm{r}_{0}$ são distribuições normalizadas.

$$
\iiint_{\text {cavidade }} \mathrm{s}_{0, \mathrm{i}}(\mathrm{x}, \mathrm{y}, \mathrm{z}) \cdot \mathrm{dV}=\iiint_{\text {cavidade }} \mathrm{r}_{0}(\mathrm{x}, \mathrm{y}, \mathrm{z}) \cdot \mathrm{dV}=1
$$

Para o caso de oscilação somente de um determinado modo na cavidade, a densidade de fótons (S) dos demais modos é nula. Desta forma, a partir da equação 50 obtém-se a equação 55.

$$
\iiint_{\text {cavidade }} \frac{\mathrm{s}_{0, \mathrm{i}}(\mathrm{x}, \mathrm{y}, \mathrm{z}) \cdot \mathrm{r}_{0}(\mathrm{x}, \mathrm{y}, \mathrm{z})}{1+\mathrm{S}_{\mathrm{i}} \cdot \mathrm{s}_{0, \mathrm{i}}(\mathrm{x}, \mathrm{y}, \mathrm{z}) / \mathrm{I}_{0}} \cdot \mathrm{dV}=\frac{\mathrm{I}_{0} \cdot \gamma_{\mathrm{i}}}{\mathrm{R}}
$$


$S_{\mathrm{i}}$ e R são experimentalmente relacionados com a potência de saída do laser $\left(\mathrm{P}_{\text {out }}\right)$ e com a potência de bombeamento absorvida $\left(\mathrm{P}_{\mathrm{abs}}\right)$, respectivamente, conforme mostrado nas equações 56 e 57.

$$
\begin{aligned}
& \mathrm{P}_{\text {out }}=\frac{\mathrm{T} \cdot \mathrm{h} \cdot \mathrm{v}_{\mathrm{L}} \cdot \gamma_{\mathrm{i}} \cdot \mathrm{S}_{\mathrm{i}}}{\mathrm{L}_{\mathrm{i}}} \\
& \mathrm{R}=\frac{\mathrm{P}_{\mathrm{abs}}}{\mathrm{h} \cdot \mathrm{v}_{\mathrm{p}}}=\frac{\mathrm{P}_{\mathrm{p}}}{\mathrm{h} \cdot \mathrm{v}_{\mathrm{p}}} \cdot \eta_{\mathrm{a}}
\end{aligned}
$$

onde $v_{\mathrm{p}}$ e $v_{\mathrm{L}}$ são as freqüências de bombeamento e de emissão do laser, respectivamente, $\mathrm{T}$ é a transmissão do espelho de saída e $\eta_{\mathrm{a}}$ é a eficiência de absorção. A potência absorvida pelo meio ativo está relacionada diretamente com a potência total de bombeamento $\left(\mathrm{P}_{\mathrm{p}}\right)$ por meio da eficiência de absorção, o que pode ser expressa da seguinte maneira

$$
\mathrm{P}_{\mathrm{abs}}=\mathrm{P}_{\mathrm{p}} \cdot \mathrm{T}_{\mathrm{cr}} \cdot\left(1-\mathrm{e}^{-\alpha \cdot \mathrm{l}_{\mathrm{b}}}\right)
$$

sendo $\mathrm{T}_{\mathrm{cr}}$ a transmissão da superfície de bombeamento, $\alpha$ o coeficiente de absorção e $l_{\mathrm{b}} \mathrm{o}$ comprimento do meio ativo na direção de bombeamento.

O limiar de oscilação do modo i pode ser obtido resolvendo a equação 55 quando $S_{\mathrm{i}}=0$.

$$
\mathrm{R}_{\mathrm{th}, \mathrm{i}}=\frac{\mathrm{I}_{0} \cdot \gamma_{\mathrm{i}}}{\iiint_{\text {cavidade }} \mathrm{s}_{0, \mathrm{i}}(\mathrm{x}, \mathrm{y}, \mathrm{z}) \cdot \mathrm{r}_{0}(\mathrm{x}, \mathrm{y}, \mathrm{z}) \cdot \mathrm{dV}}
$$

Assim, utilizando a relação 57, obtém-se a potência de bombeamento no limiar de oscilação do modo i oscilando isoladamente na cavidade.

$$
\mathrm{P}_{\mathrm{th}, \mathrm{i}}=\frac{\mathrm{L}_{\mathrm{i}} \cdot \mathrm{h} \cdot \mathrm{v}_{\mathrm{p}} \cdot \mathrm{V}_{\mathrm{eff}}}{2 \cdot 1_{\text {cav }} \cdot \sigma_{21} \cdot \tau_{\mathrm{f}} \cdot \eta_{\mathrm{a}}}
$$

em que $V_{\text {eff }}$ é o volume efetivo do modo, levando em consideração a sobreposição do feixe laser e do feixe de bombeamento. 


$$
\mathrm{V}_{\mathrm{eff}}=\frac{1}{\iiint_{\text {cavidade }} \mathrm{s}_{0, \mathrm{i}}(\mathrm{x}, \mathrm{y}, \mathrm{z}) \cdot \mathrm{r}_{0}(\mathrm{x}, \mathrm{y}, \mathrm{z}) \cdot \mathrm{dV}}
$$

Na região próxima ao limiar, em que $S_{\mathrm{i}}$ é muito pequeno, pode-se utilizar a seguinte aproximação para a equação 55

$$
\begin{aligned}
& \frac{\mathrm{I}_{0} \cdot \gamma_{\mathrm{i}}}{\mathrm{R}} \cong \iiint_{\text {cavidade }} \frac{\mathrm{s}_{0, \mathrm{i}}(\mathrm{x}, \mathrm{y}, \mathrm{z}) \cdot \mathrm{r}_{0}(\mathrm{x}, \mathrm{y}, \mathrm{z})}{1+\mathrm{S}_{\mathrm{i}} \cdot \mathrm{s}_{0, \mathrm{i}}(\mathrm{x}, \mathrm{y}, \mathrm{z}) / \mathrm{I}_{0}} \cdot \frac{1-\mathrm{S}_{\mathrm{i}} \cdot \mathrm{s}_{0, \mathrm{i}}(\mathrm{x}, \mathrm{y}, \mathrm{z}) / \mathrm{I}_{0}}{1-\mathrm{S}_{\mathrm{i}} \cdot \mathrm{s}_{0, \mathrm{i}}(\mathrm{x}, \mathrm{y}, \mathrm{z}) / \mathrm{I}_{0}} \cdot \mathrm{dV} \\
& \frac{\mathrm{I}_{0} \cdot \gamma_{\mathrm{i}}}{\mathrm{R}} \cong \iiint_{\text {cavidade }} \mathrm{s}_{0, \mathrm{i}}(\mathrm{x}, \mathrm{y}, \mathrm{z}) \cdot \mathrm{r}_{0}(\mathrm{x}, \mathrm{y}, \mathrm{z}) \cdot\left(1-\mathrm{S}_{\mathrm{i}} \cdot \mathrm{s}_{0, \mathrm{i}}(\mathrm{x}, \mathrm{y}, \mathrm{z}) / \mathrm{I}_{0}\right) \cdot \mathrm{dV}
\end{aligned}
$$

Resolvendo a equação 63 para $S_{i}$, obtém-se

$$
S_{i}=\frac{I_{0}}{\iiint_{\text {cavidade }} s_{0, i}{ }^{2}(x, y, z) \cdot r_{0}(x, y, z) \cdot d V} \cdot\left(\iiint_{\text {cavidade }} s_{0, i}(x, y, z) \cdot r_{0}(x, y, z) \cdot d V-\frac{I_{0} \cdot \gamma_{i}}{R}\right)
$$

Ao utilizar o limiar oscilação do modo obtido na equação 59, a expressão 64 passa a ser dada por

$$
\mathrm{S}_{\mathrm{i}}=\frac{\left[\iiint_{\text {cavidade }} \mathrm{s}_{0, \mathrm{i}}(\mathrm{x}, \mathrm{y}, \mathrm{z}) \cdot \mathrm{r}_{0}(\mathrm{x}, \mathrm{y}, \mathrm{z}) \cdot \mathrm{dV}\right]^{2}}{\gamma_{\mathrm{i}} \cdot \iiint_{\text {cavidade }} \mathrm{s}_{0, \mathrm{i}}{ }^{2}(\mathrm{x}, \mathrm{y}, \mathrm{z}) \cdot \mathrm{r}_{0}(\mathrm{x}, \mathrm{y}, \mathrm{z}) \cdot \mathrm{dV}} \cdot\left(\mathrm{R}-\mathrm{R}_{\mathrm{th}, \mathrm{i}}\right)
$$

Substituindo este resultado na equação 56 e, então, utilizando a equação 57, obtém-se a relação entre a potência de saída e a potência de bombeamento para oscilação do modo i próximo ao limiar.

$$
\mathrm{P}_{\text {out }}=\frac{\mathrm{T} \cdot \mathrm{v}_{\mathrm{L}}}{\mathrm{L}_{\mathrm{i}} \cdot \mathrm{v}_{\mathrm{p}}} \cdot \frac{\left[\iiint_{\text {cavidade }} \mathrm{s}_{0, \mathrm{i}}(\mathrm{x}, \mathrm{y}, \mathrm{z}) \cdot \mathrm{r}_{0}(\mathrm{x}, \mathrm{y}, \mathrm{z}) \cdot \mathrm{dV}\right]^{2}}{\iiint_{\text {cavidade }} \mathrm{s}_{0, \mathrm{i}}{ }^{2}(\mathrm{x}, \mathrm{y}, \mathrm{z}) \cdot \mathrm{r}_{0}(\mathrm{x}, \mathrm{y}, \mathrm{z}) \cdot \mathrm{dV}} \cdot \eta_{\mathrm{a}} \cdot\left(\mathrm{P}_{\mathrm{p}}-\mathrm{P}_{\mathrm{th}, \mathrm{i}}\right)
$$


A eficiência de acoplamento $\left(\eta_{\mathrm{c}}\right)$ entre o feixe laser e o feixe de bombeamento é representada da seguinte forma

$$
\eta_{\mathrm{c}}=\frac{\left[\iiint_{\text {cavidade }} \mathrm{s}_{0, \mathrm{i}}(\mathrm{x}, \mathrm{y}, \mathrm{z}) \cdot \mathrm{r}_{0}(\mathrm{x}, \mathrm{y}, \mathrm{z}) \cdot \mathrm{dV}\right]^{2}}{\iiint_{\text {cavidade }} \mathrm{s}_{0, \mathrm{i}}{ }^{2}(\mathrm{x}, \mathrm{y}, \mathrm{z}) \cdot \mathrm{r}_{0}(\mathrm{x}, \mathrm{y}, \mathrm{z}) \cdot \mathrm{dV}}
$$

Assim, a eficiência angular ou slop efficiency $\left(\eta_{\mathrm{s}}\right)$ do laser é dada por

$$
\eta_{\mathrm{s}}=\frac{\mathrm{P}_{\text {out }}}{\mathrm{P}_{\mathrm{p}}-\mathrm{P}_{\mathrm{th}, 1}}=\frac{\mathrm{T} \cdot v_{\mathrm{L}}}{\mathrm{L}_{\mathrm{i}} \cdot v_{\mathrm{p}}} \cdot \eta_{\mathrm{c}} \cdot \eta_{\mathrm{a}}
$$

\subsection{Solução analítica do limiar de oscilação para modos transversais isolados}

\subsubsection{Limiar do modo TEM $_{00}$ sob bombeamento lateral}

Para se determinar o limiar de oscilação de um determinado modo na cavidade, conforme o exemplo demonstrado nas equações 59 e 60, é preciso determinar o volume efetivo do i-ésimo modo por meio da equação 61, que por sua vez é dependente das distribuições normalizadas da densidade de fótons e da taxa de bombeamento.

Para o modo fundamental, a distribuição da densidade de fótons $\mathrm{s}_{0,1}$ é similar à distribuição de intensidade calculada na expressão 39. Para o caso de bombeamento transversal, o feixe possui um perfil gaussiano na direção y e é absorvido exponencialmente na direção $x$. Portanto, a distribuição normalizada da taxa de bombeamento pode ser expressa conforme mostrado na equação 69.

$$
\mathrm{r}_{0}=\frac{\alpha \cdot \sqrt{2}}{\sqrt{\pi} \cdot \mathrm{w}_{\mathrm{p}} \cdot\left(1-\mathrm{e}^{-\alpha \cdot \mathrm{l}_{\mathrm{b}}}\right) \cdot \mathrm{l}_{\mathrm{cr}}} \cdot \exp \left(-\alpha \cdot \mathrm{x}-\frac{2 \mathrm{y}^{2}}{\mathrm{w}_{\mathrm{p}}^{2}}\right)
$$

onde $\mathrm{w}_{\mathrm{p}}$ é o raio do feixe de bombeamento na direção y e $l_{\mathrm{cr}}$ é o comprimento bombeado do cristal na direção z. 
Desta forma, o volume efetivo para o modo $\mathrm{TEM}_{00}$ é dado por

$$
\begin{aligned}
& \mathrm{V}_{\mathrm{eff}, 1}^{-1}=\frac{2 \sqrt{2} \cdot \alpha}{\pi \cdot \sqrt{\pi} \cdot \mathrm{w}_{\mathrm{L}}{ }^{2} \cdot \mathrm{w}_{\mathrm{p}} \cdot 1_{\mathrm{cav}} \cdot 1_{\mathrm{cr}} \cdot\left(1-\mathrm{e}^{-\alpha \cdot \mathrm{l}_{\mathrm{b}}}\right)} \\
& \times \int_{0}^{\infty} \mathrm{dx} \int_{-\infty}^{\infty} \mathrm{dy} \int_{0}^{1_{\mathrm{cr}}} \mathrm{dz} \cdot \exp \left(-\alpha \cdot \mathrm{x}-\frac{2 \mathrm{x}^{2}}{\mathrm{w}_{\mathrm{L}}^{2}}\right) \cdot \exp \left(-\frac{2 \mathrm{y}^{2}}{\mathrm{w}_{\mathrm{L}}^{2}}-\frac{2 \mathrm{y}^{2}}{\mathrm{w}_{\mathrm{p}}^{2}}\right)
\end{aligned}
$$

Utilizando a solução 37 no intervalo de $-\infty$ a $+\infty$ para a integração na direção y,

$$
\mathrm{V}_{\text {eff }, 1}^{-1}=\frac{2 \alpha}{\pi \cdot \mathrm{w}_{\mathrm{L}} \cdot\left(1-\mathrm{e}^{-\alpha \cdot \mathrm{l}_{\mathrm{b}}}\right) \cdot 1_{\text {cav }}} \cdot \frac{1}{\sqrt{\mathrm{w}_{\mathrm{p}}^{2}+\mathrm{w}_{\mathrm{L}}^{2}}} \cdot \int_{0}^{\infty} \exp \left(-\alpha \cdot \mathrm{x}-\frac{2 \mathrm{x}^{2}}{\mathrm{w}_{\mathrm{L}}^{2}}\right) \cdot \mathrm{dx}
$$

Da tabela de integrais [7] tem-se que

$$
\int_{0}^{\infty} \exp \left(-\frac{x^{2}}{4 \beta}-\gamma \cdot x\right) \cdot d x=\sqrt{\pi \cdot \beta} \cdot \exp \left(\beta \cdot \gamma^{2}\right) \cdot[1-\Phi(\gamma \sqrt{\beta})] \quad[\operatorname{se} \operatorname{Re} \beta>0]
$$

onde a função erro é determinada como

$$
\Phi(\gamma \sqrt{\beta})=\frac{2}{\sqrt{\pi}} \cdot \int_{0}^{\gamma \sqrt{\beta}} \mathrm{e}^{-t^{2}} \cdot \mathrm{dt}
$$

Utilizando a solução 72 pode-se calcular a integral em $\mathrm{x}$ da equação 71 , obtendo-se o resultado do volume efetivo para o modo fundamental de acordo com a função erro.

$$
\mathrm{V}_{\mathrm{eff}, 1}^{-1}=\frac{\alpha}{\sqrt{2 \pi} \cdot\left(1-\mathrm{e}^{-\alpha \cdot \mathrm{l}_{\mathrm{b}}}\right) \cdot 1_{\mathrm{cav}}} \cdot \frac{1}{\sqrt{\mathrm{w}_{\mathrm{p}}^{2}+\mathrm{w}_{\mathrm{L}}^{2}}} \cdot \exp \left(\frac{\mathrm{w}_{\mathrm{L}}{ }^{2} \cdot \alpha^{2}}{8}\right) \cdot\left[1-\frac{2}{\sqrt{\pi}} \cdot \int_{0}^{\frac{\alpha \cdot \mathrm{w}_{\mathrm{L}}}{2 \sqrt{2}}} \mathrm{e}^{-\mathrm{t}^{2}} \mathrm{dt}\right] \text { (74) }
$$


Assim, o limiar do modo fundamental pode ser determinado através da equação 59.

$$
\begin{aligned}
& \mathrm{R}_{\mathrm{th}, 1}=\frac{\alpha \cdot \mathrm{L}_{1}}{2 \sqrt{2 \pi} \cdot 1_{\text {cav }}{ }^{2} \cdot \sigma_{21} \cdot \tau_{\mathrm{f}} \cdot\left(1-\mathrm{e}^{-\alpha \cdot \mathrm{l}_{\mathrm{b}}}\right) \cdot \sqrt{\mathrm{wp}^{2}+\mathrm{wl}^{2}}} \\
& \times \exp \left(\frac{\mathrm{w}_{\mathrm{L}}{ }^{2} \cdot \alpha^{2}}{8}\right) \cdot\left(1-\frac{2}{\sqrt{\pi}} \int_{0}^{\alpha \cdot \mathrm{w}_{\mathrm{L}} / 2 \sqrt{2}} \mathrm{e}^{-\mathrm{t}^{2}} \mathrm{dt}\right)
\end{aligned}
$$

\subsubsection{Limiar do modo TEM $_{10}$ sob bombeamento lateral}

Tal como demonstrado para o modo fundamental, o limiar de oscilação do modo $\mathrm{TEM}_{10}$ na cavidade pode ser determinado calculando-se o volume efetivo deste modo, sendo que a distribuição da densidade de fótons $\mathrm{s}_{0,2}$ obedece a distribuição de intensidade calculada na expressão 44 e a distribuição da taxa de bombeamento normalizada para o bombeamento transversal permanece a mesma para todos os modos, conforme mostrado na equação 69. Desta forma, o volume efetivo para o modo $\mathrm{TEM}_{10}$ é dado pela equação 76 .

$$
\begin{aligned}
& \mathrm{V}_{\mathrm{eff}, 2}^{-1}=\frac{8 \sqrt{2} \cdot \alpha}{\pi \cdot \sqrt{\pi} \cdot \mathrm{w}_{\mathrm{L}}^{4} \cdot \mathrm{w}_{\mathrm{p}} \cdot 1_{\mathrm{cav}} \cdot 1_{\mathrm{cr}} \cdot\left(1-\mathrm{e}^{-\alpha \cdot \mathrm{l}_{\mathrm{b}}}\right)} \\
& \times \int_{0}^{\infty} \mathrm{dx} \int_{-\infty}^{\infty} \mathrm{dy} \int_{0}^{1_{\mathrm{cr}}} \mathrm{dz} \cdot \mathrm{x}^{2} \cdot \exp \left(-\alpha \cdot \mathrm{x}-\frac{2 \mathrm{x}^{2}}{\mathrm{w}_{\mathrm{L}}^{2}}\right) \cdot \exp \left(-\frac{2 \mathrm{y}^{2}}{\mathrm{w}_{\mathrm{L}}^{2}}-\frac{2 \mathrm{y}^{2}}{\mathrm{w}_{\mathrm{p}}^{2}}\right)
\end{aligned}
$$

Utilizando, para a direção y, a solução da integração da gaussiana mostrada na equação 37 para o intervalo de $-\infty$ a $+\infty$ obtém-se, então, a equação 77.

$$
\mathrm{V}_{\text {eff }, 2}^{-1}=\frac{8 \alpha}{\pi \cdot \mathrm{w}_{\mathrm{L}}^{3} \cdot\left(1-\mathrm{e}^{-\alpha \mathrm{I}_{\mathrm{b}}}\right) \cdot \mathrm{l}_{\text {cav }}} \cdot \frac{1}{{\sqrt{\mathrm{w}_{\mathrm{p}}^{2}+\mathrm{w}_{\mathrm{L}}^{2}}}^{\infty}} \cdot \int_{0}^{\infty} \mathrm{x}^{2} \cdot \exp \left(-\alpha \cdot \mathrm{x}-\frac{2 \mathrm{x}^{2}}{\mathrm{w}_{\mathrm{L}}^{2}}\right) \cdot \mathrm{dx}
$$


A solução para integração em x é dada por

$$
\begin{aligned}
& \int_{0}^{\infty} x^{2} \cdot \exp \left(-\gamma \cdot x-a \cdot x^{2}\right) \cdot d x=\left(\frac{1}{4 a} \cdot \sqrt{\frac{\pi}{a}}+\frac{\gamma^{2}}{8 a^{2}} \cdot \sqrt{\frac{\pi}{a}}\right) \cdot \exp \left(\frac{\gamma^{2}}{4 a}\right) \\
& \left(1-\frac{2}{\sqrt{\pi}} \cdot \int_{0}^{\gamma / 2 \sqrt{a}} \mathrm{e}^{-t^{2}} \cdot d t\right)-\frac{\gamma}{4 a^{2}}
\end{aligned}
$$

Aplicando-se a solução 78, é possível calcular a integral em x da equação 77 e obter o resultado do volume efetivo para o modo $\mathrm{TEM}_{10}$, sendo que $\gamma=\alpha \mathrm{e} a=2 / \mathrm{w}_{\mathrm{L}}^{2}$.

$$
\begin{aligned}
& \mathrm{V}_{\mathrm{eff}, 2}{ }^{-1}=\frac{\alpha}{\sqrt{2 \pi} \cdot\left(1-\mathrm{e}^{-\alpha \cdot \mathrm{l}_{\mathrm{b}}}\right) \cdot 1_{\text {cav }}} \cdot \frac{1}{\sqrt{\mathrm{w}_{\mathrm{p}}^{2}+\mathrm{w}_{\mathrm{L}}^{2}}} \\
& \cdot\left[\left(1+\frac{\alpha^{2} \mathrm{w}_{\mathrm{L}}^{2}}{4}\right) \cdot \exp \left(\frac{\mathrm{w}_{\mathrm{L}}^{2} \cdot \alpha^{2}}{8}\right) \cdot\left(1-\frac{2}{\sqrt{\pi}} \cdot \int_{0}^{\alpha \cdot \mathrm{w}_{\mathrm{L}} / 2 \sqrt{2}} \mathrm{e}^{-\mathrm{t}^{2}} \cdot \mathrm{dt}\right)-\frac{\mathrm{w}_{\mathrm{L}} \cdot \alpha}{\sqrt{2 \pi}}\right]
\end{aligned}
$$

A partir do resultado do volume efetivo, é possível determinar o limiar de oscilação $\mathrm{R}_{\mathrm{th}, 2}$ do modo $\mathrm{TEM}_{10}$, conforme demonstrado na equação 59. Desta forma, a razão entre os limiares de oscilação do modo TEM $_{00}$ e do modo TEM $_{10}$ é dada por

$$
\frac{\mathrm{R}_{\mathrm{th}, 1}}{\mathrm{R}_{\mathrm{th}, 2}}=1+\frac{\alpha^{2} \mathrm{w}_{\mathrm{L}}^{2}}{4}-\frac{\alpha \cdot \mathrm{w}_{\mathrm{L}}}{\sqrt{2 \pi}} \cdot \exp \left(-\frac{\alpha^{2} \mathrm{w}_{\mathrm{L}}^{2}}{8}\right) \cdot\left(1-\frac{2}{\sqrt{\pi}} \cdot \int_{0}^{\alpha \cdot \mathrm{w}_{\mathrm{L}} / 2 \sqrt{2}} \mathrm{e}^{-\mathrm{t}^{2}} \cdot \mathrm{dt}\right)^{-1}
$$

A equação 80 está graficamente representada na figura 5, considerando um coeficiente de absorção igual a $8 \mathrm{~cm}^{-1}$, que corresponde ao valor empregado experimentalmente. 


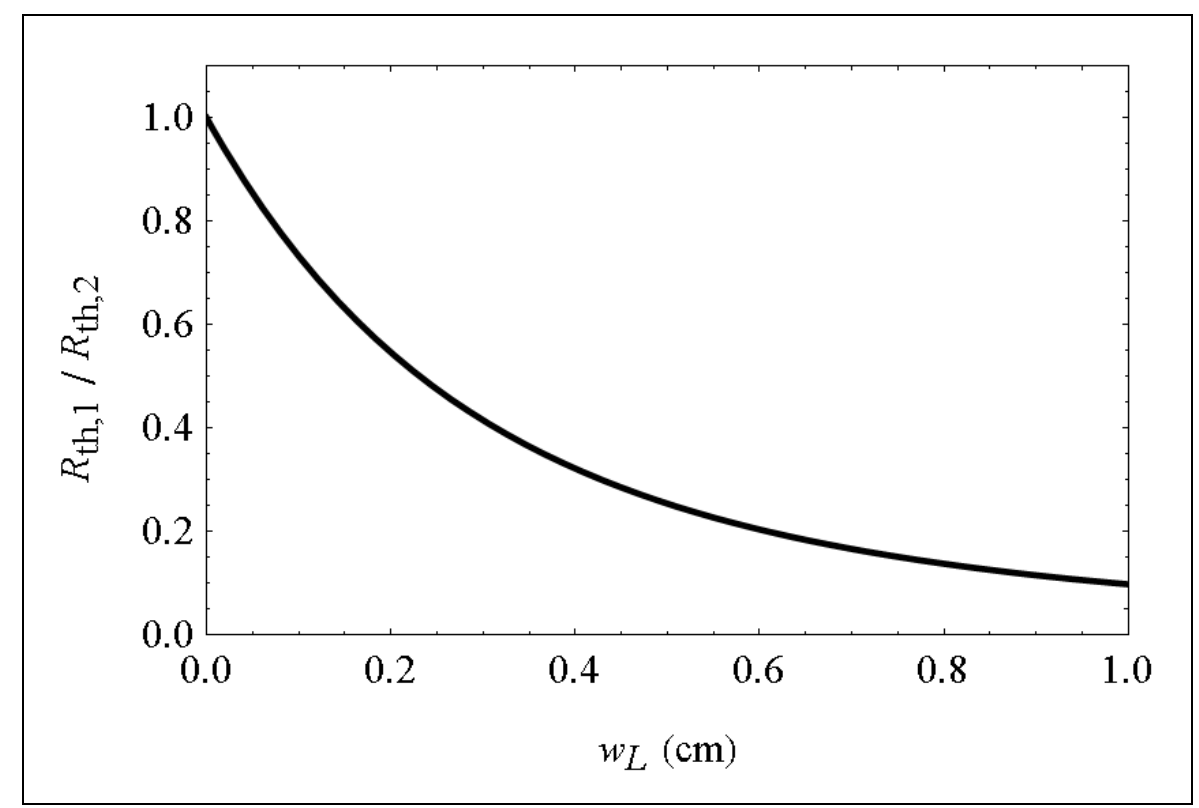

FIGURA 5: Razão entre o limiar de oscilação do modo TEM $_{00}$ e do modo TEM $_{10}$ •

De acordo com os dados apresentados na figura 5, o modo TEM $_{00}$ sempre apresenta menor limiar de oscilação que o modo $\mathrm{TEM}_{10}$, independentemente do raio do feixe intracavidade. 


\section{MEIO ATIVO E BOMBEAMENTO}

De forma geral, o funcionamento de um laser depende de três componentes principais: o meio ativo, a fonte de bombeamento e a cavidade óptica ressonante. Cada componente possui variantes distintas com vantagens e desvantagens que os tornam propícios a determinadas aplicações e determinam as características finais do laser.

\subsection{Meio ativo}

O meio ativo de um laser é o material em que ocorrem as transições enérgicas com a emissão de fótons e a conseqüente amplificação da luz. Este meio pode ser gasoso, sólido ou líquido. Os lasers que utilizam meio de ganho sólido são denominados lasers de estado sólido. Materiais para operação laser devem possuir determinadas características propícias para sua aplicação, devendo-se levar em consideração, por exemplo, a largura das linhas de emissão e absorção, a eficiência quântica na transição de interesse, a resistência mecânica, entre outras. Lasers de estado sólido têm vantagens distintas sobre lasers que utilizam gases ou líquidos, uma vez que a robustez inerente ao meio sólido proporciona uma vida operacional maior.

Os meios de ganho de estado sólido geralmente são constituídos por uma matriz ou material hospedeiro onde são incorporadas pequenas quantidades de íons dopantes, em que ocorrerão as transições entre níveis de energia. Tais íons ativos são inseridos na matriz por meio da substituição de um dos seus elementos.

Cada tipo de material hospedeiro possui características ópticas, mecânicas e térmicas distintas, além de propriedades únicas na interação com os íons dopantes. Para suportar as condições de operação de um laser, o material hospedeiro deve possuir características satisfatórias como resistência mecânica, estabilidade química, ausência de tensões internas, facilidade de fabricação, entre diversas outras.

Os materiais hospedeiros de estado sólido podem ser agrupados, de forma geral, em matrizes cristalinas ou vítreas. Os vidros apresentam a vantagem prática de maior facilidade para fabricação de amostras com tamanho grande, mantendo alta qualidade óptica. Em contrapartida, os íons ativos inseridos em matrizes vítreas, em geral, apresentam espectro de fluorescência mais largo, em virtude da ausência de um campo 
cristalino bem definido ao redor do íon, o que confere aos vidros menor secção de choque e, conseqüentemente, maior limiar de operação laser [8]. Embora linhas de emissão largas possam ser uma vantagem na obtenção de pulsos ultracurtos. Além disso, os vidros possuem condutividade térmica menor que hospedeiros cristalinos por apresentarem uma desordem estrutural, podendo acarretar em intensos efeitos térmicos ou fratura, quando operados em níveis altos de energia. Desta forma, matrizes cristalinas oferecem vantagens como maiores valores de condutividade térmica, largura de linhas de fluorescência mais estreita, limiares de operação mais baixos, e, em alguns casos, maior dureza. Em contrapartida, a qualidade óptica e a homogeneidade da dopagem nos cristais são freqüentemente mais difíceis de se obter e as linhas de absorção são geralmente mais estreitas, dificultando a ressonância com o comprimento de onda de bombeamento [2].

Os principais materiais hospedeiros cristalinos podem ser agrupados em diferentes categorias, a seguir são mostrados alguns exemplos de materiais para cada categoria:

- Óxidos: safira $\left(\mathrm{Al}_{2} \mathrm{O}_{3}\right)$, Granadas $\left(\mathrm{Y}_{3} \mathrm{Al}_{5} \mathrm{O}_{12}\right.$ ou YAG, $\mathrm{Gd}_{3} \mathrm{Ga}_{5} \mathrm{O}_{12}$ ou GGG, $\mathrm{Gd}_{3} \mathrm{Sc}_{2} \mathrm{Al}_{3} \mathrm{O}_{12}$ ou GSGG), Aluminatos ( $\mathrm{YAlO}_{3}$ ou YAP) e Oxisulfetos $\left(\mathrm{La}_{2} \mathrm{O}_{2} \mathrm{~S}\right.$ ou LOS)

- Fosfatos e Silicatos: fluor-apatita $\left(\mathrm{Ca}_{5}\left(\mathrm{PO}_{4}\right)_{3} \mathrm{~F}\right.$ ou FAP) e silicato de oxi-apatita (CaLaSOAP)

- Tungstatos, Molibdatos, Vanadatos e Berilatos: $\mathrm{CaWO}_{4}, \mathrm{CaMoO}_{4}, \mathrm{YVO}_{4} \mathrm{e}$ $\mathrm{La}_{2} \mathrm{Be}_{2} \mathrm{O}_{5}$ ou BEL

- Fluoretos: $\mathrm{YLiF}_{4}$ ou YLF, $\mathrm{GdLiF}_{4}$ ou GLF, e $\mathrm{CaF}_{2}$

O dopante da matriz é o elemento em que ocorrem as transições ópticas entre diferentes estados de energia, determinando as linhas espectrais de absorção e emissão do meio. Desta forma, existem lasers desenvolvidos a partir de diferentes combinações entre matrizes e elementos dopantes, cada qual possuindo suas próprias características que determinam as possíveis aplicações de um laser. Muitas interações entre a matriz hospedeira e o íon dopante restringem as possíveis combinações úteis, por exemplo, as propriedades espectroscópicas e a disparidade de tamanho e valência entre os íons a serem substituídos. Em geral, após serem inseridos em uma matriz, os íons ativos devem possuir uma transição radiativa útil para ação laser, com tempo de vida alto e seção de choque que leve a um ganho significativo. 
Os principais elementos dopantes incluem os íons de terras raras e os metais de transição. Os cristais dopados com íons trivalentes de terras raras são os materiais mais usados como meio ativo em lasers de estado sólido por possuírem transições laser muito finas e cobrirem quase toda a região do espectro visível e infravermelho próximo [9]. O comprimento de onda de emissão do laser varia de acordo com o íon e, de forma mais sutil, de acordo com o material hospedeiro empregado.

As terras raras são um grupo de elementos químicos constituído pelo grupo dos lantanídeos (elementos com número atômico entre 57 e 71), incluindo-se também o escândio e o ítrio. Atualmente, todos os íons de terras raras empregados como meio ativo laser pertencem ao grupo dos lantanídeos. Mesmo os elementos que não são utilizados como íons ativos para ação laser, acabam sendo empregados como codopantes, absorvedores saturáveis ou como elemento primário em cristais laser (a exemplo do ítrio nos cristais de YLF e YAG).

Uma das carcaterísticas dos íons trivalentes de terras raras é a emissão em linhas estreitas mesmo na presença de fortes campos locais da rede cristalina, como consequência da proteção oferecida pelos elétrons das camadas mais externas [10]. A configuração eletrônica típica desses elementos pode ser resumida em: [Xe] $4 \mathrm{f}^{\mathrm{n}} 5 \mathrm{~s}^{2} 5 \mathrm{p}^{6}$ $5 \mathrm{~d}^{0-1} 6 \mathrm{~s}^{2}$ com $\mathrm{n}$ de 1 a 14 . Pode-se observar que as configurações atômicas são caracterizadas por orbitais $4 \mathrm{f}$ parcialmente preenchidos que se situam internamente aos orbitais $5 \mathrm{~s}^{2} 5 \mathrm{p}^{6}$ da estrutura do Xe. Esta estrutura do Xe atua como uma "casca" opticamente inativa que blinda os níveis $4 \mathrm{f}$ do átomo às perturbações externas. Assim, as emissões estreitas dos íons de terra rara são explicadas pelo fato dos elétrons que fazem a transição a partir dos orbitais 4f estarem dentro de uma camada protetora, interagindo fracamente com outros íons.

O íon de neodímio foi o primeiro elemento do grupo das terras raras a ser utilizado como meio ativo em um laser e permanece como um dos elementos mais importantes neste grupo, sendo amplamente empregado em diversos materiais hospedeiros para ação laser em sistemas de quatro níveis. As principais emissões radiativas do $\mathrm{Nd}^{3+}$ ocorrem a partir do nível ${ }^{4} \mathrm{~F}_{3 / 2}$ para os níveis ${ }^{4} \mathrm{I}_{9 / 2},{ }^{4} \mathrm{I}_{11 / 2}$ e ${ }^{4} \mathrm{I}_{13 / 2}$ com comprimentos de onda centrados em 0,$9 ; 1,06$ e $1,35 \mu \mathrm{m}$, respectivamente, em que o nível ${ }^{4} \mathrm{I}_{9 / 2}$ é o estado fundamental.

Entre os diversos tipos de matrizes utilizadas como meio ativo para o $\mathrm{Nd}^{3+}$, pode-se destacar o YAG, o $\mathrm{YVO}_{4}$ e o YLF. Cada matriz possui características que favorecem determinadas propriedades do laser. 
O YAG é a matriz mais comumente empregada em virtude de sua boa qualidade óptica, alta condutividade térmica e dureza, proporcionando uma alta resistência do material a fraturas, podendo, assim, suportar altas taxas de bombeamento [11]. Além disso, sua estrutura cúbica favorece linhas de emissão estreitas, alto ganho e baixo limiar de operação. Contudo, o YAG apresenta forte lente térmica e despolarização do feixe em virtude da isotropia do cristal, podendo ocasionar perda de potência de saída do laser [12].

Os vanadatos, como o $\mathrm{GdVO}_{4}$ e o $\mathrm{YVO}_{4}$, são caracterizados por apresentarem secção de choque de emissão estimulada e coeficiente de absorção óptica muito maiores que outros materiais, o que os torna muito eficiente em determinadas configurações [13, 14]. Além disso, sua birrefringência natural elimina perdas por despolarização termicamente induzida. No entanto, são materiais que apresenta forte distorção óptica e lente termicamente induzida [15].

Ação laser com o cristal de YLF (tetrafluoreto de ítrio e lítio) já foi reportada com dopantes como $\mathrm{Ce}^{3+}, \mathrm{Pr}^{3+}, \mathrm{Nd}^{3+}, \mathrm{Tb}^{3+}, \mathrm{Ho}^{3+}, \mathrm{Er}^{3+}$ e $\mathrm{Tm}^{3+}$, com comprimentos de onda de emissão entre $0,32 \mu \mathrm{m}\left(\mathrm{Ce}^{3+}\right)$ e $3,9 \mu \mathrm{m}\left(\mathrm{Ho}^{3+}\right)$. Contudo, o neodímio é seu principal dopante, usualmente utilizado com concentrações inferiores a $2 \mathrm{~mol} \%$. Recentemente, o $\mathrm{Nd}$ :YLF tem ganhado interesse e lasers de alta potência com alta qualidade de feixe têm sido desenvolvidos a partir dele [16, 17]. Lasers de Nd:YLF possuem diversas aplicações tais como bombeamento de outros lasers de estado sólido [18], tratamento médico [19], operações industriais [20] e monitoração ambiental por LIDAR (Light Detection and Ranging) [21]. O Nd:YLF apresenta características importantes para lasers de alta potência no infravermelho próximo, principalmente em regimes de funcionamento intermitentes como o chaveamento-Q, em que o seu maior tempo de vida no nível laser superior, cerca de duas vezes maior que o do YAG, permite uma maior inversão de população estacionária. A secção de choque de emissão do YLF, por sua vez, é cerca de duas vezes menor que a do YAG, levando a valores menores da taxa de decaimento por emissão estimulada. Devido a essas características, o meio ativo tem mais energia armazenada durante a ação laser que pode ser convertida em pulsos ópticos mais intensos [22].

As principais emissões do Nd:YLF são polarizadas devido ao efeito do campo cristalino, estando esquematizadas na figura $6[23,24]$. A polarização paralela ao eixo c do cristal (eixo óptico) é denominada $\pi$, ao passo que a polarização perpendicular ao eixo c é denominada $\sigma$. A partir do nível laser superior ${ }^{4} \mathrm{~F}_{3 / 2}$, pode ocorrer decaimento radiativo por duas possíveis transições: para o nível ${ }^{4} \mathrm{I}_{13 / 2}$ com emissão em $1321 \mathrm{~nm}(\pi)$ [25] ou $1313 \mathrm{~nm}$ 
$(\sigma)$ [26] e para o nível ${ }^{4} \mathrm{I}_{11 / 2}$ com emissão em $1047 \mathrm{~nm}(\pi)$ [16, 17] ou 1053nm ( $\sigma$ ) [27]. Em geral, a emissão na polarização $\pi$ tende a ser predominante se nenhum mecanismo é utilizado para suprimi-la, uma vez que a secção de choque de emissão é maior do que em $\sigma$, ocasionando maior ganho. A transição do Nd:YLF em $1053 \mathrm{~nm}$, correspondente à polarização perpendicular ao eixo c do cristal, possui uma boa sobreposição com lasers de neodímio em matrizes vítreas de fosfatos e fluorfosfatos sendo, desta maneira, utilizado como oscilador principal em sistemas amplificadores usando esses vidros.

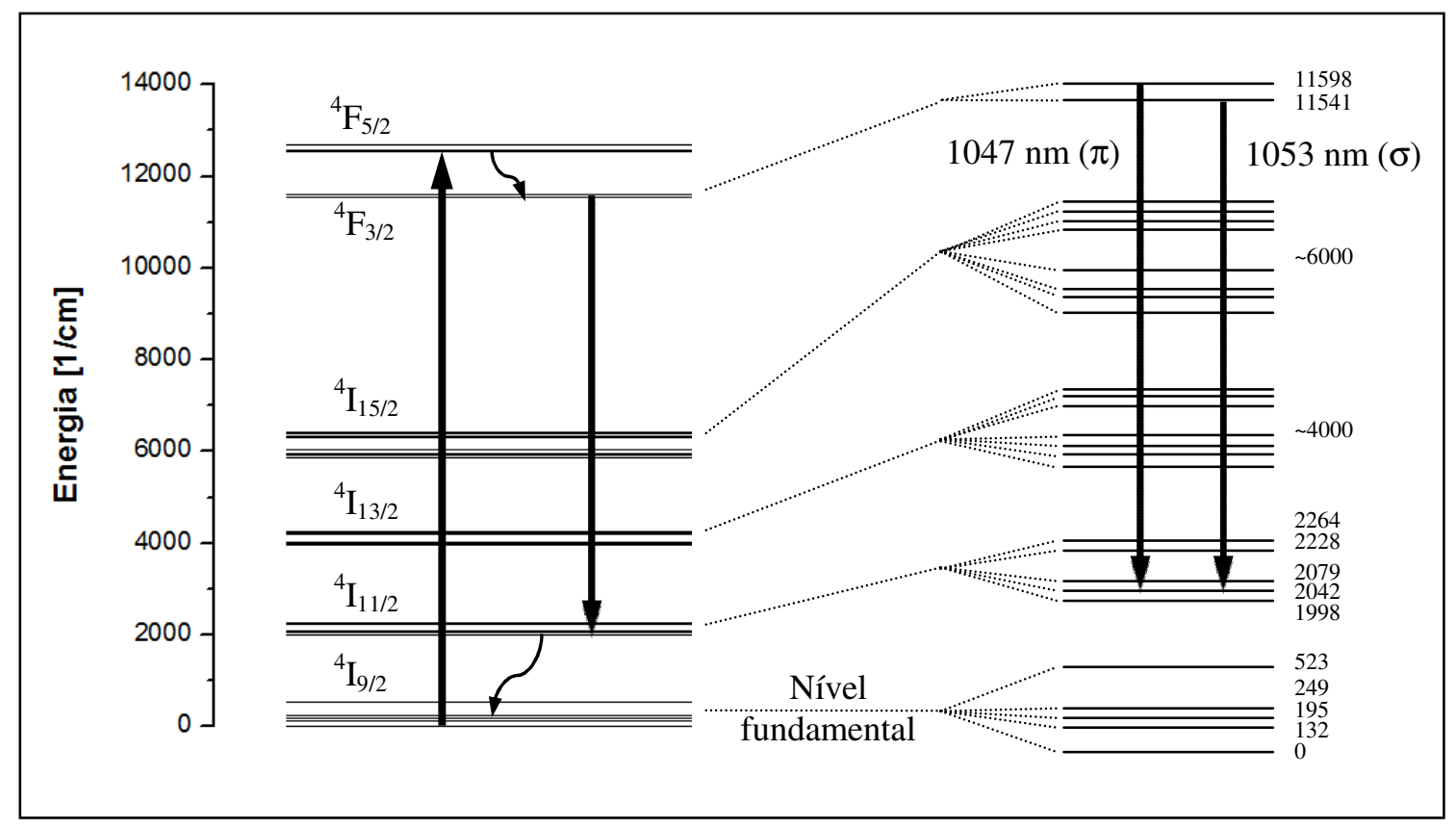

FIGURA 6: Diagrama de níveis de energia simplificado do Nd:YLF.

No entanto, as principais qualidades do cristal de Nd:YLF são suas boas características termo-ópticas, uma vez que sua alta birrefringência natural subjuga efeitos de birrefringência termicamente induzida, eliminando os problemas de despolarização que ocorrem em matrizes isotrópicas. Além disso, sua fraca lente térmica, principalmente na polarização correspondente à transição de $1053 \mathrm{~nm}$, resulta em uma alta qualidade do feixe de saída $[12,28]$. Esta fraca lente térmica, observada sobretudo sob oscilação laser, é uma consequiência do decréscimo do índice de refração com o aumento da temperatura (coeficiente termo-óptico negativo), criando uma componente negativa da lente térmica que parcialmente compensa as componentes positivas [29].

A principal desvantagem do Nd:YLF é o baixo limite de fratura que o cristal apresenta em decorrência de sua baixa resistência mecânica e baixa condutividade térmica quando comparado com outras matrizes [30]. 
$\mathrm{Na}$ tabela 1 apresenta-se algumas características das matrizes discutidas dopadas com $\mathrm{Nd}^{3+}[2,31,32,33]$.

Tabela 1: Propriedades mecânicas ópticas e térmicas de diferentes matrizes dopadas com $\mathrm{Nd}^{3+}$.

\begin{tabular}{|c|c|c|c|c|}
\hline Propriedade & Nd:YLF & Nd:YAG & $\mathrm{Nd}: \mathrm{YVO}_{4}$ & Nd:GdVO \\
\hline Fórmula química & $\mathrm{YLiF}_{4}$ & $\mathrm{Y}_{3} \mathrm{Al}_{5} \mathrm{O}_{12}$ & $\mathrm{YVO}_{4}$ & $\mathrm{GdVO}_{4}$ \\
\hline $\begin{array}{l}\text { Simetria cristalina/ } \\
\text { grupo pontual }\end{array}$ & $\begin{array}{c}\text { Tetragonal/ } \\
\mathrm{C}_{4 \mathrm{~h}}^{6}\end{array}$ & $\begin{array}{l}\text { Cúbico/ } \\
\mathrm{O}_{\mathrm{h}}^{10}\end{array}$ & $\begin{array}{c}\text { Tetragonal/ } \\
\mathrm{D}_{4 \mathrm{~h}}\end{array}$ & $\begin{array}{c}\text { Tetragonal/ } \\
\mathrm{D}_{4 \mathrm{~h}}\end{array}$ \\
\hline $\begin{array}{l}\text { Constante da rede } \\
\text { cristalina }[\AA]\end{array}$ & $\begin{array}{l}a=5,26 \\
c=10,94\end{array}$ & 12,01 & $\begin{array}{c}a=b=7,12 \\
c=6,29\end{array}$ & $\begin{array}{c}a=b=7,2 \\
c=6,35\end{array}$ \\
\hline $\begin{array}{l}\text { Índice de refração } \\
\qquad(\lambda=1 \mu \mathrm{m})\end{array}$ & $\begin{array}{l}1,4481\left(\mathrm{n}_{\mathrm{o}}\right) \\
1,4704\left(\mathrm{n}_{\mathrm{e}}\right)\end{array}$ & 1,82 & $\begin{array}{l}1,9573\left(\mathrm{n}_{\mathrm{o}}\right) \\
2,1652\left(\mathrm{n}_{\mathrm{e}}\right)\end{array}$ & $\begin{array}{c}1,9854\left(\mathrm{n}_{\mathrm{o}}\right) \\
2,198\left(\mathrm{n}_{\mathrm{e}}\right)\end{array}$ \\
\hline Densidade $\left[\mathrm{g} / \mathrm{cm}^{3}\right]$ & 3,99 & 4,56 & 4,22 & 5,47 \\
\hline Ponto de fusão $\left[{ }^{\circ} \mathrm{C}\right]$ & 825 & 1970 & $1750-1900$ & 1780 \\
\hline Dureza [Mohs] & $4-5$ & 8,5 & 5,5 & 5 \\
\hline $\begin{array}{c}\text { Condutividade térmica } \\
\qquad\left[\mathrm{W} \mathrm{m}^{-1} \mathrm{~K}^{-1}\right]\end{array}$ & $\begin{array}{l}5,8(\text { eixo c) } \\
7,2(\text { eixo a) }\end{array}$ & 14 & $\begin{array}{l}5,23(\text { eixo c }) \\
5,10(\text { eixo a })\end{array}$ & 11,7 \\
\hline $\begin{array}{l}\text { Coeficiente de expansão } \\
\text { térmica }\left[10^{-6} \mathrm{~K}^{-1}\right]\end{array}$ & $\begin{array}{l}8(\text { eixo c) } \\
13(\text { eixo a) }\end{array}$ & 7,8 & $\begin{array}{c}11,37 \text { (eixo c) } \\
4,43 \text { (eixo a) }\end{array}$ & $\begin{array}{l}7,3 \text { (eixo c) } \\
1,5 \text { (eixo a) }\end{array}$ \\
\hline $\begin{array}{l}\text { Coeficiente termo-óptico } \\
(\mathrm{dn} / \mathrm{dT})\left[10^{-6} \mathrm{~K}^{-1}\right]\end{array}$ & $\begin{array}{l}-4,3 \text { (eixo c) } \\
-2(\text { eixo a) }\end{array}$ & 8,3 & $\begin{array}{c}3(\text { eixo c) } \\
8,5(\text { eixo a) }\end{array}$ & 4,7 \\
\hline $\begin{array}{c}\text { Secção de choque de } \\
\text { emissão estimulada } \\
{\left[10^{-19} \mathrm{~cm}^{2}\right]}\end{array}$ & $\begin{array}{l}1,8(\pi) \\
1,2(\sigma)\end{array}$ & 2,8 & 25 & 7,6 \\
\hline $\begin{array}{l}\text { Tempo de vida de } \\
\text { fluorescência }[\mu \mathrm{s}]\end{array}$ & 520 & 230 & 90 & 95 \\
\hline $\begin{array}{l}\text { Comprimento de onda da } \\
\text { transição }{ }^{4} \mathrm{~F}_{3 / 2} \rightarrow{ }^{4} \mathrm{I}_{11 / 2} \\
{[\mathrm{~nm}]}\end{array}$ & $\begin{array}{l}1047(\pi) \\
1053(\sigma)\end{array}$ & 1064 & 1064 & 1063,1 \\
\hline $\begin{array}{l}\text { Comprimento de onda da } \\
\text { transição }{ }^{4} \mathrm{~F}_{3 / 2} \rightarrow{ }^{4} \mathrm{I}_{13 / 2} \\
{[\mathrm{~nm}]}\end{array}$ & $\begin{array}{l}1321(\pi) \\
1313(\sigma)\end{array}$ & 1320 & 1342 & 1341,3 \\
\hline
\end{tabular}




\subsection{Bombeamento}

A fonte de energia é responsável pela excitação do meio ativo a um estado energético apropriado, realizando o bombeamento com energia ressonante entre os níveis excitado e fundamental. Em lasers de estado sólido, o bombeamento óptico em geral é realizado por lâmpada ou por lasers de diodo.

Devido à busca por lasers compactos e de alto desempenho, tem-se tornado cada vez mais comum à utilização do diodo laser como fonte de bombeamento. Grande parte dos lasers desenvolvidos tradicionalmente utiliza tecnologia de bombeamento por lâmpada; no entanto, os lasers de semicondutor vêm se expandindo rapidamente no mercado e uma grande parcela dos lasers comumente utilizados está atualmente sendo substituída por lasers de estado sólido bombeados por diodo, em vista das vantagens em termos de eficiência e tamanho oferecidos pelo diodo laser. Embora apresente custo mais elevado, o diodo apresenta diversas vantagens em relação à lâmpada, tal como possuir uma vida útil maior que as lâmpadas do tipo arco ou "flash". Enquanto as lâmpadas apresentam tempo de vida da ordem de $10^{8}$ pulsos ou cerca de 500h para operação contínua, o diodo laser apresenta duração da ordem de $10^{9}$ pulsos ou $10^{4} \mathrm{~h}$ em operação contínua.

No entanto, a maior vantagem do diodo laser é a alta eficiência na utilização da energia de bombeamento. Embora as lâmpadas possuam maior eficiência na conversão da energia elétrica aplicada em radiação eletromagnética (até 70\%), quando comparadas com os diodos (25-50\%), o seu espectro de emissão de emissão é muito largo, de forma que apenas uma pequena parte da radiação de bombeamento é absorvida pelo meio ativo. Uma vez que os diodos possuem banda de emissão estreita e podem ser sintonizados pela temperatura, o uso de diodos como fonte de bombeamento permite alta sobreposição entre o seu espectro de emissão e o espectro de absorção do meio ativo. Tem-se, assim, a obtenção de eficiências de conversão óptico-óptico da ordem de 30\% a 65\% dependendo do material hospedeiro $[34,35]$, ao passo que a utilização de lâmpadas tipicamente resulta em eficiências da ordem de $1 \%$ a $3 \%$ [36] (conversão de energia luminosa da lâmpada em energia luminosa do laser).

A melhor utilização da energia de bombeamento diminui o calor gerado no meio ativo pela energia não absorvida, diminuindo a necessidade de refrigeradores de grande porte e alto custo. A menor geração de calor também permite a utilização de maiores potências de bombeamento antes de ocorrer fratura do meio ativo por tensões térmicas. Por fim, também causa a atenuação dos efeitos termo-ópticos que são gerados no 
cristal em virtude do excesso de calor, como lente térmica e birrefringência termicamente induzida, resultando, portanto, em uma melhor qualidade do feixe emitido pelo laser.

Em contraste às lâmpadas, a emissão dos diodos laser é altamente direcional, possibilitando a utilização de diversos arranjos para transferir a radiação de bombeamento para o meio de ganho. Uma vez que o feixe emitido pelo diodo pode ser focalizado e reconfigurado, é fundamental desenvolver configurações de bombeamento que permitam maximizar a sobreposição entre da região excitada pelo bombeamento e o volume ocupado pelos modos de baixa ordem no ressonador, para otimizar a eficiência e a qualidade do feixe laser de saída.

Tipicamente, o bombeamento do meio ativo pode ser realizado por duas configurações diferentes, nomeadas bombeamento longitudinal e bombeamento transversal. O bombeamento longitudinal é realizado ao longo da direção de propagação do feixe laser intracavidade, em geral de forma colinear com o eixo do ressonador. Já no bombeamento transversal ou lateral, a radiação do diodo é depositada no meio ativo perpendicularmente ao eixo do feixe laser.

O bombeamento longitudinal é a configuração mais eficiente para a transferência de energia ao meio ativo, por permitir o máximo aproveitamento da energia de bombeamento, se propriamente configurado para promover um bom acoplamento entre a radiação de bombeamento e o modo transversal do ressonador. Além disso, a utilização deste tipo de configuração naturalmente permite maior otimização do acoplamento com o modo fundamental do laser. Contudo, os diodos laser de alta potência emitem feixes não gaussianos e extremamente assimétricos que necessitam de uma complexa óptica de reconfiguração em feixes circulares para sua aplicação em geometrias baseadas em bombeamento longitudinal [37, 38, 39, 40]. Os melhores desempenhos em lasers de Nd:YLF bombeados por diodo foram obtidos utilizando o bombeamento longitudinal, em que foi reportada uma eficiência óptica máxima de 53\% para oscilação em 1047nm [41] e $54 \%$ para oscilação em $1053 \mathrm{~nm}$ no modo fundamental [42]. No entanto, a alta concentração da energia do diodo restringe a potência de bombeamento devido ao risco de fratura e causa fortes efeitos termo-ópticos devido ao gradiente de temperatura gerado.

A utilização de bombeamento transversal permite aliviar estes efeitos, pois não requer a reconfiguração do feixe do diodo e possibilita que a potência de bombeamento possa ser mais distribuída ao longo do cristal. Desta forma, permite o aumento da potência de bombeamento, bem como o uso de múltiplas fontes de bombeamento. Contudo, esta 
configuração dificulta o acoplamento com o feixe intracavidade, podendo ocasionar baixa eficiência, principalmente quando operando no modo fundamental.

O uso de cristais com secção retangular (slab) e múltiplas reflexões internas do feixe intracavidade é largamente empregado no desenvolvimento de lasers de estado sólido devido aos benefícios térmicos proporcionados por esses arranjos, no que se refere à diminuição de birrefringência e lente termicamente induzidos [43]. Muitas variações dessas configurações já foram reportadas na literatura, em geral, com a radiação de bombeamento bem distribuída dentro do cristal [44], permitindo aumentar a potência de bombeamento até níveis de $\mathrm{kW}$ [45]. Algumas cavidades utilizando Nd:YLF com múltiplas reflexões internas sob bombeamento transversal já demonstraram alta eficiência durante operação no modo fundamental. Baer et al. demonstraram isto utilizando uma configuração com diversas dobras na face de bombeamento com o uso de filmes finos, em que cada reflexão foi alinhada para maximizar o acoplamento com a radiação emitida por um único emissor da barra de diodos [46]. Dergachev et al. desenvolveram uma configuração com múltiplos passos para otimizar a obtenção do modo $\mathrm{TEM}_{00}$, obtendo a maior eficiência (43\%) já reportada para um laser de Nd:YLF bombeado transversalmente por diodo na transição em 1047nm [47, 48].

Utilizando meios de ganho com alto coeficiente de absorção, uma interessante configuração sob bombeamento lateral foi proposta por Bernard et al. usando incidência em ângulo rasante, para explorar a alta inversão de população localizada próximo à superfície de bombeamento, em que o feixe laser realizar uma dobra por reflexão interna total [13]. Usando Nd: $\mathrm{YVO}_{4}$ com esta configuração, Minassian et. al. obtiveram $68 \%$ de eficiência óptica com um feixe de saída multimodo e $58 \%$ de eficiência no modo fundamental, melhorando a qualidade do feixe por meio de uma cavidade assimétrica [14]. Em seguida, demonstraram que a qualidade do feixe também poderia ser melhorada, obtendo-se o modo fundamental, utilizando uma geometria com duas dobras na face de bombeamento com uma cavidade composta por quatro espelhos [49]. 


\section{MATERIAIS E MÉTODOS}

\subsection{Meio ativo}

A etapa inicial no processo de construção do protótipo laser foi a caracterização e preparação do cristal empregado como meio ativo. O cristal de tetrafluoreto de ítrio e lítio (YLF) utilizado foi crescido pelo método Czochralski no Centro de Lasers e Aplicações do Instituto de Pesquisas Energéticas e Nucleares (IPEN). O cristal, até então com a forma de um tarugo cilíndrico, primeiramente foi submetido a uma análise de orientação cristalográfica a fim de se averiguar a direção do eixo c (eixo óptico), determinando-se que este se localizava longitudinalmente ao eixo do tarugo. Esta análise foi feita incidindo o feixe de um laser de He-Ne no cristal disposto entre polarizadores cruzados e analisando o efeito da birrefringência do cristal no feixe emergente. $\mathrm{O}$ eixo c caracteriza-se por formar uma cruz na imagem emergente do arranjo.

O cristal possuía uma dopagem de $0,8 \mathrm{~mol} \%$ de neodímio, apresentando um coeficiente de absorção de $8 \mathrm{~cm}^{-1}$ no comprimento de onda de $792 \mathrm{~nm}$ e de $6 \mathrm{~cm}^{-1} \mathrm{em} 797 \mathrm{~nm}$ para a luz polarizada paralela ao eixo c do cristal (polarização $\pi$ ). O espectro de absorção do cristal, que pode ser observado na figura 7, foi obtido através de um espectrofotômetro da Varian, modelo CARY 17/OLIS, que se encontra instalado no laboratório de absorção óptica do Centro de Lasers e Aplicações do IPEN.

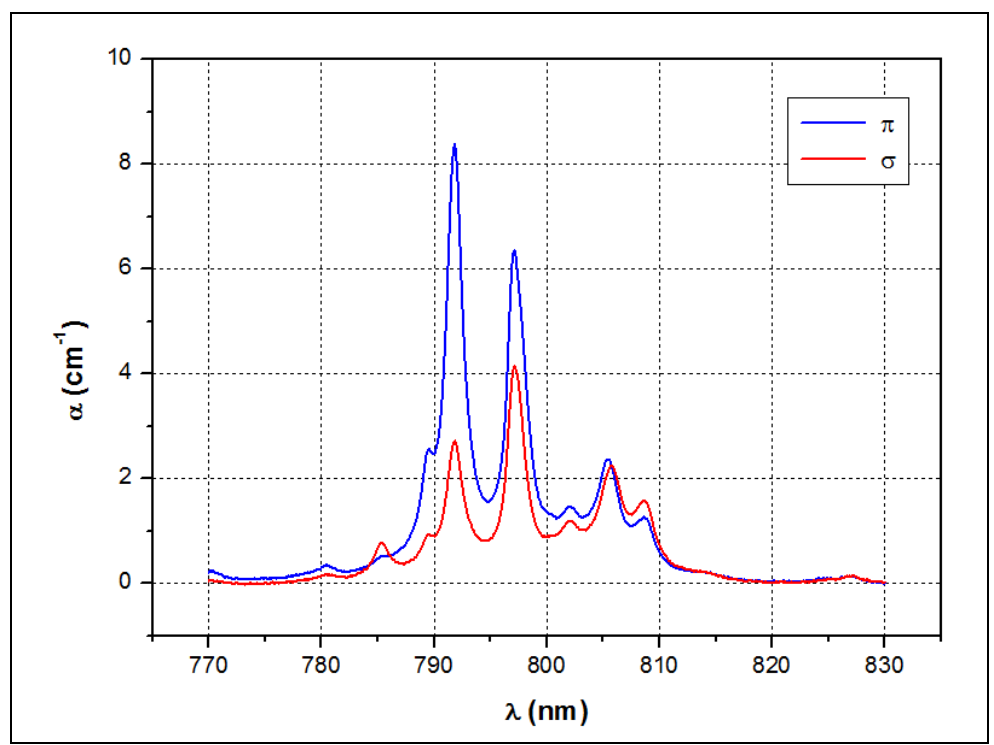

FIGURA 7: Espectro de absorção do cristal de Nd:YLF dopado com 0,8mol\% de neodímio. 
Dessa forma, depois de constatadas as características do cristal, deu-se início à preparação da amostra que seria utilizada na cavidade laser mediante etapas de corte, lapidação e polimento [50], com o objetivo de conceder-lhe a geometria e a qualidade óptica necessária para sua aplicação.

Primeiramente, o tarugo de Nd:YLF foi cortado em amostras retangulares mantendo o eixo c na posição conveniente à cavidade a ser montada; neste caso, perpendicular à face mais larga, para que ocorresse absorção paralela ao eixo c. Com o objetivo de que os danos mecânicos e térmicos à que a amostra de cristal teve de ser submetida fossem mínimos, os cortes foram realizados em uma máquina de corte a fio por abrasão (modelo 2006-A wire saw do fabricante LASTEC), utilizando carbureto de silício com granulometria de 600 mesh como agente de abrasão e etilenoglicol como solvente.

Após dar forma à amostra por meio do processo de corte, cada superfície foi submetida às etapas de lapidação e polimento, que são processos de abrasão cujo intuito é conferir à amostra as dimensões finais e o acabamento superficial necessário à sua aplicação como material óptico [51]. A lapidação é utilizada para eliminar imperfeições e erros macrogeométricos de forma. Já o polimento acentua a planicidade e elimina os danos superficiais da amostra atenuando, assim, a rugosidade da superfície, o que diminui eventuais perdas por espalhamento e reflexão difusa.

Os processos de lapidação e polimento são semi-automatizados pelo uso de um suporte ajustável, em que a amostra é presa por cera de abelha. Os ajustes deste suporte, aliado à utilização de um autocolimador, permitem realizar o controle do paralelismo e da perpendicularidade entre as faces do cristal. Este suporte rotaciona automaticamente em um braço móvel sobre uma base de fricção giratória (figura 8). A lapidação foi realizada sobre um disco de ferro fundido utilizando, como agente abrasivo, óxido de alumínio com granulometria das partículas da ordem de 2000 mesh e etilenoglicol como solvente. Além de veículo do agente abrasivo, o etilenoglicol também acumula a função de refrigeração da amostra. Durante o processo de lapidação, as dimensões da amostra foram controladas pelo uso de um relógio comparador. 


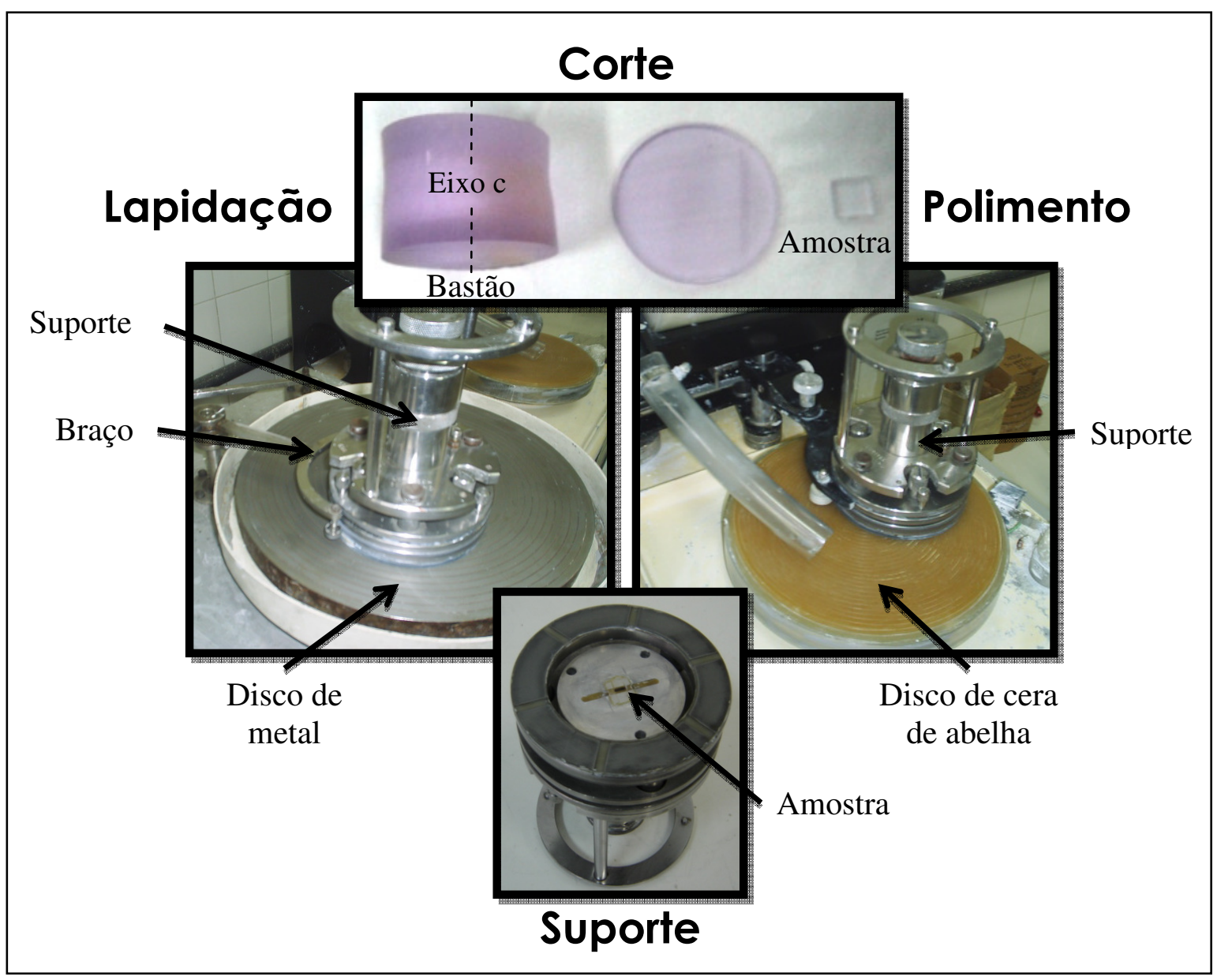

FIGURA 8: Processo de preparação de amostras de cristais laser - Corte (centro superior), lapidação (esquerda) e polimento (direita).

Logo em seguida à lapidação, a amostra foi submetida ao processo de polimento realizado em uma politriz automática (modelo PM2A, marca Logitech). Esta etapa é caracterizada por um longo processo de abrasão sobre um disco de cera de abelha, utilizando-se uma suspensão de óxido de alumínio com granulometria das partículas de $0,5 \mu \mathrm{m}$. Após o polimento, a qualidade das superfícies da amostra foi analisada em um microscópio óptico com aumento de 40 vezes, constatando-se a ausência de riscos

Ao final de todo o processo de preparação, obteve-se uma amostra de cristal de Nd:YLF com secção retangular medindo $14 \mathrm{~mm}$ x $13 \mathrm{~mm}$ de lado e $3,7 \mathrm{~mm}$ de espessura. Sendo que o eixo c está orientado perpendicularmente à superfície mais larga do cristal, isto é, paralelo à direção de $3,7 \mathrm{~mm}$, conforme ilustrado na Figura 9. 


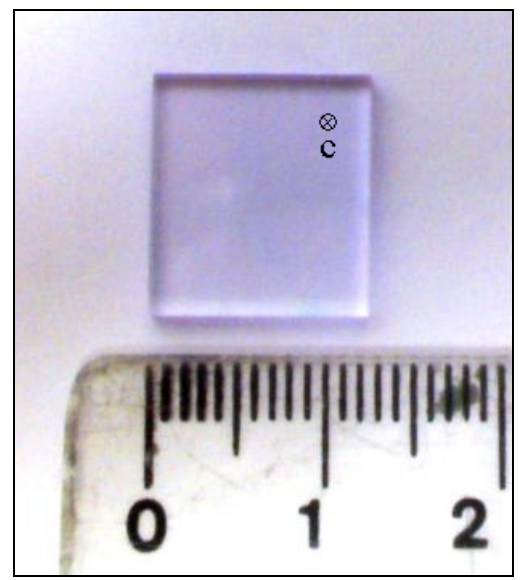

FIGURA 9: Cristal de Nd:YLF preparado com dimensões de 14mm x 13mm x 3,7mm.

\section{$5.2 \quad$ Bombeamento}

O bombeamento do meio ativo foi realizado através de uma barra de diodo laser de 20W da Coherent Inc. com emissão polarizada TM (transverse magnetic), o que corresponde à polarização perpendicular à junção. A orientação do eixo c no cristal empregado na cavidade foi determinada, durante o processo de preparação da amostra, de forma que o bombeamento fosse realizado com a polarização do diodo paralela ao eixo c do cristal, que corresponde à polarização com os maiores coeficientes de absorção (polarização $\pi$ ). Para obter-se alta absorção da radiação de bombeamento, o comprimento de onda de bombeamento foi determinado de forma que correspondesse ao maior pico de absorção do cristal.

A grande vantagem do bombeamento por diodo laser é a alta eficiência na utilização da energia de bombeamento, uma vez que o diodo possui emissão estreita e pode ser sintonizado pela temperatura. $\mathrm{O}$ diodo utilizado possui largura espectral a meia altura (FWHM) de 3,2nm e, embora apresente emissão nominal em torno de 795nm sob regime contínuo, pôde ser sintonizado pela temperatura para 792nm quando operado em regime pulsado, garantindo, assim, alta sobreposição do seu espectro de emissão com o espectro de absorção do meio ativo no comprimento de onda correspondente ao seu maior coeficiente de absorção, como pode ser visto no espectro apresentado na figura 10, que foi retirado com um espectrômetro óptico comercial (modelo HR2000, marca Ocean Optics). Para emissão em torno do comprimento de onda de 792nm, o diodo foi mantido a uma temperatura de $24,5^{\circ} \mathrm{C}$. O controle da temperatura do diodo foi realizado por um circuito fechado com um controlador da Eurotherm conectado a um módulo Peltier (pastilha termoelétrica). 


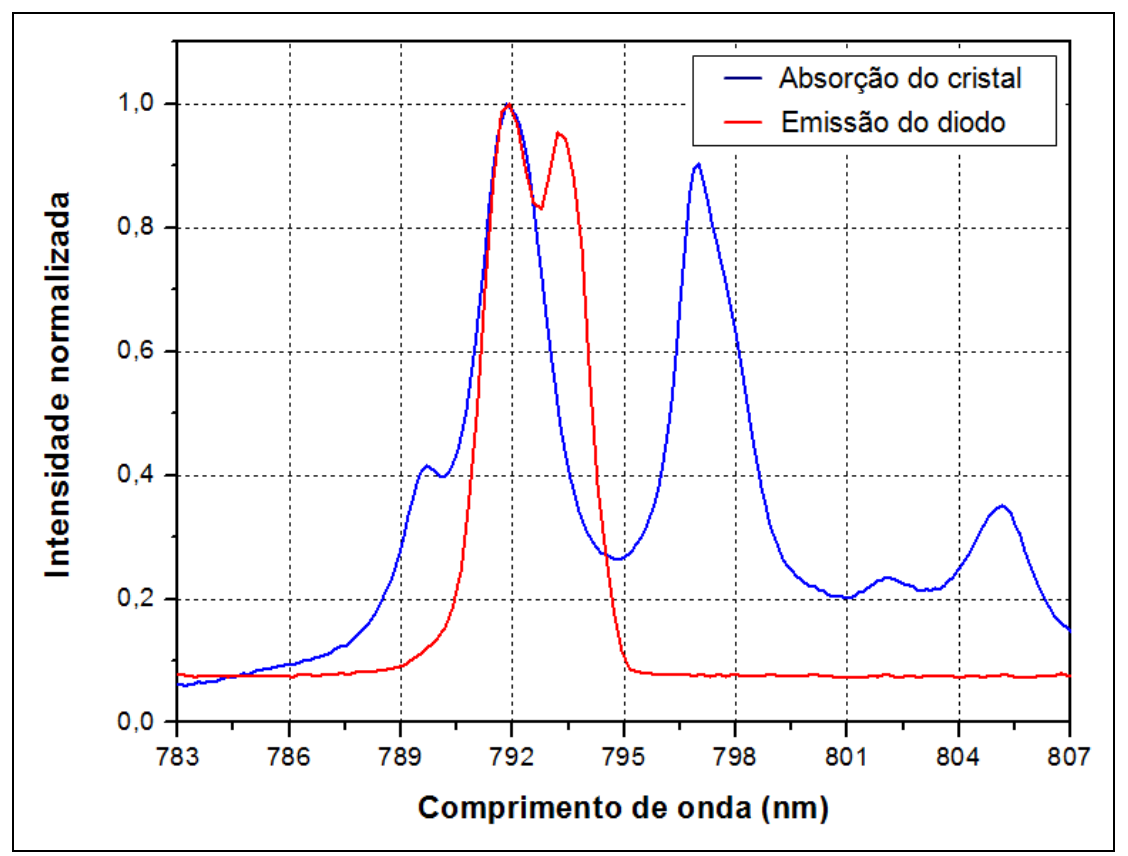

FIGURA 10: Espectro de emissão do diodo de 20W sob regime pulsado.

Além dos propósitos relacionados à sintonização do comprimento de onda, o diodo foi operado em regime pulsado para evitar fratura devido a tensões térmicas. Portanto, foi utilizado um ciclo útil da fonte de alimentação de 7\% com duração do pulso de $2 \mathrm{~ms}$ e taxa de repetição de $35 \mathrm{~Hz}$. A operação em regime contínuo do laser é descrita no apêndice A [52].

A barra de diodos utilizada é formada por 19 emissores montados em intervalos com cerca de $550 \mu \mathrm{m}$, cada um com face emissora de $150 \mu \mathrm{m}$ de largura por $1 \mu \mathrm{m}$ de altura, resultando em uma largura total de $1 \mathrm{~cm}$. Na direção horizontal (eixo lento), o feixe possui qualidade bastante ruim, possuindo um ângulo de divergência de cerca de $10^{\circ}$ e fator de qualidade $\mathrm{M}^{2}$ próximo a 2000. Na direção vertical (eixo rápido), o diodo possui abertura muito estreita gerando um feixe com alta divergência, em torno de $35^{\circ}$. Entretanto, o diodo possui uma microlente cilíndrica, montada de fábrica em frente aos emissores, para a colimação na direção vertical, o que diminui o ângulo de divergência para aproximadamente $6^{\circ}$.

É utilizado um arranjo de bombeamento transversal, em que não é necessário realizar uma complexa reconfiguração do feixe do diodo, dispensando a necessidade de complicados arranjos ópticos e permitindo aumentar a potência de bombeamento, uma vez que a energia é melhor distribuída no cristal, o que é muito propício ao cristal de YLF que possui baixo limiar de fratura. 
Uma lente esférica com distância focal de $2,5 \mathrm{~cm}$ foi utilizada a frente do diodo para focalizar seu feixe na face de bombeamento, resultando em um feixe de bombeamento com secção transversal de 4,3mm na horizontal e $97 \mu \mathrm{m}$ na vertical. De acordo com a sobreposição espectral entre a emissão do diodo e a absorção do cristal na polarização $\pi$, foi desenvolvida uma simulação pelo prof. Niklaus U. Wetter demonstrando o comportamento de absorção da radiação de bombeamento dentro do cristal (figura 11), determinando-se a porcentagem de potência absorvida em função da profundidade de propagação do feixe de bombeamento. De acordo com a simulação mostrada na figura 11, na temperatura de operação do diodo de $24,5^{\circ} \mathrm{C}$, foi determinado que $50 \%$ da radiação de bombeamento é absorvida nos $2 \mathrm{~mm}$ iniciais no cristal e $90 \%$ é absorvida com cerca de $13 \mathrm{~mm}$.

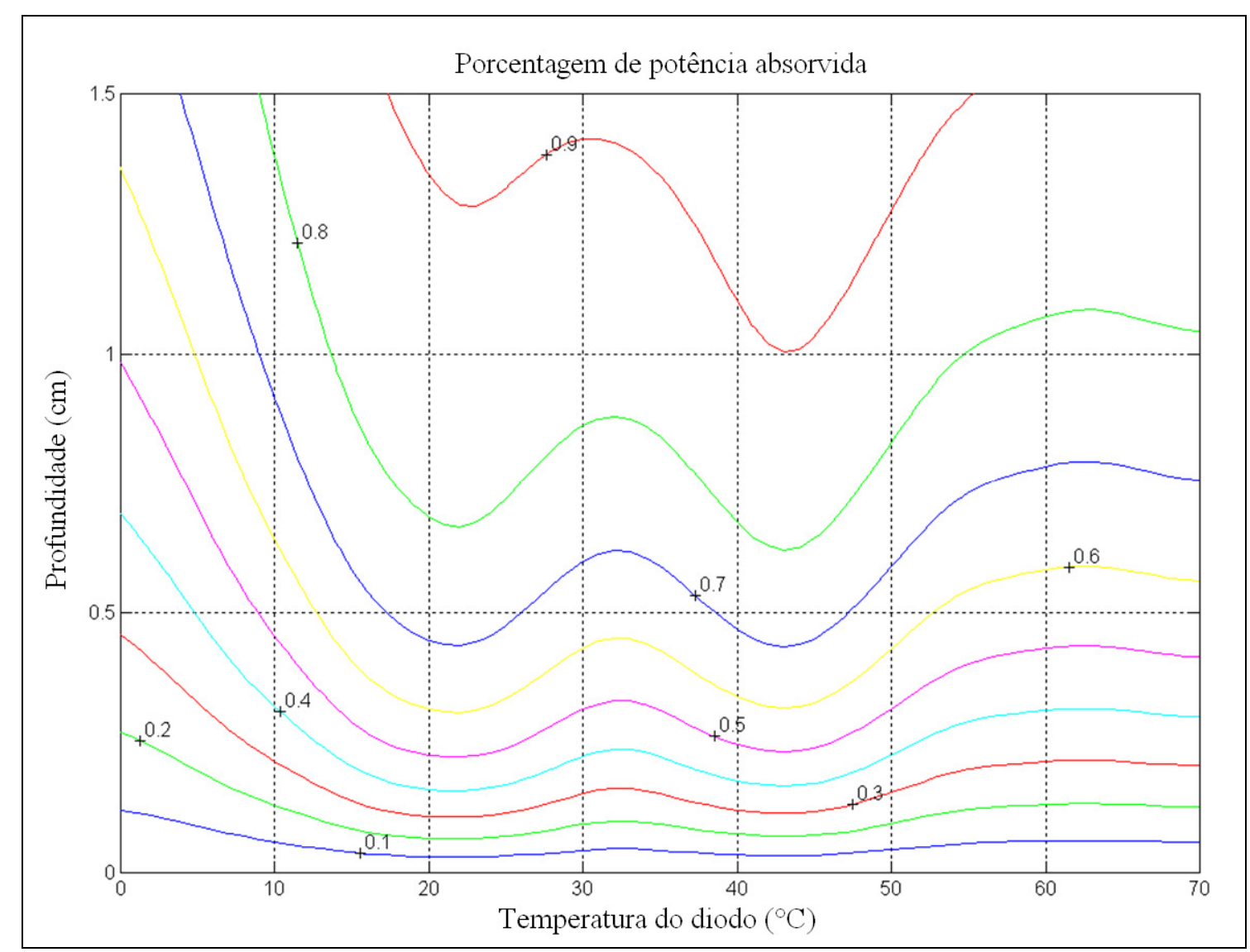

FIGURA 11: Porcentagem de potência absorvida em função da profundidade da radiação de bombeamento. 


\subsection{Arranjo laser}

Em arranjos com bombeamento transversal, é muito importante garantir uma alta sobreposição entre a região excitada pelo bombeamento e o volume do feixe intracavidade para otimizar a eficiência e a qualidade do feixe de saída. No arranjo utilizado, para otimizar este acoplamento é necessário que o feixe laser passe o mais próximo possível da região de bombeamento, onde ocorre a maior parte da absorção e o ganho é maior. Isto pode ser realizado por meio de uma configuração baseada na reflexão do feixe laser na superfície de bombeamento.

Desta forma, devido à configuração da cavidade estudada, é muito importante obter-se alta absorção da radiação de bombeamento, para que a maior parte da absorção ocorra na região próxima à face de bombeamento, onde há uma melhor sobreposição com o modo intracavidade, justificando a necessidade de absorção na polarização $\pi$, em que o coeficiente de absorção é significativamente maior. Assim, o eixo óptico foi orientado perpendicularmente ao eixo de propagação do feixe laser no ressonador, o que é denominado como uma configuração com cristal a-cut. Mesmo na configuração correspondente ao maior pico de absorção, o cristal utilizado necessita de um longo comprimento para a absorção da radiação de bombeamento, conforme foi mostrado na figura 11. Assim, na configuração de bombeamento lateral utilizada, o feixe intracavidade dispensa a necessidade de incidência em ângulo rasante no acoplamento com o feixe de bombeamento, tal como ocorre com cristais de alto ganho [13, 14]. Em vista disto, foi possível utilizar uma cavidade em que o feixe laser incide em ângulo de Brewster no cristal, minimizando as perdas por reflexão nas superfícies de entrada e saída [53] sem a necessidade de utilizar filmes finos anti-refletores [54].

$\mathrm{Na}$ configuração $a$-cut, o cristal de Nd:YLF pode emitir tanto em $1047 \mathrm{~nm}$ (polarização $\pi$ ) quanto em $1053 \mathrm{~nm}$ (polarização $\sigma$ ). Como a polarização $\pi$ possui secção de choque de emissão cerca de 1,5 vezes maior que na polarização $\sigma$, a oscilação em $1047 \mathrm{~nm}$ tenderá a ser predominante. A seleção da transição em 1053nm no Nd:YLF já foi reportada, por exemplo, por meio de cristais com o eixo óptico orientado paralelamente ao eixo do ressonador (c-cut) [55] e por meio da diferença de lente térmica entre as duas polarizações do cristal [27].

A presença do ângulo de Brewster $\left(\theta_{\mathrm{B}}\right)$ no arranjo utilizado privilegia a emissão da polarização $\sigma$, criando um eficiente mecanismo de seleção da polarização sem a necessidade de adição de qualquer outro elemento intracavidade. Isto ocorre porque, 
neste ângulo, toda luz refletida é linearmente polarizada na direção perpendicular ao plano de incidência (neste caso, o plano das faces de 14 x $13 \mathrm{~mm}^{2}$ do cristal). Consequentemente, a radiação transmitida pelo cristal com a polarização paralela ao plano de incidência não possui perdas por reflexão, sendo a direção preferencial de oscilação do laser. Com a escolha da orientação do eixo c perpendicular ao plano de incidência, o ângulo de Brewster privilegia a polarização ortogonal ao eixo c; portanto, o laser oscila no comprimento de onda de 1053nm. A descrição de uma cavidade com oscilação em 1047nm, utilizando outra orientação do eixo c, pode ser encontrada no apêndice B.

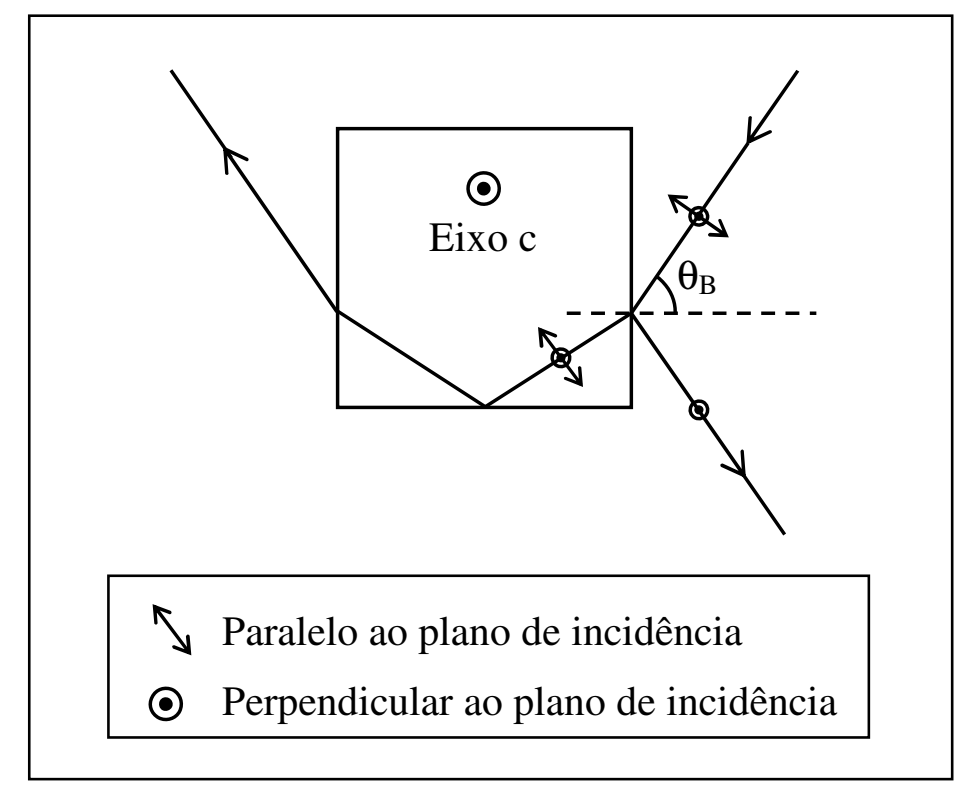

FIGURA 12: Seleção da polarização $\sigma$ por meio do ângulo de Brewster.

A emissão em 1053nm, embora apresente menor secção de choque, podendo resultar em menor ganho, possui a grande vantagem de a lente térmica ser mais fraca do que na transição em $1047 \mathrm{~nm}$, propiciando uma melhor qualidade do feixe de saída.

Há diversas configurações para melhorar a qualidade do modo do feixe laser no bombeamento transversal, entretanto elas podem ser separadas em duas categorias distintas: introduzindo perdas maiores para os modos de ordem superior ou privilegiando o ganho para o modo fundamental. A introdução de perdas para os modos de ordem superior pode ser realizada pela utilização de dispositivos que criam uma abertura espacial, tal como uma fenda ou uma íris, que é grande o suficiente para permitir a passagem do modo fundamental; mas também é pequena o suficiente para causar perdas para os demais modos. A desvantagem destes dispositivos é que normalmente também causam perdas para o modo fundamental. A outra maneira de melhorar a qualidade do feixe laser é favorecer o 
modo fundamental através de uma configuração que propicie um ganho maior para este modo do que para os modos de ordem superior. Por exemplo, criando um modo TEM $_{00}$ tão grande que, praticamente, englobe todo o volume da região bombeada, tal que o volume invertido remanescente não seja suficiente para permitir a oscilação de um modo de ordem maior.

Dois experimentos com diferentes arranjos de cavidade ressonante foram realizados para demonstrar a melhora da qualidade do feixe. Inicialmente, foi desenvolvida uma cavidade com uma dobra do feixe laser, em que foi inserida uma lâmina em seu interior para bloquear a passagem dos modos de ordem superior. Em seguida, foi desenvolvida uma configuração com duas dobras, em que apenas o modo $\mathrm{TEM}_{00}$ conseguia uma boa sobreposição com a inversão de população e, portanto, apresentava o maior ganho.

\subsubsection{Cavidade com uma dobra}

Primeiramente, foi desenvolvido um ressonador em que o feixe intracavidade realiza uma dobra na superfície de bombeamento por reflexão interna total, como mostrado na figura 13. Para a montagem desta configuração foram utilizados dois espelhos: um espelho curvo altamente refletor e um espelho plano semitransparente para o comprimento de onda de emissão do laser. Diversas combinações de espelhos foram testadas para se determinar a combinação que apresentava o melhor desempenho na cavidade, variando-se a transmissão do espelho de saída e o raio de curvatura do espelho altamente refletor.

A cavidade foi desenvolvida de modo que o feixe intracavidade incidisse no cristal em ângulo de Brewster para minimizar as perdas por reflexão nas interfaces com o meio. O ângulo de Brewster é numericamente igual ao arco-tangente do índice de refração do meio de incidência; desta forma, para oscilação do laser em 1053nm, o ângulo de Brewster no cristal de Nd:YLF corresponde a 55,4 $4^{\circ}$.

A refrigeração do cristal foi feita por condução através de sua face inferior (face de $14 \mathrm{~mm} \times 13 \mathrm{~mm}$ ), posicionando-o sobre um suporte de cobre refrigerado por água. No contato entre o cristal e o suporte de cobre também foi utilizada pasta térmica para aprimorar o contato térmico, melhorando a transferência de calor. 


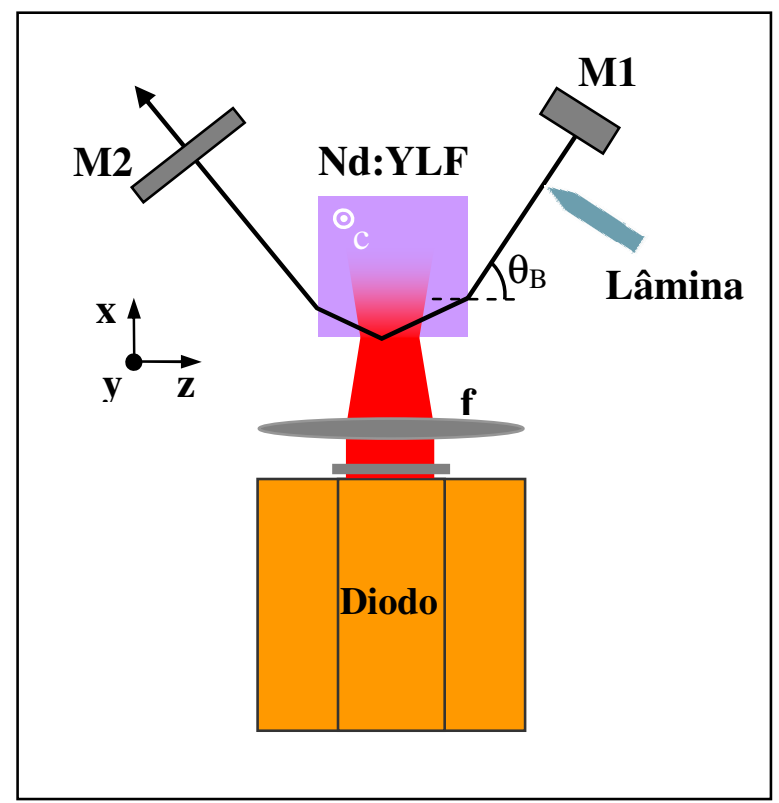

FIGURA 13: Diagrama da cavidade com uma dobra. M1 é o espelho curvo altamente refletor, M2 é o espelho plano de saída e f é a lente esférica de bombeamento.

Esta configuração de cavidade com uma dobra se caracteriza por ser altamente compacta. No protótipo desenvolvido, o comprimento óptico da cavidade era de aproximadamente $11 \mathrm{~cm}$. Uma fotografia desta configuração é mostrada na figura 14.

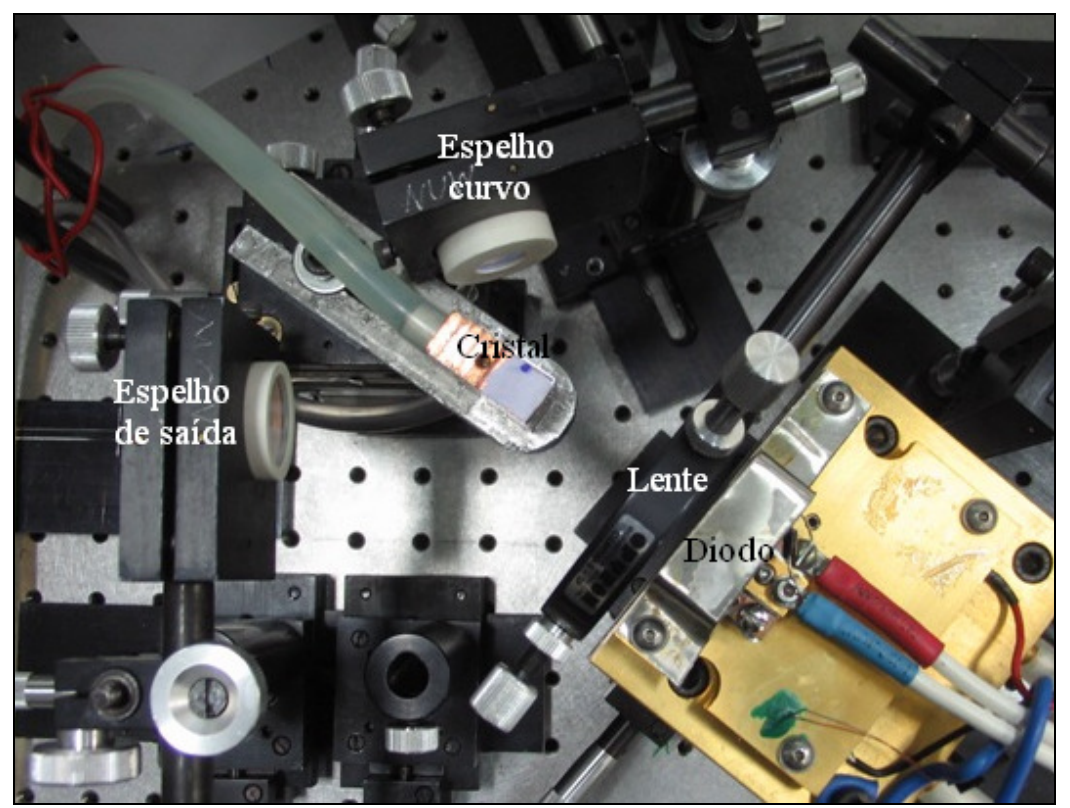

FIGURA 14: Foto da cavidade laser com uma dobra. 
A análise de Findlay-Clay também foi realizada para estimar as perdas por duplo passo na cavidade [56]. Uma vez que o limiar de operação do laser indica quando as perdas do sistema são compensadas pelo ganho do laser, esta análise relaciona o limiar de operação com as perdas do sistema durante a ação laser, incluindo, por exemplo, perdas por espalhamento, difração e absorção. Esta análise foi realizada mantendo o espelho altamente refletor fixo e variando-se a transmissão do espelho de saída de 3,5\% a $22 \%$.

Nesta configuração com uma dobra, o longo comprimento necessário para a absorção da energia de bombeamento, devido ao baixo coeficiente de absorção do cristal, ocasiona a existência de um grande volume de região excitada pelo diodo em que pode ocorrer o acoplamento com modos de alta ordem. Desta forma, já era esperado que o feixe de saída fosse multimodo.

Assim, após caracterizar os resultados do arranjo com oscilação em multimodo, uma lâmina plana de metal foi inserida gradativamente no interior da cavidade entre o espelho plano e o cristal para suprimir os modos transversais de ordem superior, bloqueando a passagem de tal forma que somente o modo fundamental possuísse espaço para oscilar. A lâmina funciona como uma íris intracavidade; entretanto, como não havia modos de ordem superior na vertical para se eliminar, optou-se por utilizar uma lâmina para suprimir os modos na direção horizontal, pois o alinhamento é mais simples e não interfere na qualidade do feixe na direção vertical.

Em cada configuração foi analisado o comportamento da potência de saída em função da potência de bombeamento utilizando um detector de alta potência da Newport. $\mathrm{O}$ feixe de saída foi visualizado por meio de uma câmera CCD acoplada a um computador e a qualidade do feixe laser foi medida pelo método de varredura por faca (knife edge), ajustando-se uma curva do fator $\mathrm{M}^{2}$ [57].

Para conhecer a qualidade do feixe laser, é essencial medir o seu diâmetro em diversas posições ao longo do eixo de propagação. Para a medição do diâmetro de feixes de ordem superior, a norma ISO 11146 [58] introduziu um critério para a medição do diâmetro de qualquer feixe independentemente do perfil de oscilação. Este critério está relacionado com o conceito estatístico de segundo momento, em que existe $86,5 \%$ de probabilidade de se encontrar o valor verdadeiro dentro de uma largura de distribuição predefinida. Para a definição do diâmetro do feixe, o critério do segundo momento estabelece que o diâmetro do feixe deve conter $86 \%$ da energia total da distribuição.

O arranjo experimental possuía um suporte mecânico de varredura com transladores micrométricos, no qual foi fixada uma lâmina plana de metal com ponta afiada 
(lâmina de estilete). Este arranjo foi utilizado para varrer o feixe em diversas posições do seu eixo de propagação após passar por uma lente com 7,5cm de distância focal. Em cada posição, mediu-se o diâmetro do feixe por cortes transversais feitos pela lâmina na frente de um detector de potência. $\mathrm{O}$ diâmetro de corte do feixe foi dado pela diferença entre dois níveis de corte, definidos a partir do bloqueio de $10 \%$ e $90 \%$ da potência do laser. O diâmetro efetivo do feixe laser foi obtido pela multiplicação do diâmetro de corte por um fator de correlação, que relaciona o diâmetro medido com o diâmetro definido pelo método do segundo momento, como requer a norma ISO 11146. A partir dos níveis de corte utilizados e independentemente do perfil do feixe analisado, pode-se adotar, com uma pequena margem de erro, um único fator de correlação igual a 1,561 [59]. A curva do fator de qualidade $\mathbf{M}^{2}$ foi ajustada a partir da equação 33 .

\subsubsection{Cavidade com duas dobras}

Para se obter um feixe de saída com melhor qualidade, sem que fosse necessária a inserção de perdas, como fora realizado com a lâmina intracavidade, foi montada uma cavidade com dois passos dentro do cristal por meio de duas reflexões internas totais na face de bombeamento, otimizando o acoplamento dos modos de baixa ordem com a região excitada pelo bombeamento. Para tanto, acrescentou-se outro espelho plano na configuração estudada anteriormente, conforme mostrado na figura 15 , sendo que este espelho não funciona como faca para os modos de ordem superior.

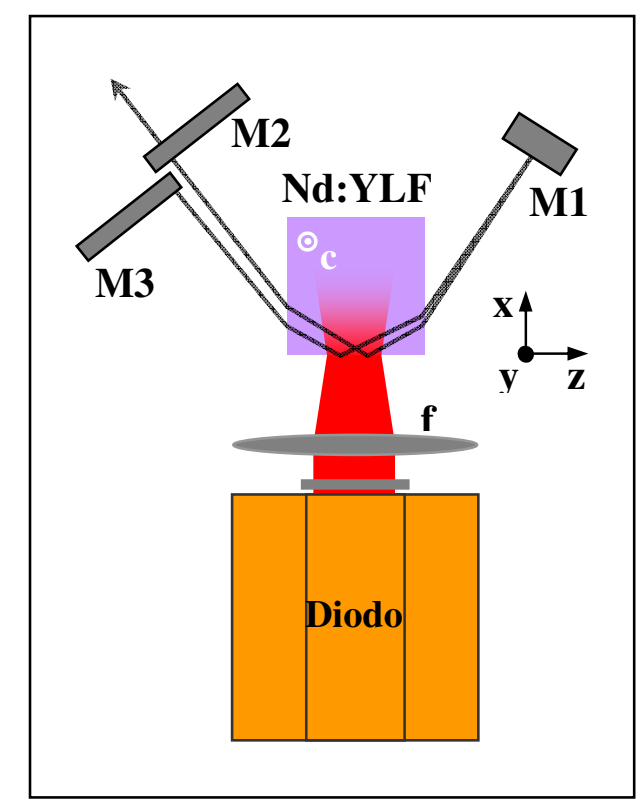

FIGURA 15: Diagrama da cavidade com duas dobras. M1 é o espelho curvo altamente refletor, M2 é o espelho plano de saída, M3 é o espelho plano altamente refletor e f é a lente esférica de bombeamento. 
Desta forma, a cavidade foi montada utilizando três espelhos: um espelho curvo altamente refletor, um espelho plano semitransparente para o comprimento de onda do laser e um espelho plano altamente refletor. O cristal e o diodo utilizados no arranjo com duas dobras foram os mesmos empregados na configuração com uma dobra. À frente do diodo também se conservou a mesma lente esférica utilizada anteriormente com distância focal de $2,5 \mathrm{~cm}$. Uma foto da cavidade com duas dobras pode ser vista na figura 16.

Novamente foram efetuadas as medidas de potência e qualidade do feixe de saída nas diferentes combinações de espelhos testadas, bem como a medida das perdas da cavidade.

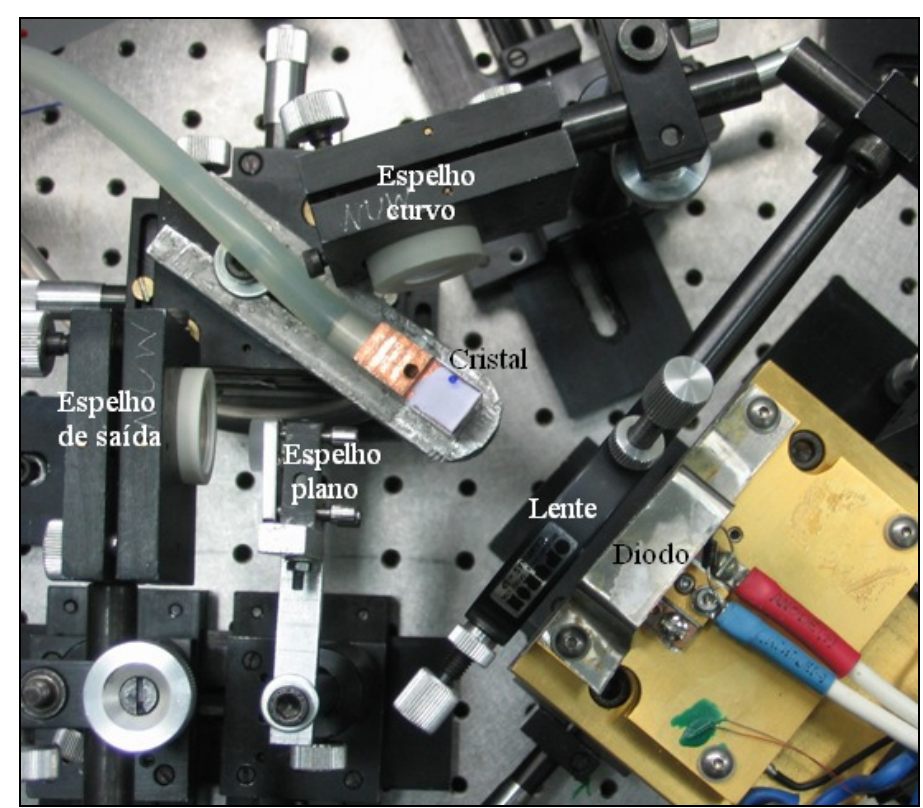

FIGURA 16: Foto da cavidade laser com duas dobras.

A teoria de Kubodera e Otsuka descrita na secção $3.3[5,6]$ pode ser utilizada para estimar a potência de saída e o modo que oscila numa determinada configuração. Contudo, para as configurações com dobra intracavidade utilizada neste trabalho, foi necessário estender a teoria já existente, para considerar a sobreposição do feixe sobre si mesmo. Desta forma, para o modo $\mathrm{TEM}_{00}$ a distribuição da densidade de fótons passa a ser dada pela equação 35 (secção 3.2.3).

Com o intuito de compreender melhor o mecanismo de seleção dos modos transversais na cavidade, o prof. Dr. Niklaus U. Wetter desenvolveu um programa em Matlab a partir desta teoria, que é capaz de estimar a potência de limiar dos modos de 
ordem superior em cada configuração, podendo-se, também, demonstrar a influência de determinados parâmetros geométricos da cavidade na oscilação dos modos.

O acoplamento do feixe intracavidade com a região excitada pelo bombeamento possui uma estreita dependência com três parâmetros principais: o ângulo de incidência, o diâmetro do feixe e a distância entre as duas passagens do feixe intracavidade [60]. A incidência do feixe foi sempre mantida em ângulo de Brewster para minimizar as perdas por reflexões. Já o diâmetro do feixe laser, determinado pelo raio de curvatura do espelho altamente refletor, foi escolhido empiricamente de acordo com os melhores resultados obtidos. Desta forma, a distância (d) entre as duas passagens do feixe na configuração com duas dobras (figura 17) recebeu um estudo mais meticuloso, tanto teórico, como experimentalmente, avaliando-se o efeito da variação desta distância sobre o limiar de oscilação dos modos de ordem superior ao passo que os outros parâmetros eram mantidos constantes.

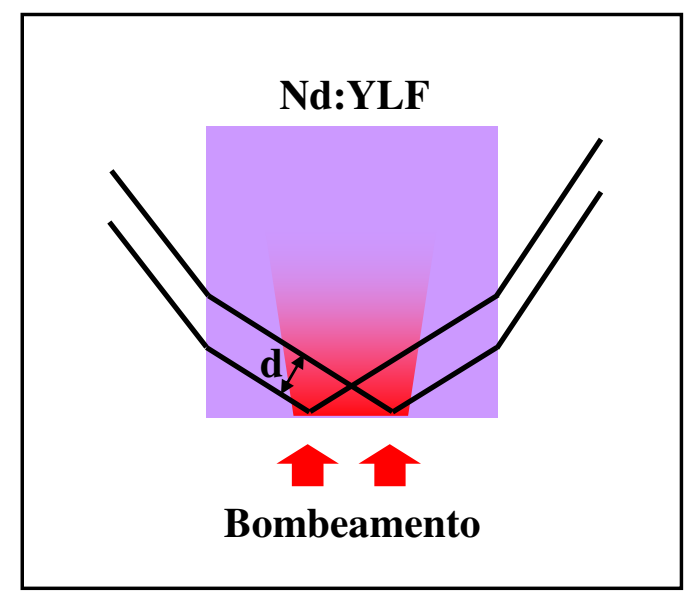

FIGURA 17: Distância d entre as duas passagens do feixe intracavidade na configuração com duas dobras. 


\section{RESULTADOS}

\subsection{Cavidade com uma dobra}

A utilização do ângulo de Brewster em conjunto com a orientação do eixo c no cristal ocasionou a oscilação do laser na polarização $\sigma$. Conforme pode ser observado no espectro mostrado na figura 18, o laser possuía o pico de emissão centrado no comprimento de onda de $1053,53 \mathrm{~nm}$ com largura a meia altura de $0,3 \pm 0,11 \mathrm{~nm}$. O espectro de emissão do laser foi retirado com um espectrômetro modelo HR2000 da Ocean Optics.

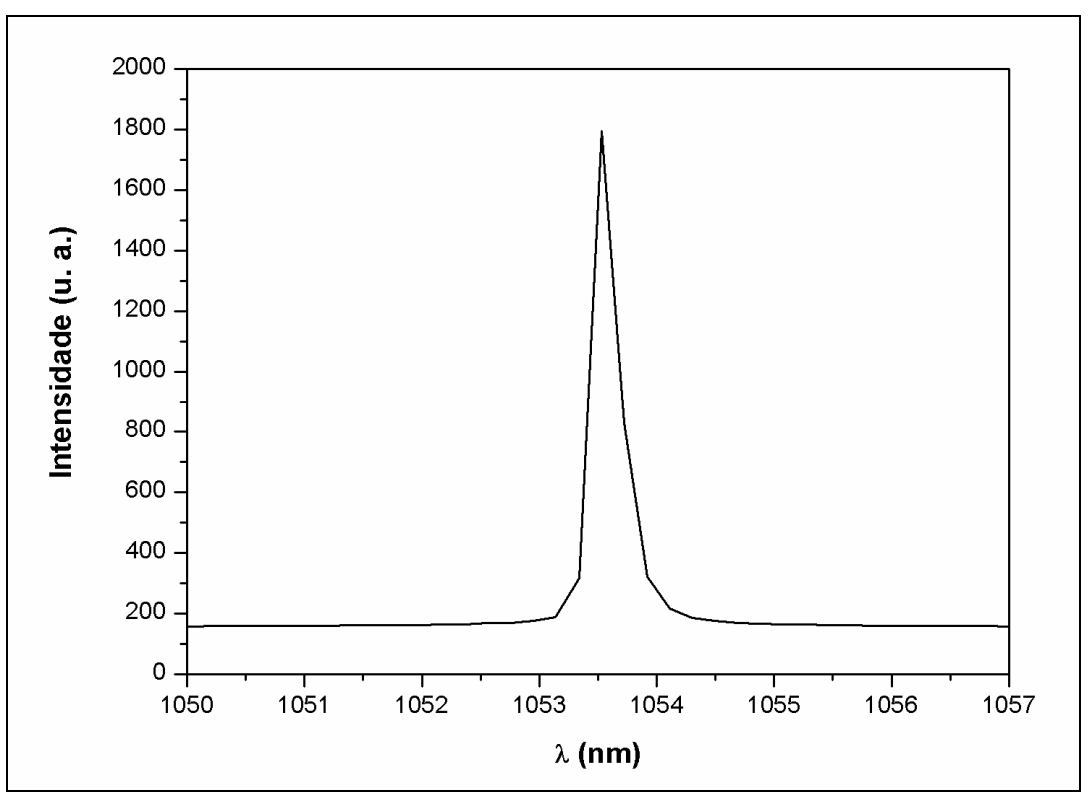

FIGURA 18: Espectro de emissão do laser.

Diversas combinações de espelhos foram testadas, verificando-se que o melhor desempenho da cavidade com uma dobra foi obtido utilizando um espelho altamente refletor com $30 \mathrm{~cm}$ de raio de curvatura e um espelho plano de saída com $7 \%$ de transmissão. Nesta configuração, o laser apresentou uma potência máxima de saída de 9,5W para uma potência de bombeamento de $21 \mathrm{~W}$ (figura 19), o que corresponde a $45 \%$ de conversão óptica e 49\% de eficiência angular (slop efficiency). Ao nosso conhecimento, esta é a maior eficiência já reportada em um laser de Nd:YLF bombeado lateralmente por diodo com oscilação em 1053nm [48, 61]. 


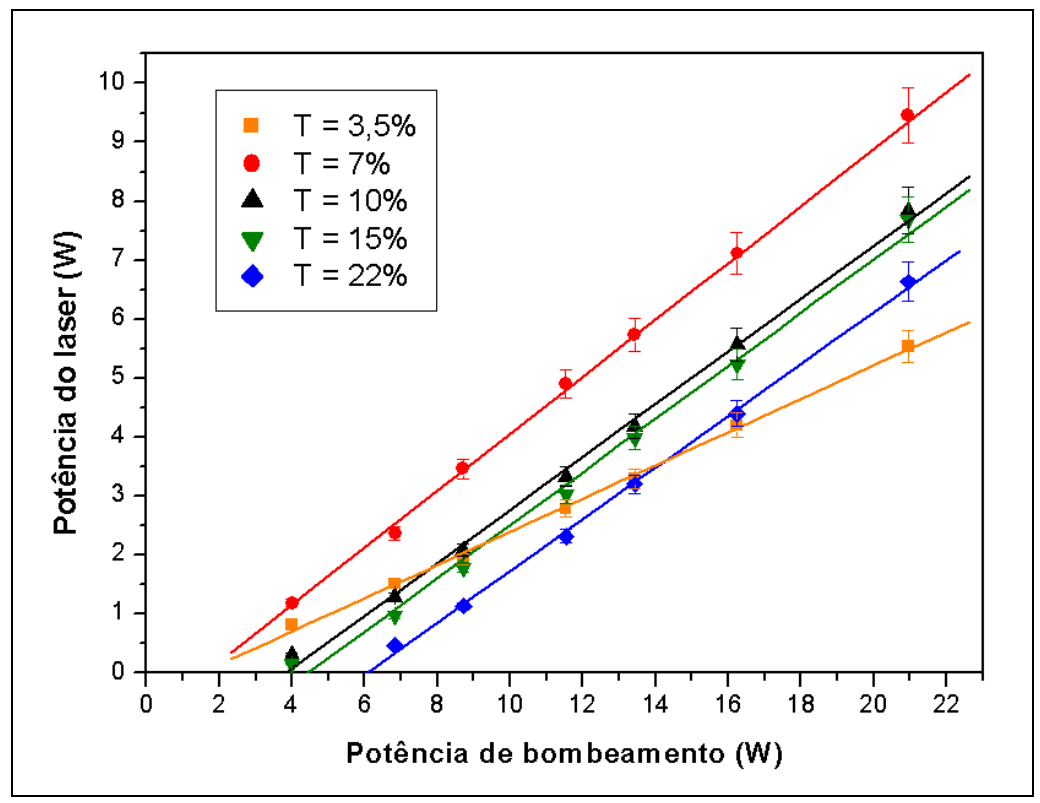

FIGURA 19: Potência de saída em função da potência de bombeamento da cavidade com uma dobra usando diferentes transmissões (T) do espelho de saída.

O baixo coeficiente de absorção do cristal ocasiona a existência de um grande volume de região excitada pelo bombeamento, permitindo a oscilação de modos de ordem superior. Desta forma, no arranjo montado com uma dobra, o feixe de saída era multimodo apresentando valores de $\mathrm{M}^{2}$ de 61,04 x 1,65 nas direções horizontal e vertical, respectivamente. O perfil do feixe de saída, logo após o espelho, é mostrado na figura 20, com dimensões de $3,6 \mathrm{~mm}$ na horizontal e $820 \mu \mathrm{m}$ na vertical. Na figura 21 são apresentadas as curvas e os ajustes da qualidade do feixe.

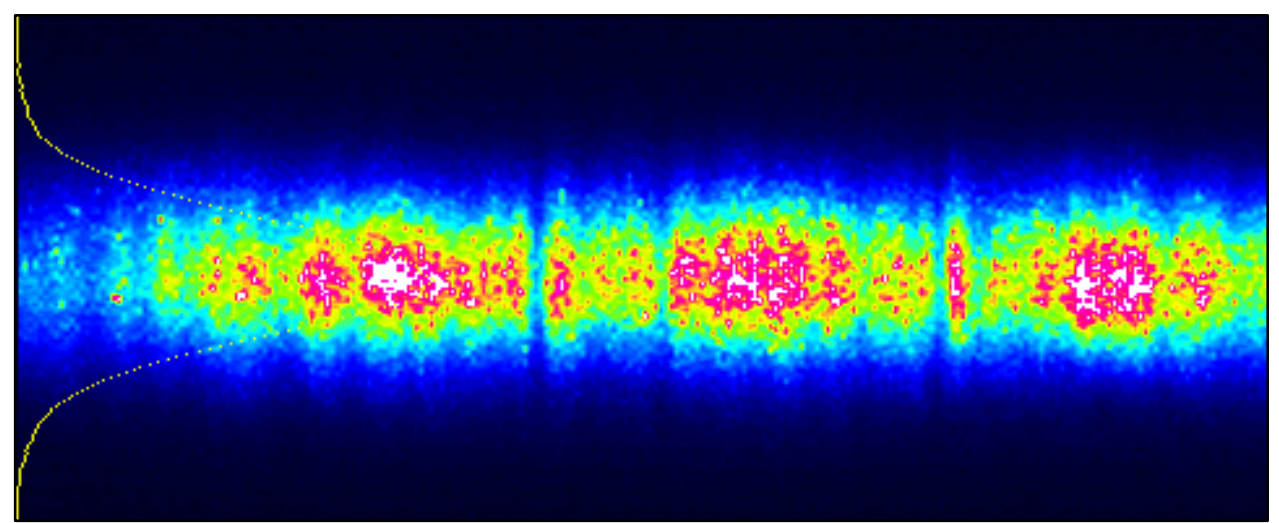

FIGURA 20: Perfil do feixe de saída na cavidade com uma dobra. 

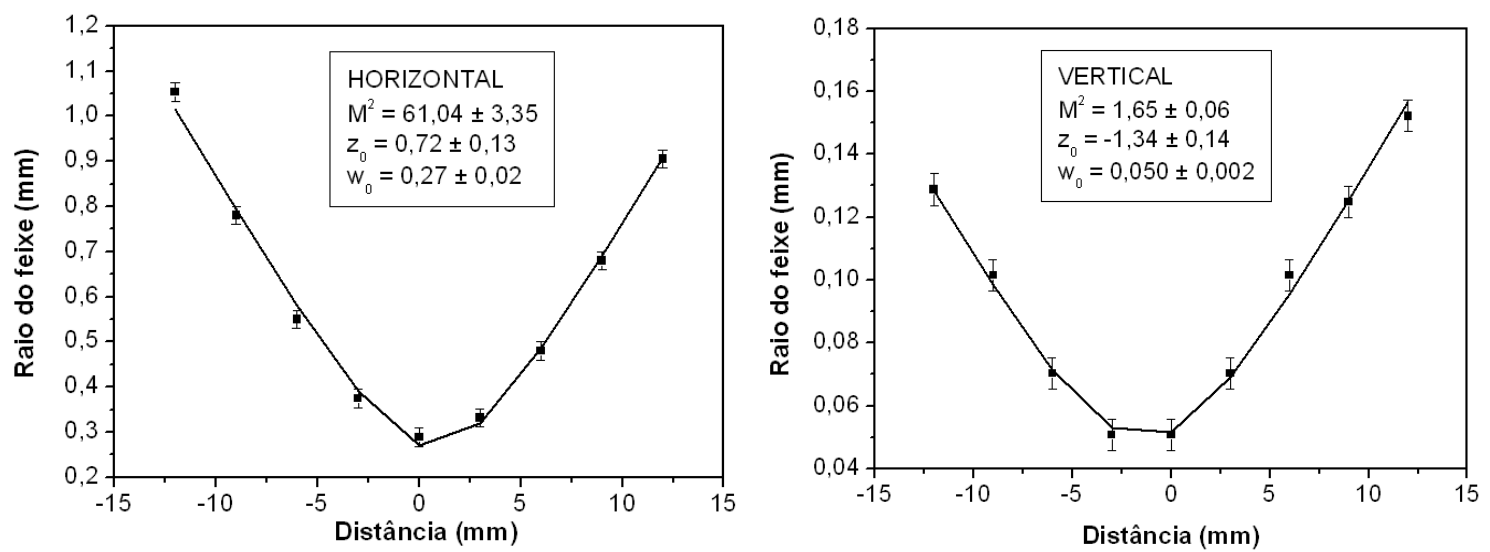

FIGURA 21: Qualidade do feixe laser na horizontal (esquerda) e na vertical (direita) para a cavidade com uma dobra.

Uma análise de Findlay-Clay foi realizada para se determinar as perdas por duplo passo na cavidade (figura 22). Nesta análise, as perdas do laser são obtidas na intersecção da reta com o eixo das ordenadas no gráfico da potência de limiar em função da transmissão do espelho de saída (usando uma aproximação do logaritmo neperiano da reflexão $\mathrm{R}$ do espelho de saída). Na análise da cavidade com uma dobra, foi constatada a existência de $2,21 \%$ de perdas. Nesta análise são consideradas todas as perdas do feixe laser intrínsecas à cavidade. Todavia, como a espessura do cristal era relativamente maior que o diâmetro do feixe laser, pode-se desconsiderar a existência de perda por difração. Desta forma, pode-se estimar que as perdas na cavidade eram decorrentes principalmente de fatores como a qualidade óptica do cristal, a qualidade superficial da amostra, a reflexão nas faces do cristal devido a um desvio no ângulo de Brewster e devido à deformação da superfície de bombeamento (apêndice C).

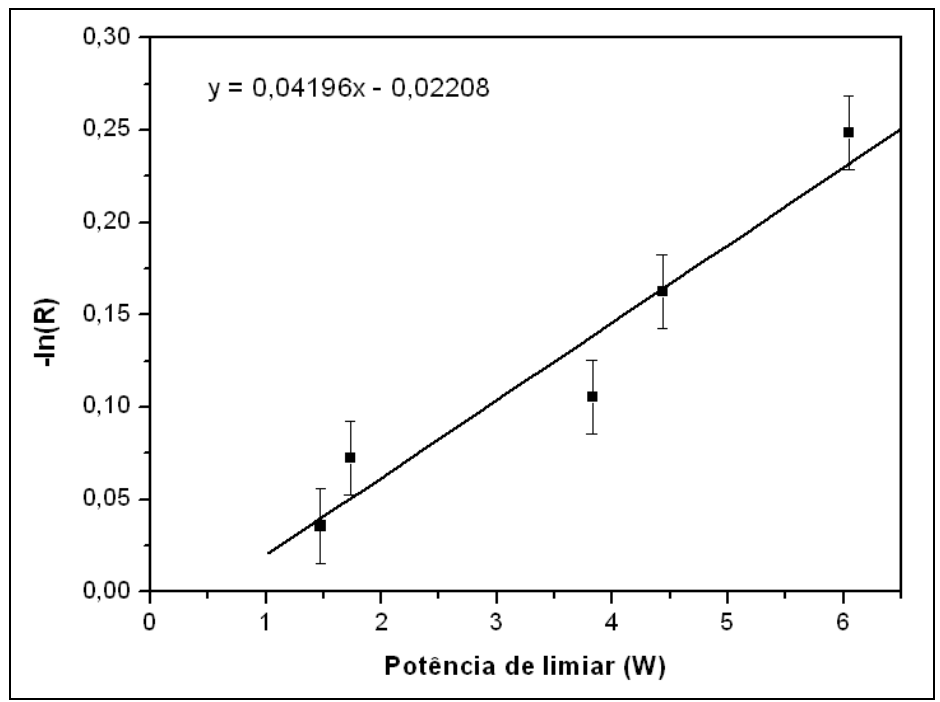

FIGURA 22: Análise de Findlay-Clay para a cavidade com uma dobra. 


\subsection{Cavidade com uma dobra e lâmina intracavidade}

Neste arranjo, a cavidade com uma dobra foi montada novamente, porém utilizando um espelho com raio de curvatura maior, para aumentar o diâmetro do feixe e diminuir a quantidade de modos que podiam oscilar, permitindo ao modo fundamental um maior aproveitamento da região de ganho. Utilizando um espelho altamente refletor com $50 \mathrm{~cm}$ de raio de curvatura e um espelho plano de saída com $7 \%$ de transmissão, foi possível obter melhor qualidade do feixe de saída com $\mathrm{M}^{2}$ igual a 25,25 x 1,33 nas direções horizontal e vertical, respectivamente, ao custo de uma pequena redução na potência de saída $(8,3 \mathrm{~W})$.

Em seguida, para se obter um feixe de saída somente com o modo fundamental, a lâmina de metal foi gradativamente inserida no interior da cavidade para suprimir os modos de ordem superior. Conforme a lâmina era inserida na cavidade, o feixe diminuía homogeneamente das bordas para o centro em virtude do bloqueio dos modos, constatando-se oscilação isoladamente do modo $\mathrm{TEM}_{20}$, em seguida do modo $\mathrm{TEM}_{10}$ e, finalmente, o laser apresentou uma potência máxima de saída no modo fundamental de $3,4 \mathrm{~W}$ para $21 \mathrm{~W}$ de potência de bombeamento, correspondendo a $16 \%$ de conversão óptica e $17 \%$ de eficiência angular (figura 23).

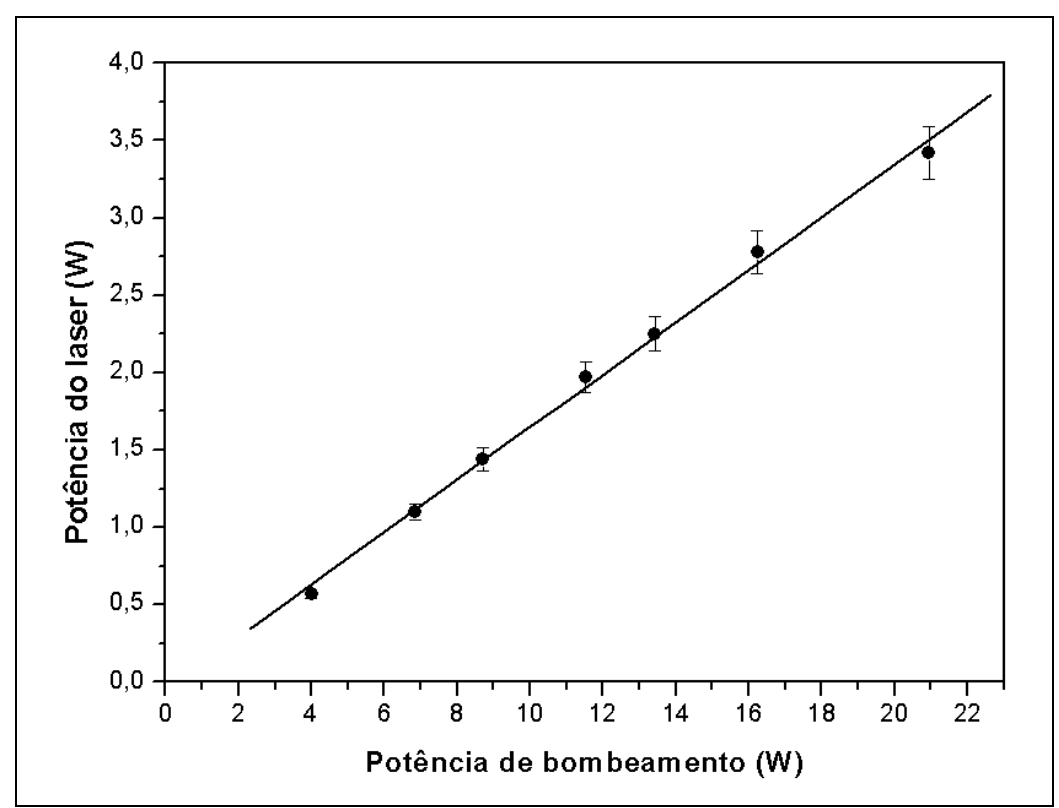

FIGURA 23: Potência de saída em função da potência de bombeamento do arranjo com uma dobra usando lâmina intracavidade para obtenção do modo fundamental. 
Utilizando a lâmina intracavidade, obteve-se um feixe de saída no modo fundamental com fator qualidade $\mathrm{M}^{2}$ igual a 1,30 x 1,15 nas direções horizontal e vertical, respectivamente, conforme mostrado na figura 24.
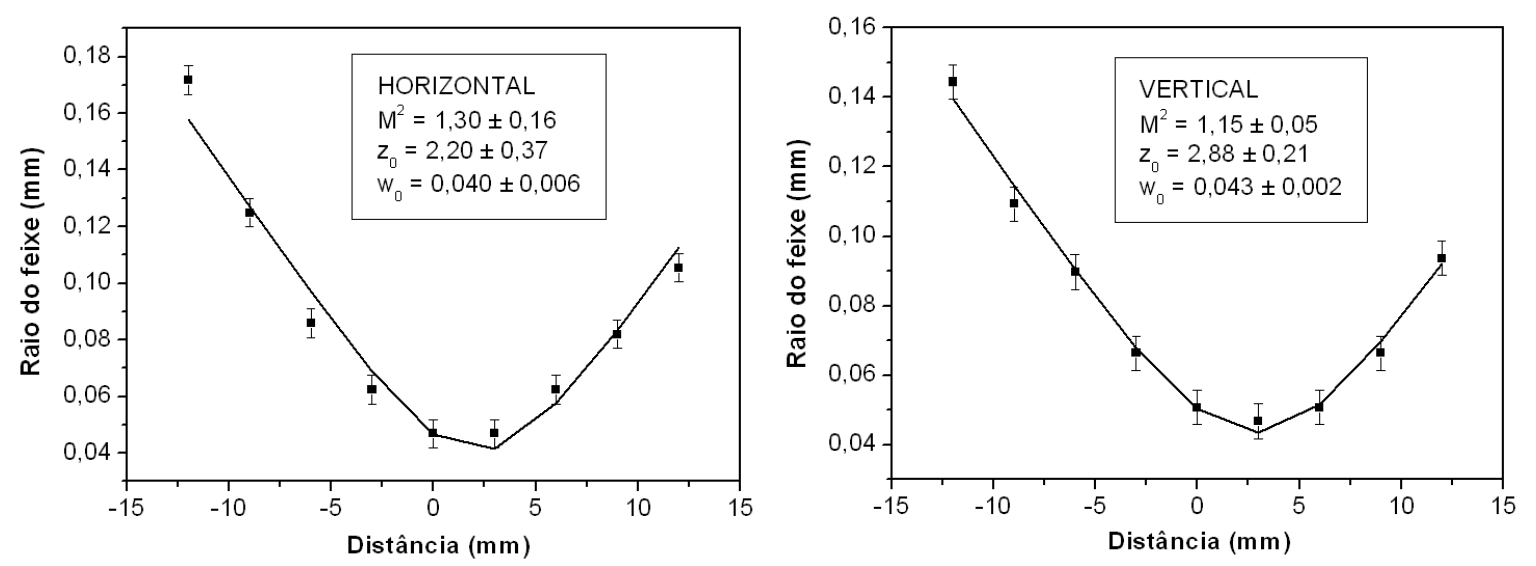

FIGURA 24: Qualidade do feixe laser na horizontal (esquerda) e na vertical (direita) com uma dobra e lâmina intracavidade.

\subsection{Cavidade com duas dobras}

A maior potência de saída do laser na configuração com duas dobras foi obtida utilizando-se uma cavidade constituída por um espelho de raio de curvatura igual a $50 \mathrm{~cm}$, um espelho plano altamente refletor e um espelho plano de saída com 15\% de transmissão. O laser apresentou baixa perda de eficiência em relação à cavidade com uma dobra, emitindo uma potência máxima de saída de $6,4 \mathrm{~W}$ para uma potência de bombeamento de $16,2 \mathrm{~W}$, o que equivale a $40 \%$ de eficiência óptica e $51 \%$ de eficiência angular (figura 25). Uma análise de Findlay-Clay determinou que as perdas na cavidade eram de 3,6\% (figura 26). Nesta configuração com duas dobras, o aumento das perdas pode ser justificado pela maior suscetibilidade a perdas em virtude de defeitos na qualidade superficial, devido à maior quantidades de passos pelo cristal e por perdas introduzidas durante a segunda passagem, uma vez que o feixe entra no cristal fora do ângulo de Brewster. 


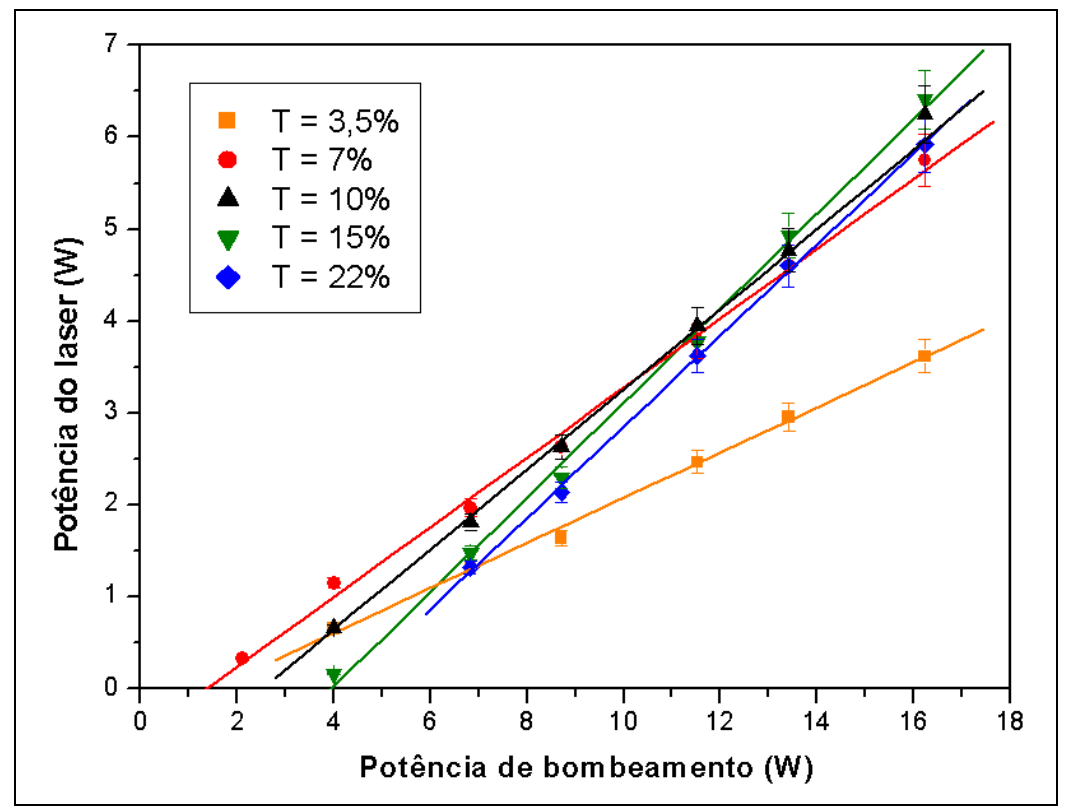

FIGURA 25: Potência de saída em função da potência de bombeamento da cavidade com duas dobras na configuração com maior eficiência.

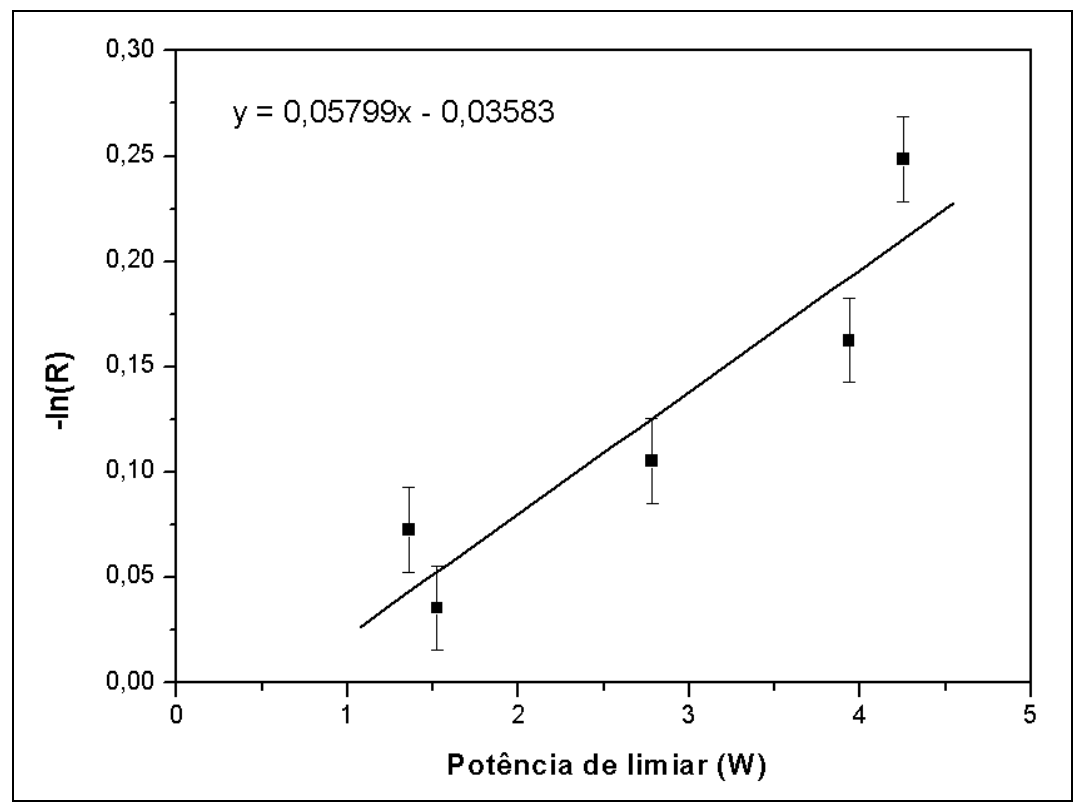

FIGURA 26: Análise de Findlay-Clay para a cavidade com duas dobras na configuração com maior eficiência.

O perfil do feixe de saída foi observado como câmera CCD, constatando-se que nesta configuração ocorria oscilação multimodo (figura 27). A qualidade do feixe foi novamente medida, apresentando um fator $\mathrm{M}^{2}$ igual a 6,23 x 2,16 nas direções horizontal e vertical, respectivamente, (figura 28) correspondendo a uma melhora de nove vezes na qualidade da direção horizontal em relação ao resultado obtido na cavidade com uma dobra. 


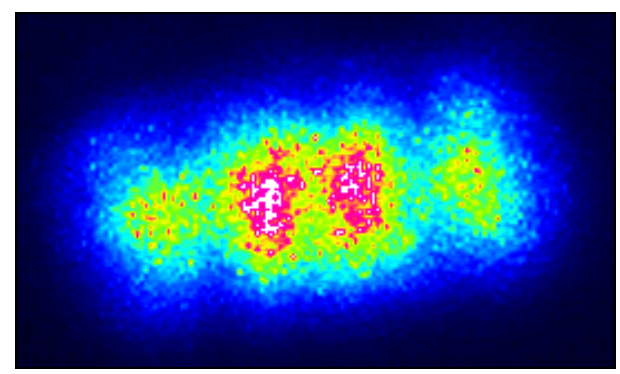

FIGURA 27: Perfil do feixe de saída na cavidade com duas dobras na configuração com maior eficiência.
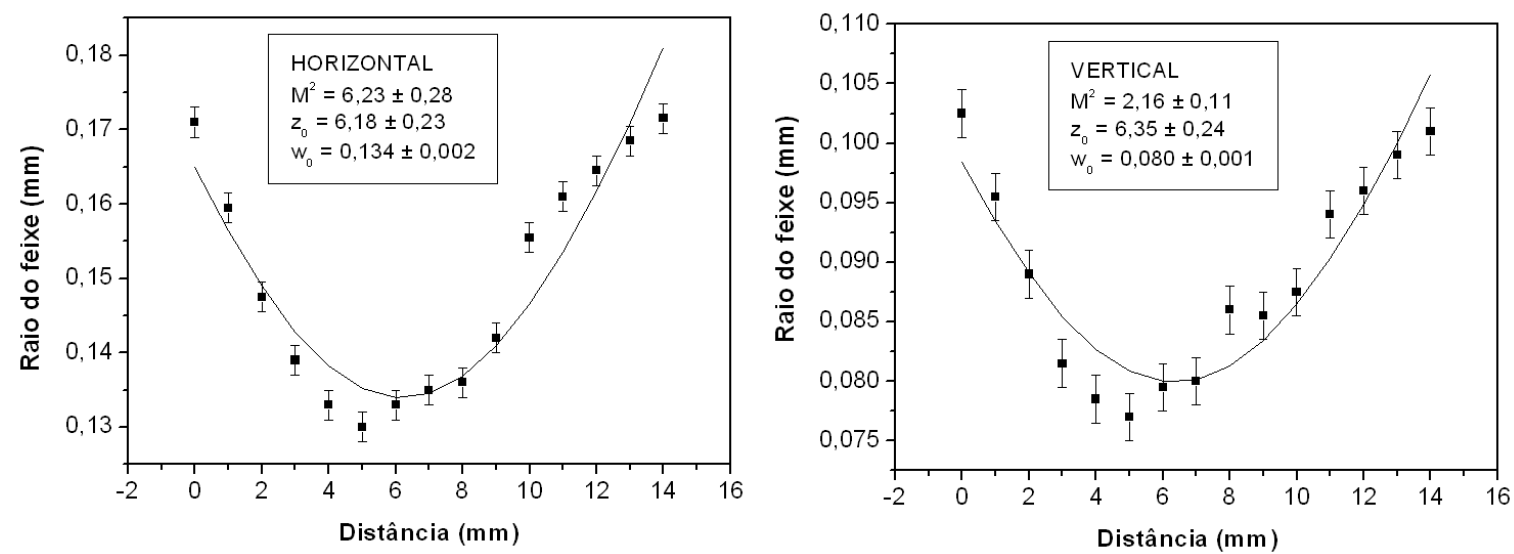

FIGURA 28: Qualidade do feixe laser para a cavidade com duas dobras na configuração com maior eficiência.

A oscilação somente do modo fundamental (figura 29) foi obtida aumentando o diâmetro do feixe intracavidade, por meio do uso de um espelho com raio de curvatura de $3 \mathrm{~m}$, para promover um melhor acoplamento do modo fundamental com o bombeamento. $\mathrm{O}$ melhor desempenho foi obtido com um espelho de saída com $10 \%$ de transmissão, em que o laser apresentou uma potência máxima de saída de $6,9 \mathrm{~W}$ para o bombeamento com $21 \mathrm{~W}$, o que corresponde a 33\% de eficiência óptica e $42 \%$ de eficiência angular (figura 30).

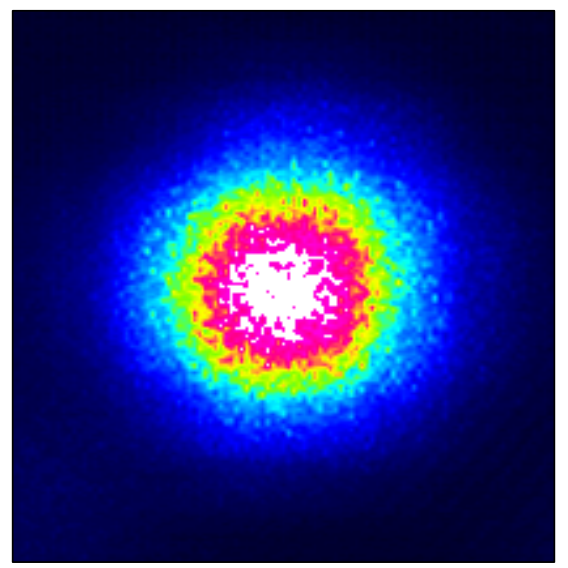

FIGURA 29: Perfil do feixe na cavidade com duas dobras no modo fundamental. 


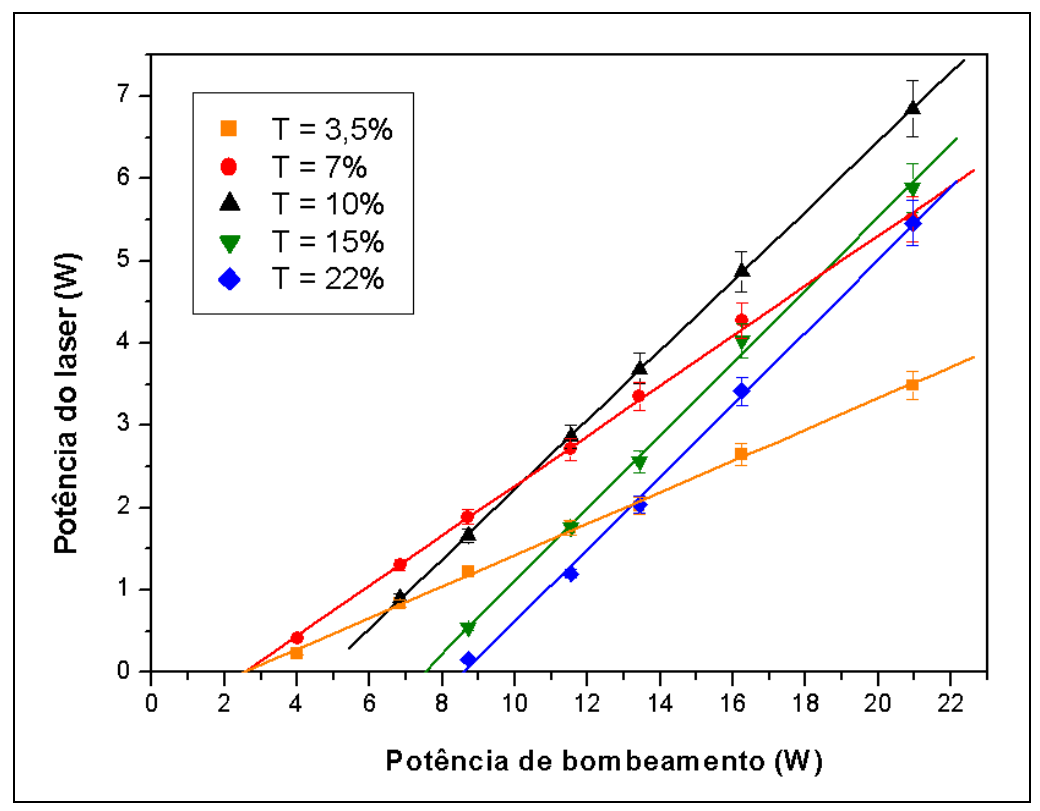

FIGURA 30: Potência de saída em função da potência de bombeamento da cavidade com duas dobras no modo fundamental.

Nesta cavidade oscilando somente com o modo fundamental, o laser apresentou alta qualidade do feixe de saída com $\mathrm{M}^{2}$ de 1,16 x 1,05 nas direções horizontal e vertical, respectivamente. As curvas ajustadas para qualidade do feixe laser na potência máxima podem ser vistas na figura 31. A melhor qualidade do ajuste destas curvas se deve à maior quantidade de pontos experimentais próximo ao foco.
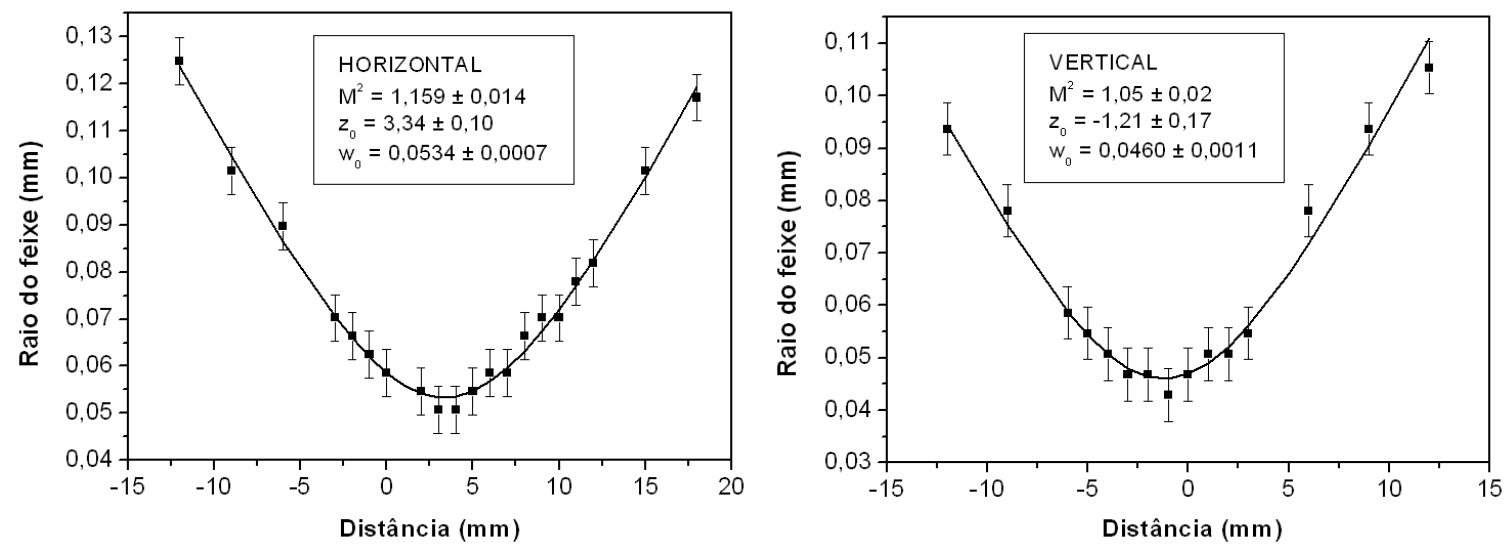

FIGURA 31: Qualidade do feixe laser para a cavidade com duas dobras no modo fundamental.

A análise de Findlay-Clay da cavidade com duas dobras oscilando no modo fundamental determinou a existência de baixas perdas no laser, tendo sido calculado um valor de 2,17\% (figura 32), o que é similar às perdas observadas nas configurações anteriores com oscilação de feixes multimodos. Desta forma, demonstra-se que a obtenção do modo fundamental não foi obtida pela inserção de perdas na cavidade. A diminuição da 
eficiência em relação à cavidade com oscilação em multimodo pode ser explicada pelo menor aproveitamento da região de bombeamento; desta forma, é imprescindível promover um acoplamento ainda melhor com esta região para otimizar a eficiência da cavidade. Para tanto, seria necessário diminuir a profundidade em que a energia de bombeamento é absorvida, o que implicaria na utilização de cristais com um maior coeficiente de absorção.

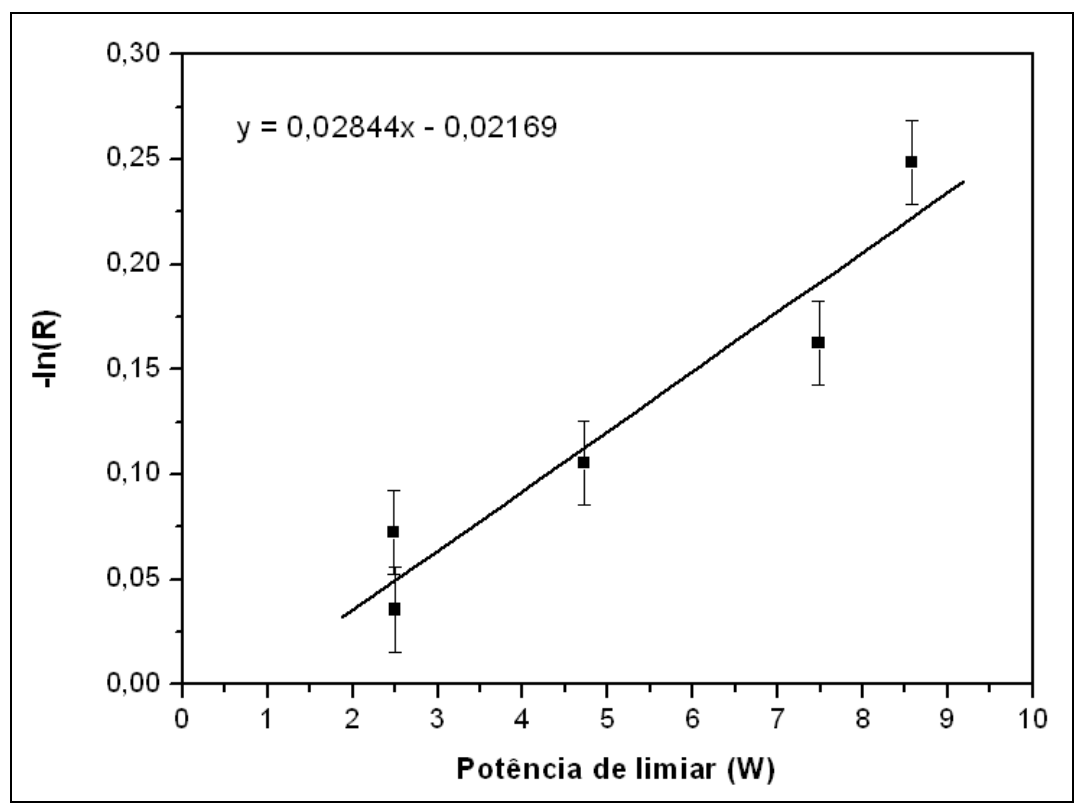

FIGURA 32: Análise de Findlay-Clay para a cavidade com duas dobras no modo fundamental.

Na figura 33, uma simulação realizada pelo professor Niklaus U. Wetter para esta configuração mostra diversas secções do cristal no plano xy ao longo do eixo z, representando a passagem do feixe laser pela região de bombeamento. A cintura do feixe dentro do ressonador foi simulada utilizando um programa desenvolvido em MATLAB baseado na teoria de matrizes $\mathrm{ABCD}$ [62] para propagação de feixes gaussianos. Por meio desta simulação, pode-se notar que a segunda passagem do feixe laser pelo cristal gera uma competição com a primeira passagem pela região de ganho, diminuindo o volume existente para a oscilação dos modos de ordem superior, desta forma apenas o modo fundamental consegue uma boa sobreposição com a região de inversão de população, apresentando o maior ganho. 


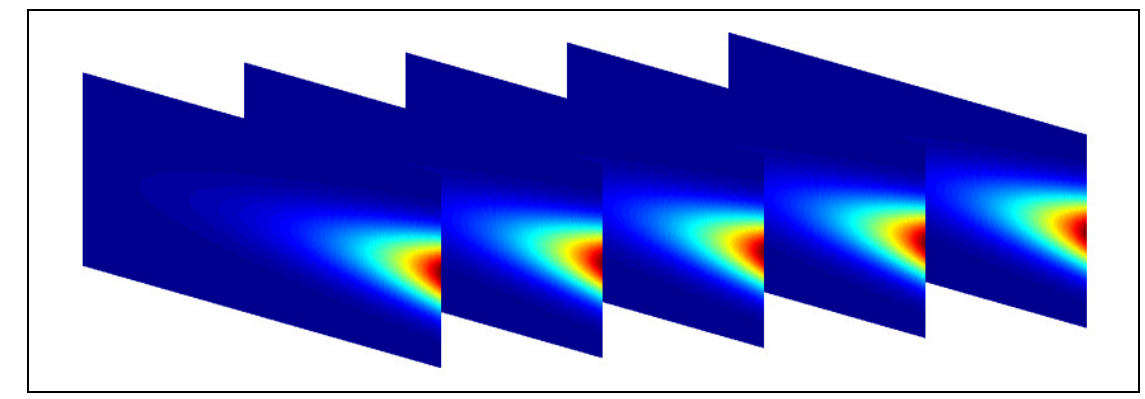

(a)

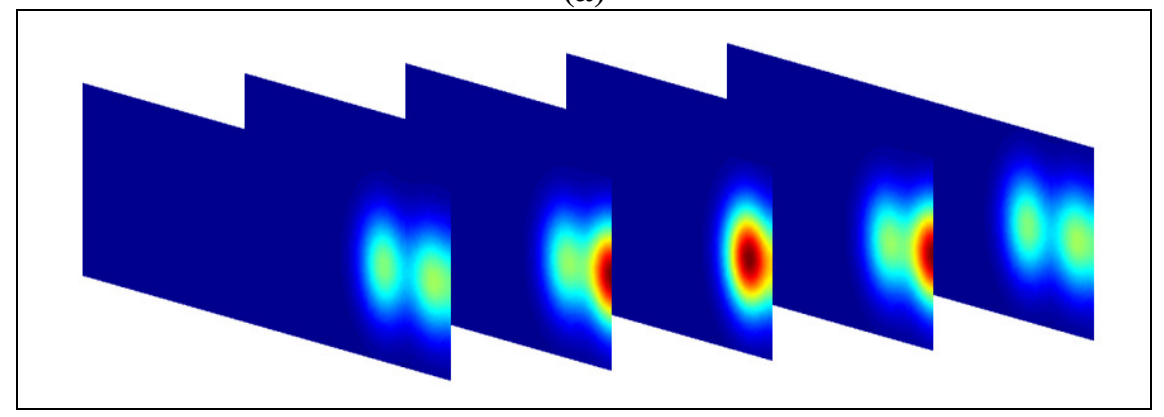

(b)

FIGURA 33: Secções xy do cristal na região de bombeamento. a) distribuição da intensidade de bombeamento; b) distribuição da intensidade dos modos $\mathbf{T E M}_{00}$ paralelos em reflexão interna total.

Como pode ser observado na figura 33, existe uma boa sobreposição entre a área ocupada pelas duas passagens do feixe em modo fundamental (figura 33b) e a área de inversão de população gerada pelo bombeamento (figura 33a). No entanto, isto só é possível em um determinado intervalo de distância entre as duas passagens do feixe. Se a separação entre as duas passagens for muito grande, parte do feixe passa fora da região de bombeamento, desperdiçando uma parte desta região, o que diminui a eficiência de acoplamento do modo fundamental e permite a oscilação de modos de ordem superior. Por outro lado, se a distância for muito pequena, as duas passagens atravessam a mesma região de ganho, de forma que uma parte do bombeamento não é aproveitada pelo modo fundamental.

$\mathrm{Na}$ figura 34 são mostrados resultados experimentais e teóricos desta distância no centro do cristal em função da máxima potência de bombeamento que ainda permite oscilação no modo $\mathrm{TEM}_{00}$ antes que o modo $\mathrm{TEM}_{10}$ oscile. De acordo com os resultados, o maior limiar de operação do modo $\mathrm{TEM}_{10}$ foi obtido para distâncias em torno de $1,6 \mathrm{~mm}$, podendo-se observar uma boa concordância entre a simulação (linha) e os resultados experimentais (pontos). Estes resultados foram obtidos para uma cavidade com um espelho de $3 \mathrm{~m}$ de raio de curvatura e um espelho plano de saída com $7 \%$ de transmissão. 


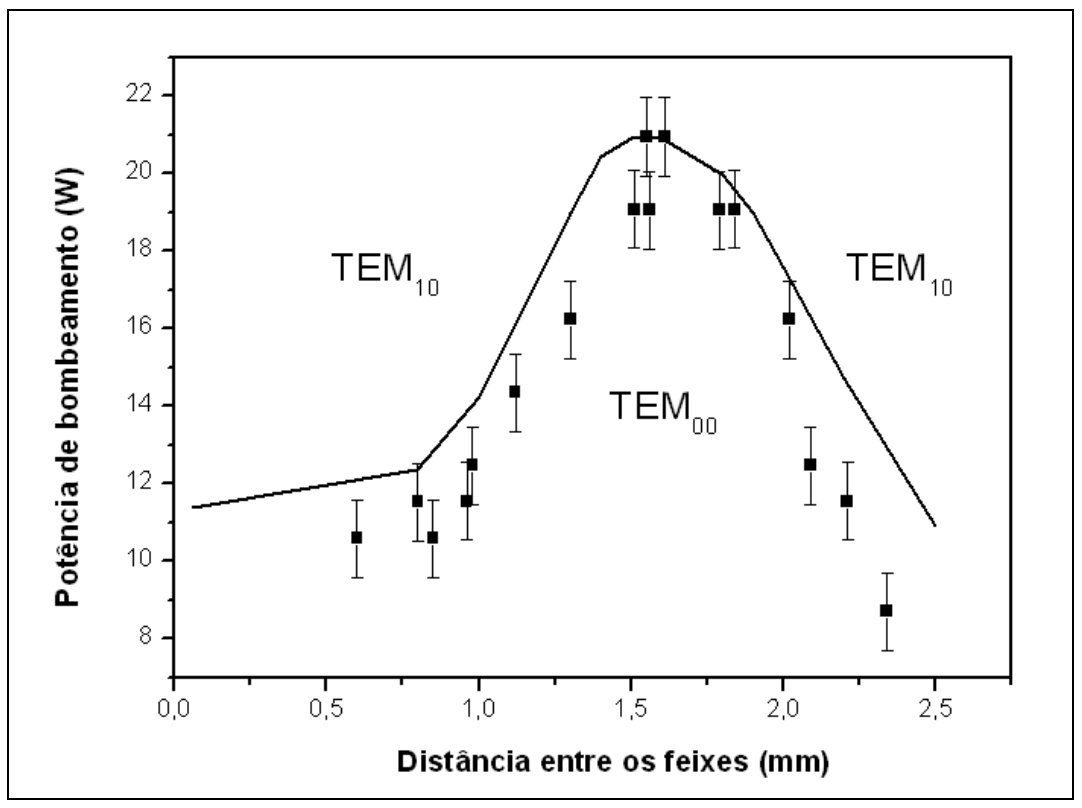

FIGURA 34: Limiar de oscilação do modo TEM 10 em função da distância entre as duas passagens do feixe na configuração com duas dobras: simulação (linha) e resultados experimentais (pontos). 


\section{CONCLUSÕES}

Foram investigadas prática e teoricamente as melhores condições para se desenvolver uma cavidade que possuísse alta eficiência e qualidade do feixe de saída. Assim, foram desenvolvidos protótipos de cavidades para um laser de Nd:YLF bombeado transversalmente por diodo e com oscilação laser no comprimento de onda de $1053 \mathrm{~nm}$, utilizando a reflexão interna total na face de bombeamento para aproveitar a maior concentração de inversão de população nesta região.

A cavidade desenvolvida neste trabalho com uma dobra na face de bombeamento possui a maior eficiência já reportada em um laser de Nd:YLF bombeado transversalmente com oscilação em 1053nm. Nesta cavidade, funcionando em regime pulsado, é possível extrair $45 \%$ de eficiência óptica, tendo sido obtida uma potência máxima de saída de 9,5W para $21 \mathrm{~W}$ de bombeamento. No entanto, o feixe de saída apresentava baixa qualidade com $\mathrm{M}^{2}$ de 61,04 x 1,65 nas direções horizontal e vertical, respectivamente.

A melhora da qualidade do feixe de saída foi demonstrada com o desenvolvimento de um ressonador com duas dobras na face de bombeamento, otimizando a sobreposição entre o volume dos modos de baixa ordem e a região excitada pelo bombeamento. A principio, com baixa perda de eficiência em relação à cavidade com apenas uma dobra, foi constatada uma melhora de nove vezes da qualidade do feixe. Em seguida, também foi possível extrair somente o modo fundamental com excelente qualidade, apresentando $\mathrm{M}^{2}$ de 1,16 x 1,05 nas direções horizontal e vertical, respectivamente, obtendo-se $6,9 \mathrm{~W}$ de potência de saída para os mesmos $21 \mathrm{~W}$ de bombeamento, o que corresponde a $33 \%$ de eficiência óptica. 


\section{APÊNDICE A - Operação em regime contínuo}

Uma amostra do cristal de Nd:YLF dopado com 0,8 mol\% de neodímio foi preparada utilizando os procedimentos descritos na secção 5.1. No entanto, a amostra teve a espessura diminuída para $2 \mathrm{~mm}$ com o intuito de melhorar a refrigeração do cristal, possibilitando que o laser fosse operado em regime contínuo.

O bombeamento foi realizado transversalmente utilizando o diodo de $20 \mathrm{~W}$ com polarização TM, para absorção na polarização $\pi$. À frente do diodo, manteve-se a lente esférica com distância focal de $2,5 \mathrm{~cm}$, para a focalização do feixe de bombeamento no cristal. Para a ressonância entre o espectro de emissão do diodo e o espectro de absorção do cristal, o diodo foi termicamente sintonizado para operar inicialmente em 792nm e, depois, em $797 \mathrm{~nm}$ com temperaturas em torno de $15^{\circ} \mathrm{C}$ e $30^{\circ} \mathrm{C}$ respectivamente.

A cavidade foi montada utilizando a configuração com uma dobra na face de bombeamento por reflexão interna total (figura 13). Portanto, foram empregados dois espelhos: um espelho curvo altamente refletor com $30 \mathrm{~cm}$ de raio de curvatura e um espelho plano com $7 \%$ de transmissão.

Durante regime pulsado o cristal foi bombeado com $21 \mathrm{~W}$ sem danos térmicos, pois a potência média depositada no cristal era de apenas $1,5 \mathrm{~W}$ para o ciclo útil de $7 \%$. No entanto, em regime contínuo o cristal necessita de um melhor sistema de refrigeração para evitar fratura por tensões térmicas. Desta forma, o cristal foi posicionado sobre o suporte de cobre refrigerado a água, passando a ser refrigerado por condução nas faces superior e inferior. Entre o cristal e o suporte de cobre foram utilizadas folhas de índio de $0,1 \mathrm{~mm}$ de espessura para melhorar a transferência de calor (figura 35). 


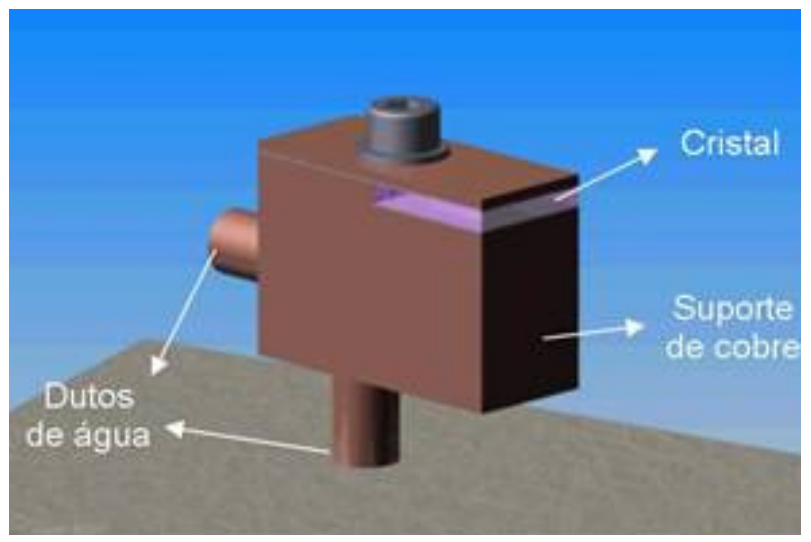

FIGURA 35: Representação do suporte para refrigeração do cristal

Sob regime pulsado em 792nm, o arranjo utilizando este cristal apresentou uma potência máxima de saída de 5,6W para uma potência de bombeamento de $16,2 \mathrm{~W}$, o que corresponde a $35 \%$ de conversão óptica e $41 \%$ de eficiência angular. No regime contínuo, a potência de bombeamento em $792 \mathrm{~nm}$ foi restringida a $11,3 \mathrm{~W}$ devido a limitações de sintonização do diodo, resultando em uma potência de saída de $3,7 \mathrm{~W}$ com $33 \%$ de eficiência óptica e 37\% de eficiência angular (figura 36). Durante operação em 797nm, a potência de bombeamento do diodo pôde ser elevada a 16,7W antes que ocorresse fratura do cristal devido a tensões térmicas, obtendo-se uma potência de saída de $4,4 \mathrm{~W}$, o que corresponde a uma conversão óptica de $26 \%$ e eficiência angular de $31 \%$. Desta forma, o limiar de fratura do cristal para esta configuração foi determinado por volta de $17 \mathrm{~W}$. A fratura ocorreu no centro da superfície de bombeamento próximo à face superior de refrigeração.

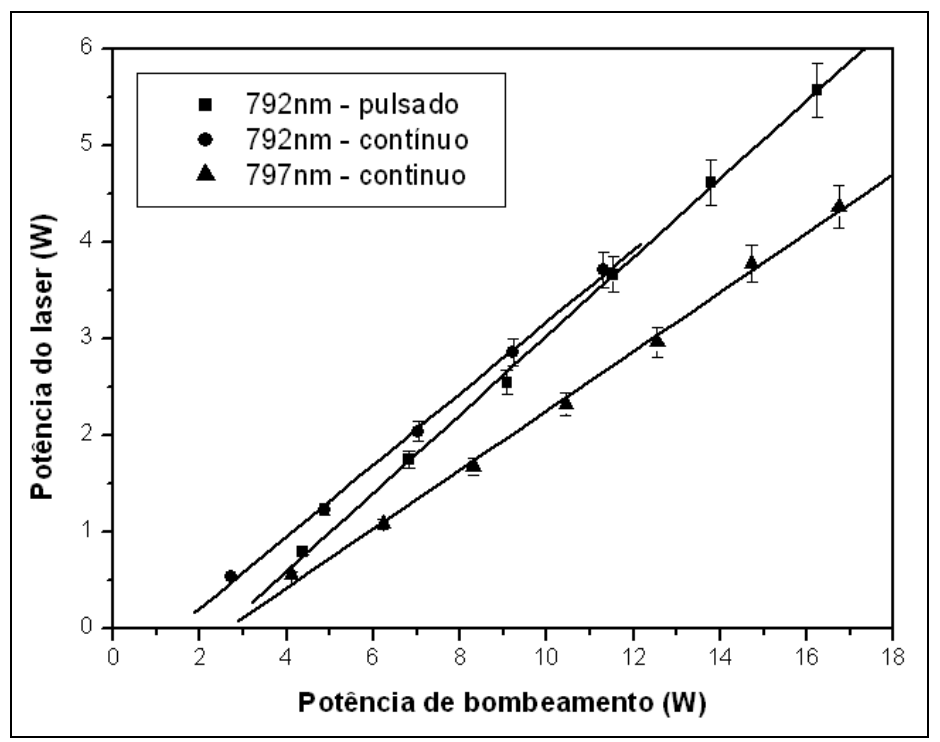

FIGURA 36: Potência de saída em função da potência de bombeamento do arranjo com uma dobra sob regime contínuo. 
Mesmo sob regime pulsado, o laser utilizando este cristal com $2 \mathrm{~mm}$ de espessura apresentou perda de eficiência em relação ao laser com os melhores resultados descritos anteriormente na secção 6.1. A provável causa desta perda de eficiência é a pior qualidade da superfície óptica e do paralelismo entre as faces do cristal, em virtude de um processo de preparação da amostra menos rigoroso. Com bombeamento em 792nm, o laser apresentou eficiência semelhante nos regimes pulsado e contínuo. Contudo houve uma perda de eficiência no bombeamento em $797 \mathrm{~nm}$ devido ao menor coeficiente de absorção neste comprimento de onda, degradando o acoplamento entre o feixe laser e o feixe de bombeamento.

A diferença de energia entre a absorção em 792 ou 797nm e a emissão em $1053 \mathrm{~nm}$ é convertida em calor dentro do cristal, de forma que cerca de $24 \%$ da energia de bombeamento é convertida em calor. O calor é distribuído na forma de um gradiente de temperatura no meio ativo, o que implica em diferentes regiões de deformação, de modo que a rede cristalina fica submetida a tensões mecânicas que podem levar à fratura do material.

O baixo limiar de fratura do cristal de YLF pode ser atribuído em parte à sua baixa condutividade térmica e à sua baixa resistência mecânica. Por exemplo, a condutividade térmica do YLF é, aproximadamente, duas vezes menor que a do YAG (tabela 1) e a sua resistência mecânica $(30 \mathrm{MPa})$ é cerca de cinco vezes menor que a do YAG (150 MPa). No entanto, bombeamento com até 160W de potência já foi reportado no cristal de Nd:YLF [17]. Desta forma, supõe-se que seja necessário realizar um tratamento térmico, após o crescimento, para melhorar a resistência do YLF às altas potências de bombeamento. 


\section{APÊNDICE B - Cavidade com emissão em 1047nm}

A obtenção da oscilação na polarização $\pi$, correspondente à emissão no comprimento de onda de $1047 \mathrm{~nm}$, foi obtida utilizando uma amostra de cristal de Nd:YLF com a orientação do eixo c paralela ao plano de incidência do feixe intracavidade e ao longo da direção do eixo x (figura 37). A amostra de Nd:YLF utilizada possuía secção quadrada com dimensões de $11 \mathrm{~mm}$ x $11 \mathrm{~mm}$ x $1,2 \mathrm{~mm}$.

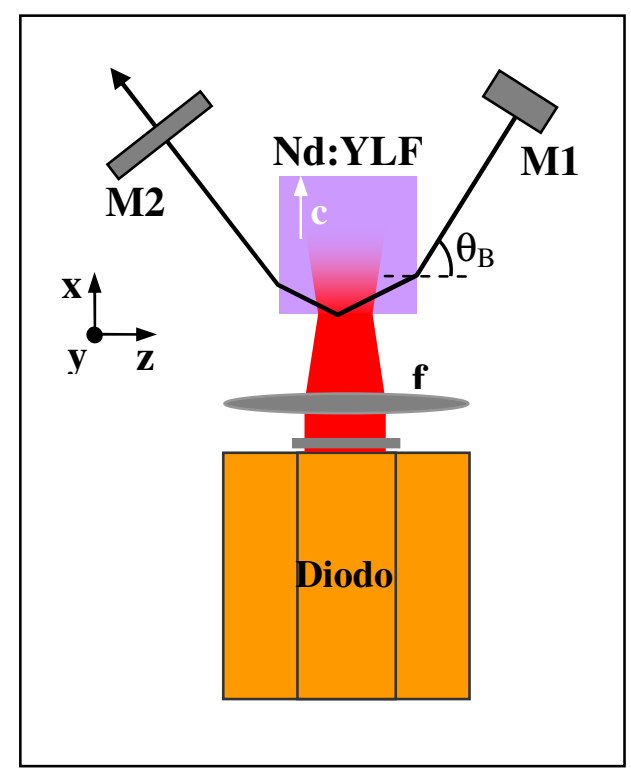

FIGURA 37: Diagrama da cavidade com uma dobra e emissão em 1047nm. M1 é o espelho curvo altamente refletor, M2 é o espelho plano de saída e f é a lente esférica de bombeamento.

O bombeamento foi realizado transversalmente utilizando uma barra de diodo de 50W com polarização TM. Desta forma, a absorção da radiação de bombeamento ocorre na polarização $\sigma$, em que a absorção do cristal é substancialmente menor. Para tentar amenizar a diminuição do coeficiente de absorção, foi utilizado um cristal com maior concentração de íons dopantes, possuindo $1,3 \mathrm{~mol} \%$ de neodímio. O espectro de absorção deste cristal é mostrado na figura 38. 


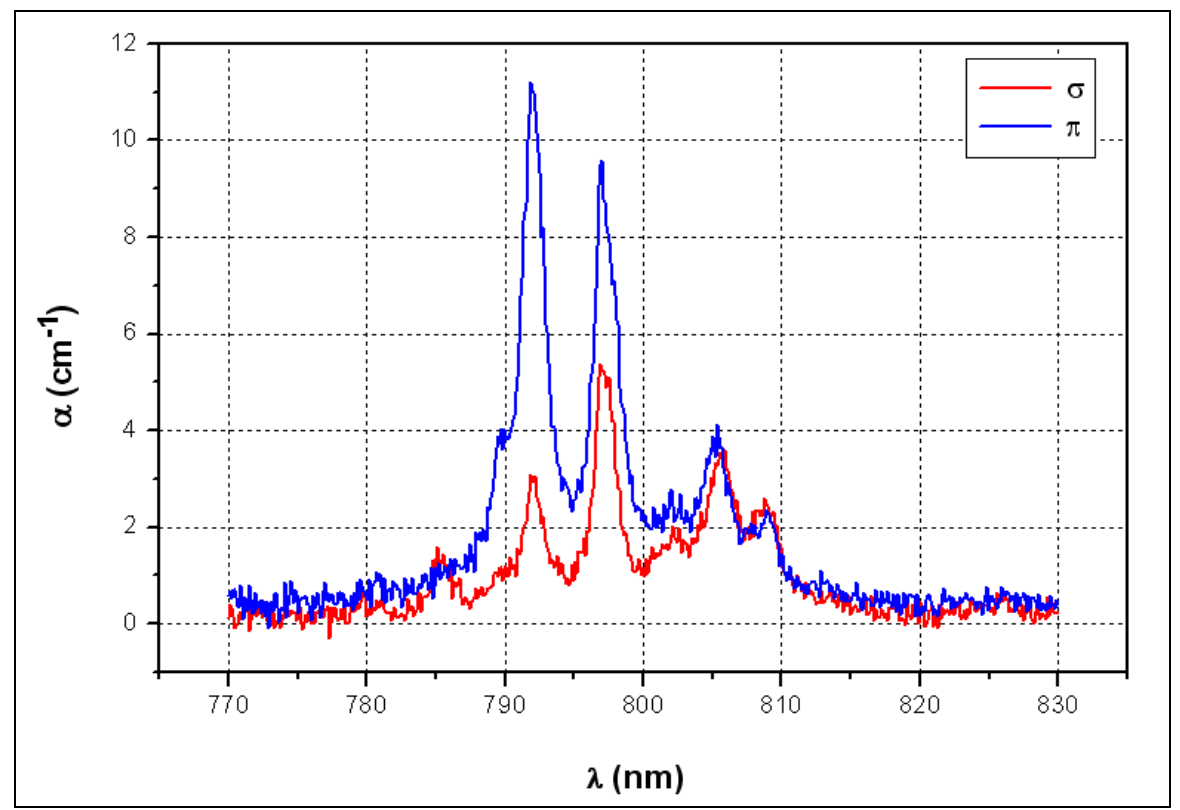

FIGURA 38: Espectro de absorção do cristal de Nd:YLF dopado com 1,3mol\% de neodímio.

Como na polarização $\sigma$ a absorção era maior no comprimento de onda de 797nm, o diodo foi termicamente sintonizado para operar neste comprimento de onda, em que o coeficiente de absorção é de cerca de $5 \mathrm{~cm}^{-1}$. Para realizar a sintonização, o diodo foi operado a $25^{\circ} \mathrm{C}$ e em um regime pulsado com ciclo útil de $35 \%$. Uma vez que o cristal apresentava baixa absorção e foi preparado com espessura fina, pode-se utilizar este alto ciclo útil sem ocorrência de danos térmicos; além disto, a potência média de bombeamento não ultrapassou o limite de fratura determinado no apêndice A.

A cavidade foi montada na configuração com uma dobra na face de bombeamento por reflexão interna total (figura 37), utilizando um espelho curvo altamente refletor com $10 \mathrm{~cm}$ de raio de curvatura e um espelho plano com $7 \%$ de transmissão. Neste caso, foi utilizado um espelho com menor raio de curvatura para diminuir o diâmetro do feixe intracavidade, minimizando a ocorrência de perda por difração, uma vez que o cristal possui espessura mais fina.

Conforme pode ser observado no espectro da figura 39, foi constatada a emissão na polarização $\pi$, com pico de emissão centrado no comprimento de onda de $1047,73 \mathrm{~nm}$ e largura a meia altura de $0,7 \mathrm{~nm}$. 


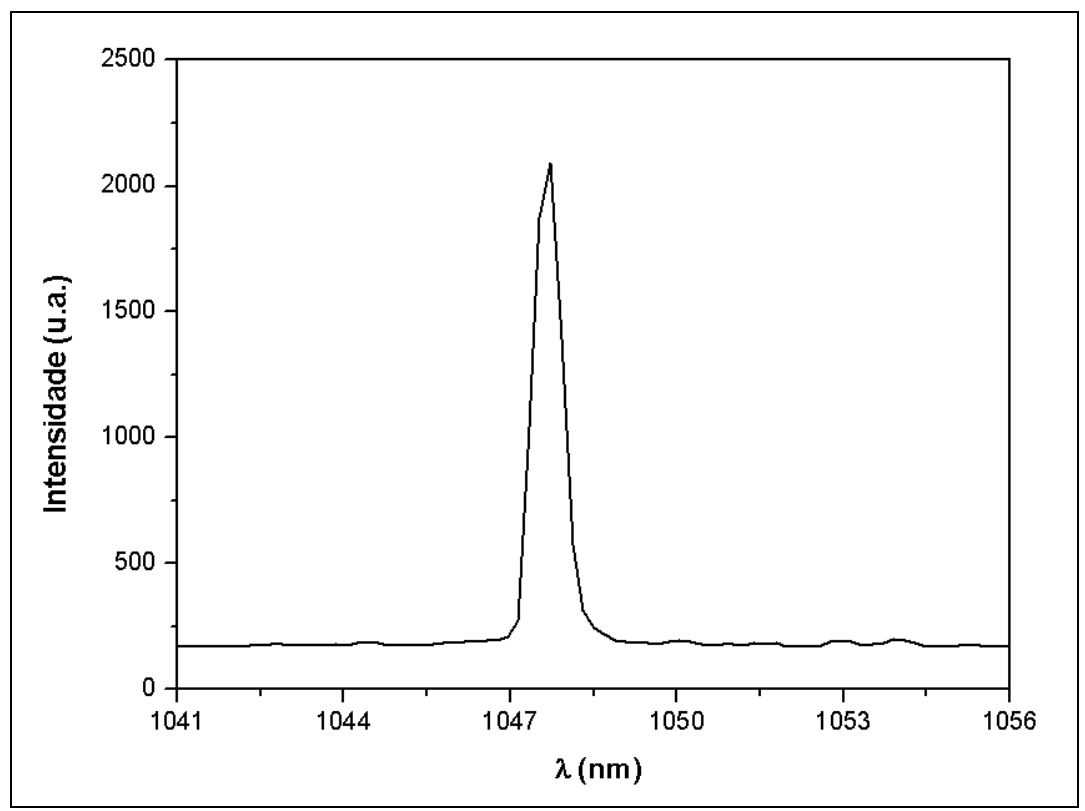

FIGURA 39: Espectro de emissão do laser na polarização $\pi$.

Nesta configuração, o feixe de saída era multimodo e o laser apresentou uma potência máxima de saída de $8,2 \mathrm{~W}$ para uma potência de bombeamento de $26,3 \mathrm{~W}$, o que corresponde a $31 \%$ de eficiência óptica e $41 \%$ de eficiência angular (figura 40).

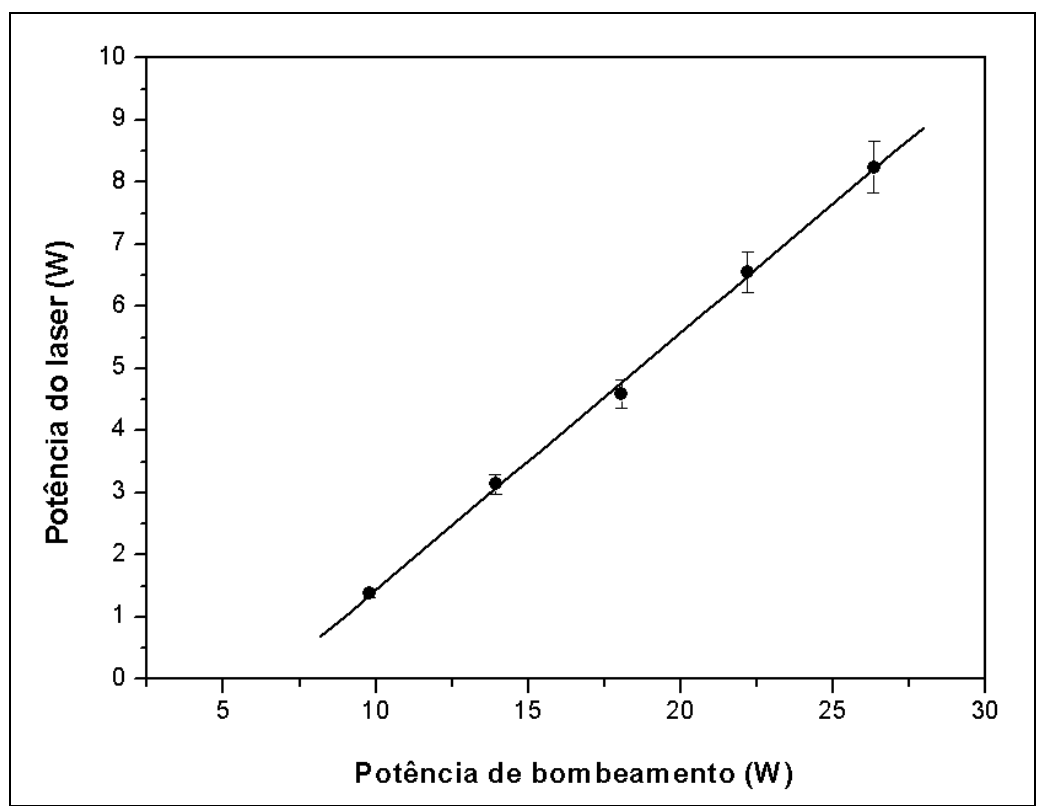

FIGURA 40: Potência de saída em função da potência de bombeamento do arranjo com emissão em $1047 \mathrm{~nm}$.

A emissão em 1047nm apresenta maior secção de choque de emissão, resultando em maior ganho do que a emissão em 1053nm (polarização $\sigma$ ). No entanto, mesmo utilizando um cristal com maior dopagem, a absorção foi reduzida em comparação 
à configuração com emissão na polarização $\sigma$. Consequentemente, houve uma degradação do acoplamento do feixe laser com a região excitada pelo bombeamento, contribuindo para a queda de eficiência apresentada em relação aos resultados obtidos na configuração com emissão na polarização $\sigma$ (45\% de eficiência óptica, conforme secção 6.1). 


\section{APÊNDICE C - Medidas de lente térmica}

A energia de bombeamento não aproveitada pelo laser se converte em calor, que é distribuído no cristal na forma de um gradiente de temperatura, cuja distribuição espacial depende da geometria do cristal, do bombeamento utilizado e das condições de resfriamento. $\mathrm{O}$ calor depositado no meio ativo leva à ocorrência de efeitos termicamente induzidos como lente térmica, aberrações e birrefringência. Estes efeitos podem ocasionar uma diminuição da qualidade do feixe de saída e perda de eficiência e estabilidade do ressonador. Desta forma, para se otimizar o desempenho de lasers de alta potência, é necessário conhecer os efeitos térmicos no meio ativo.

A lente térmica é ocasionada por uma variação do caminho óptico dentro do cristal, devido a três fatores principais: o índice de refração do cristal varia ao longo do gradiente de temperatura, o material se deforma mecanicamente resultando em uma curvatura das suas faces e a expansão não uniforme gera tensões que também ocasionam mudança do índice de refração [29].

A averiguação dos efeitos térmicos do bombeamento sob o cristal empregado nos arranjos experimentais deste trabalho (cristal descrito na secção 5.1) foi realizada por meio de medidas da lente térmica e da curvatura da face de bombeamento. Estas medidas foram realizadas passando um feixe de He-Ne pelo cristal e avaliando-se a alteração do seu diâmetro quando o bombeamento era acionado. A distância focal da lente térmica se comporta de forma diferente em situações de ausência ou presença de ação laser no cristal, já tendo sido reportada uma distância focal seis vezes maior para situações em que não há laser [29]. Desta forma, as medidas foram realizadas com a cavidade apresentando ação laser na configuração com uma dobra.

Devido à reflexão do feixe laser na face de bombeamento, a deformação causada pelo bombeamento nesta face possui grande influência na lente térmica, por isso as medidas foram realizadas incidindo o feixe de He-Ne no cristal em um ângulo que permitisse a ocorrência de reflexão interna total na face de bombeamento (figura 41). Nenhuma lente foi utilizada para colimar ou focalizar o feixe de He-Ne. Desta forma, antes de incidir no cristal, o feixe possuía uma divergência $\theta_{1}$ com um raio $r_{1}$ a uma distância $L_{1}$ do cristal. Após emergir do cristal, o feixe possuía uma divergência $\theta_{2}$ e incidia com um 
raio $\mathrm{r}_{2}$ sobre uma câmera de $\mathrm{CCD}$ a uma distância $\mathrm{L}_{2}$ do cristal. $\mathrm{O}$ cálculo da distância focal (f) da lente térmica induzida foi feito por meio de matrizes, como mostrado na equação 81 [63].

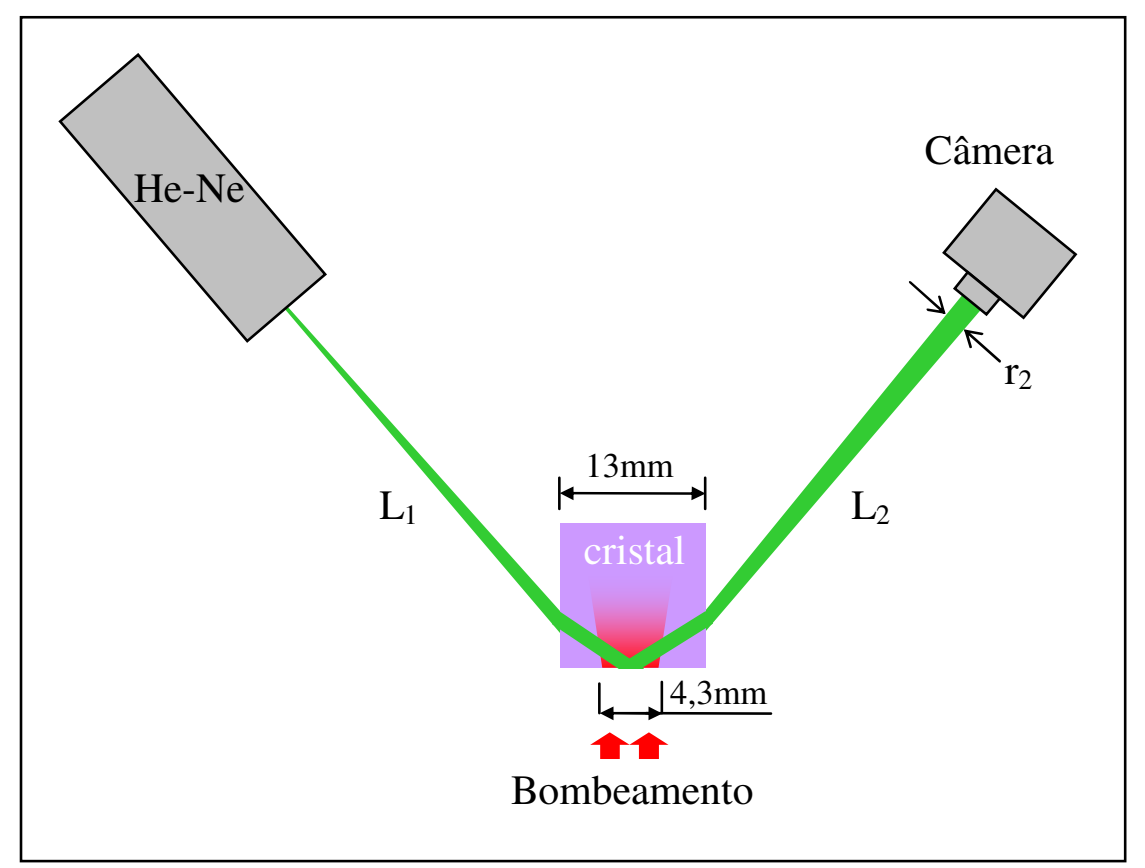

FIGURA 41: Arranjo experimental para a determinação da distância focal da lente térmica no cristal.

$$
\left[\begin{array}{l}
\mathrm{r}_{2} \\
\theta_{2}
\end{array}\right]=\left[\begin{array}{cc}
1 & \mathrm{~L}_{2} \\
0 & 1
\end{array}\right] \cdot\left[\begin{array}{cc}
1 & 0 \\
-1 / \mathrm{f} & 1
\end{array}\right] \cdot\left[\begin{array}{cc}
1 & \mathrm{~L}_{1} \\
0 & 1
\end{array}\right] \cdot\left[\begin{array}{c}
\mathrm{r}_{1} \\
\theta_{1}
\end{array}\right]
$$

em que o primeiro termo do lado direito da equação corresponde à matriz do espaço livre entre o cristal e a câmera, o segundo termo é a matriz característica de uma lente e o terceiro termo é matriz do espaço livre entre a posição inicial do feixe de He-Ne e o cristal. A partir da equação 81 , chega-se à equação 82 , que fornece a distância focal da lente térmica em função do raio do feixe de He-Ne no cristal $\left(r_{1}{ }^{\prime}\right)$ e da diferença entre o raio do feixe em $L_{2}$ na ausência ( $\left.r_{2}{ }^{\prime}\right)$ e na presença de bombeamento $\left(r_{2}\right)$.

$$
\mathrm{f}=\frac{\mathrm{L}_{2} \cdot \mathrm{r}_{1}{ }^{\prime}}{\mathrm{r}_{2}{ }^{\prime}-\mathrm{r}_{2}}
$$

Na montagem experimental, o feixe de He-Ne possuía um raio ( $\left.\mathrm{r}_{1}{ }^{\prime}\right)$ de $500 \mu \mathrm{m}$ sobre o cristal. A câmera foi posicionada a uma distância $L_{2}$ de $47,5 \mathrm{~cm}$ do cristal e a 
variação do feixe de He-Ne com o bombeamento foi obtida por meio da subtração entre o raio do feixe medido antes e após o bombeamento com o diodo operando a $21 \mathrm{~W}$ em regime pulsado com ciclo útil de $7 \%$, tal como foi empregado nos procedimentos experimentais durante a montagem das cavidades. Os resultados obtidos podem ser vistos na figura 42 para diversas posições na direção horizontal da face de bombeamento.

Em frente à câmera foi posicionado um filtro para barrar a passagem do laser, mas permitir a transmissão do He-Ne. Também foi utilizado um polarizador para eliminar a separação do feixe devido à birrefringência, permitindo somente a passagem da polarização $\sigma$, que corresponde à polarização do laser.

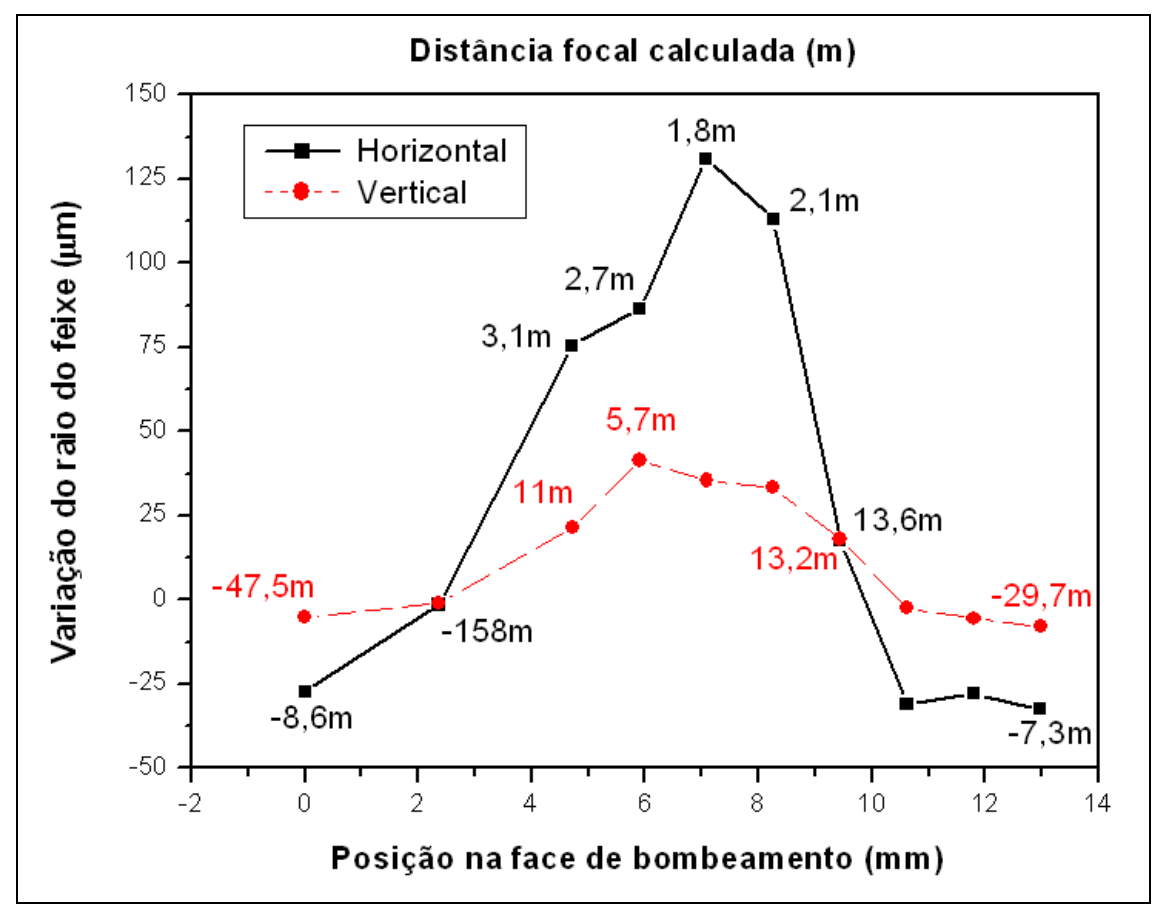

FIGURA 42: Diferença entre o raio do feixe de He-Ne antes e após o bombeamento ( $\left.\mathbf{r}_{2}{ }^{\prime}-\mathbf{r}_{2}\right)$, em virtude da lente térmica. Os valores sobre a curva indicam a distância focal calculada.

De acordo com os resultados mostrados na figura 42, é possível constatar que a lente térmica induzida varia de acordo com a posição analisada na face de bombeamento. Dentro da região de bombeamento, que possui cerca de $4,3 \mathrm{~mm}$ de largura, o feixe de HeNe sofreu uma contração (focalização) com o acionamento do bombeamento, sendo que a contração máxima se encontra no centro da região de bombeamento. Assim, de acordo com a equação 82, dentro desta região, a lente térmica do cristal apresenta um comportamento convergente com uma distância focal mínima de $1,8 \mathrm{~m}$ na horizontal e $5,7 \mathrm{~m}$ na vertical. Conforme o feixe foi sendo deslocado para fora da região de bombeamento, sua contração com o bombeamento foi diminuindo, de forma que a 
distância focal foi aumentando até apresentar um comportamento divergente próximo às bordas do cristal.

Como a deformação da face de bombeamento possui grande importância, ela foi medida separadamente da lente térmica, de forma similar à empregada anteriormente. Porém, o feixe de He-Ne foi incidido diretamente na face de bombeamento, como é mostrado na figura 43.

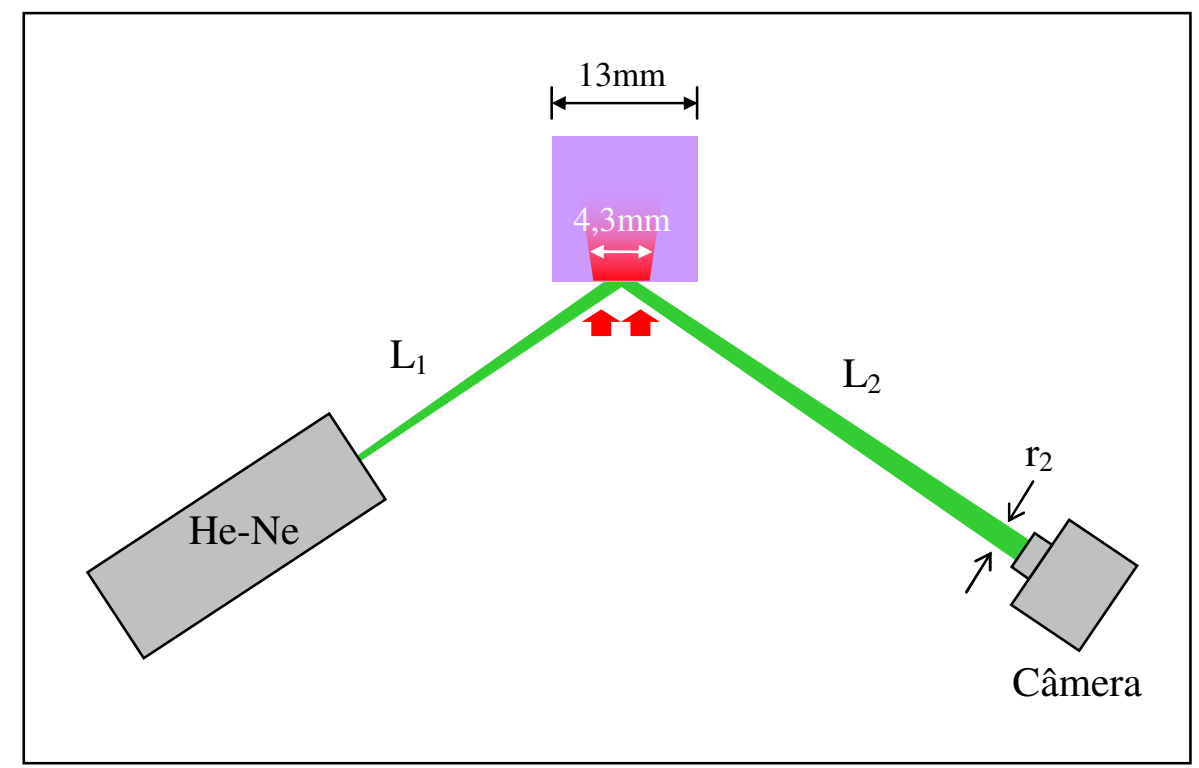

FIGURA 43: Arranjo experimental para a determinação do raio de curvatura da superfície de bombeamento.

Neste arranjo, a superfície de bombeamento funciona como um espelho curvo, desta forma o cálculo do seu raio de curvatura $\left(R_{c}\right)$ foi realizado utilizando a matriz característica para espelhos curvos, conforme mostrado na equação 83.

$$
\left[\begin{array}{l}
\mathrm{r}_{2} \\
\theta_{2}
\end{array}\right]=\left[\begin{array}{cc}
1 & \mathrm{~L}_{2} \\
0 & 1
\end{array}\right] \cdot\left[\begin{array}{cc}
1 & 0 \\
-2 / \mathrm{R}_{\mathrm{c}} & 1
\end{array}\right] \cdot\left[\begin{array}{cc}
1 & \mathrm{~L}_{1} \\
0 & 1
\end{array}\right] \cdot\left[\begin{array}{c}
\mathrm{r}_{1} \\
\theta_{1}
\end{array}\right]
$$

Assim, o raio de curvatura também é dado de acordo com a diferença entre o raio do feixe de $\mathrm{He}-\mathrm{Ne}$ na ausência e na presença do bombeamento, sendo $\mathrm{R}_{\mathrm{c}}>0$ para espelhos convexos.

$$
\mathrm{R}_{\mathrm{c}}=\frac{2 \mathrm{~L}_{2} \cdot \mathrm{r}_{1}{ }^{\prime}}{\mathrm{r}_{2}{ }^{\prime}-\mathrm{r}_{2}}
$$


Na montagem experimental, o feixe de He-Ne possuía um raio $\left(r_{1}{ }^{\prime}\right)$ de $450 \mu m$ sobre o cristal e a câmera foi posicionada a $10 \mathrm{~cm}$ do cristal $\left(\mathrm{L}_{2}\right)$. Similarmente, o raio do feixe de He-Ne foi medido antes e após o bombeamento com o diodo operando nas mesmas condições de $21 \mathrm{~W}$ e ciclo útil de $7 \%$.

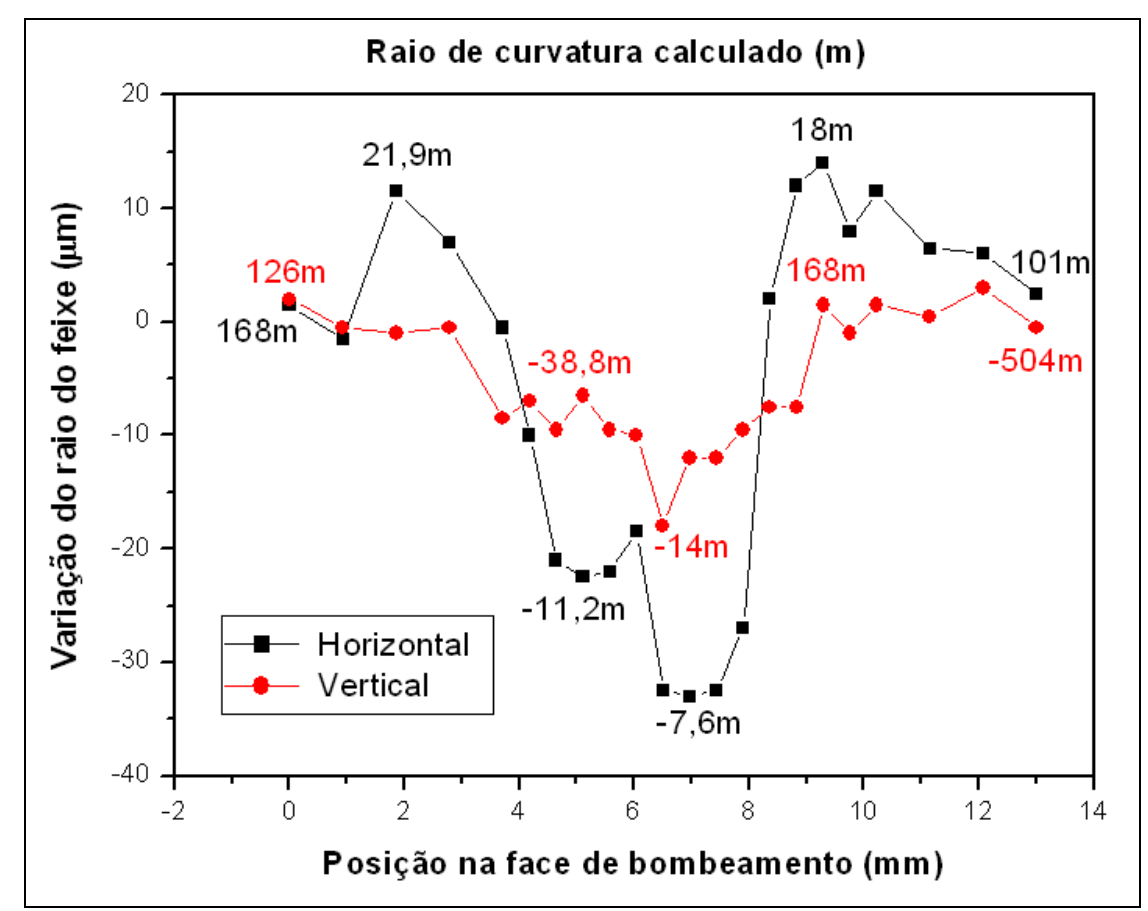

FIGURA 44: Diferença entre o raio do feixe de He-Ne antes e após o bombeamento $\left(r_{2}{ }^{\prime}-r_{2}\right)$, em virtude da curvatura da face de bombeamento. Os valores sobre a curva indicam o raio de curvatura calculado.

Os resultados mostrados na figura 44 indicam que, dentro da região de bombeamento (posições entre $4 \mathrm{~mm}$ e $8 \mathrm{~mm}$ ), o feixe de He-Ne sofreu expansão após o acionamento do bombeamento. Assim, esta região se deforma e funciona de maneira semelhante a um espelho convexo, aumentando a divergência do feixe. Também é possível observar uma mudança de comportamento com a presença de dois vales. Na posição próximo a $5 \mathrm{~mm}$, ocorria ação laser e a superfície apresentava um raio de curvatura com cerca de $-11,2 \mathrm{~m}$, segundo a equação 84 . Na posição em $7 \mathrm{~mm}$, ocorria bombeamento sem ação laser, apresentando um raio de curvatura mínimo de $-7,6 \mathrm{~m}$. Nas regiões laterais ao bombeamento, o feixe sofreu contração, de forma que a superfície apresentou um perfil côncavo com raio de curvatura com cerca de $21 \mathrm{~m}$. Nas bordas do cristal, longe da região de bombeamento, a superfície apresentava um perfil plano. 
11. APÊNDICE D - Produção Bibliográfica

\section{Artigo aceito para publicação:}

WETTER, N. U.; SOUSA, E. C.; CAMARGO, F. A.; RANIERI, I. M.; BALDOCHI, S. L. Efficient and compact diode-side-pumped Nd:YLF laser operating at $1053 \mathrm{~nm}$ with high beam quality. Journal of Optics A, Pure and Applied Optics, 2008.

\section{Artigo Completo publicado em periódico:}

SOUSA, E. C.; RANIERI, I. M.; BALDOCHI, S. L.; WETTER, N. U. Compact diodeside-pumped Nd:YLF laser with high beam quality. AIP Conference Proceedings, v. 992, p. 426-430, 2008.

Trabalhos completos publicados em anais de congressos:

SOUSA, E. C.; CAMARGO, F. A.; RANIERI, I. M.; BALDOCHI, S. L.; WETTER, N. U. CW operation of diode side pumped Nd:YLF laser. In: Encontro Nacional de Física da Matéria Condensada, 2007, São Lourenço/MG. Optics Technical Digest. São Paulo: Sociedade Brasileira de Física, 2007. p. 166-169.

SOUSA, E. C.; RANIERI, I. M.; BALDOCHI, S. L.; WETTER, N. U. TEM 00 mode efficiency enhancement in diode-side-pumped Nd:YLF laser. In: Encontro Nacional de Física da Matéria Condensada, 2008, Águas de Lindóia/SP. Optics Technical Digest. São Paulo: Sociedade Brasileira de Física, 2008.

\section{Resumos publicados em anais de congressos:}

SOUSA, E. C.; FERRARI, M. A.; CAMARGO, F. A.; WETTER, N. U.; RANIERI, I. M.; BALDOCHI, S. L. Compact diode side pumped Nd:YLF Laser with high beam quality. In: RIAO/OPTILAS, 2007, Campinas. RIAO/OPTILAS 2007, 2007. p. 53.

FERRARI, M. A.; SOUSA, E. C.; WETTER, N. U.; RANIERI, I. M.; BALDOCHI, S. L.; LANDULFO, E. High power, diode side-pumped Nd:YLF laser with a novel multiple pass ressonator. In: RIAO/OPTILAS, 2007. RIAO/OPTILAS 2007, 2007. p. 54. 


\section{REFER̂̂NCIAS BIBLIOGRÁFICAS}

[1] EISBERG, R.; RESNICK, R. Física quântica: átomos, moléculas, sólidos, núcleos e partículas. 2.ed. Rio de Janeiro: Editora Campus, 1983.

[2] KOECHNER, W. Solid-State Laser Engineering. 5 ed. Nova York: Editora Springer, 1999.

[3] SILFVAST, W.T. Laser Fundamentals. Nova York: Cambridge University Press, 1996.

[4] HECHT, E. Óptica. 2.ed. Editora Calouste Gulbenkian, 2002.

[5] KUBODERA, K.; OTSUKA, K. Single-transverse-mode $\mathrm{LiNdP}_{4} \mathrm{O}_{12}$ slab waveguide laser. Applied Physics, v. 50, p. 653-659, 1979.

[6] KUBODERA, K.; OTSUKA, K.; MIYAZAWA, S. Stable LiNdP $\mathrm{O}_{12}$ miniature laser. Appl. Opt., v. 18, p. 884-890, 1979.

[7] GRADSHTEYN, I. S. Table of integrals. 5. ed. San Francisco: Academic Press, 1996.

[8] Disponível em: < http://www.rp-photonics.com/laser_crystals_versus_glasses.html>. Acesso em: 27 jun. 2008.

[9] DIEKE, G. H.; CROSSWHITE, H. M. The spectra of the doubly and triply ionized rare earth. Appl. Opt., v. 2, n. 7, p. 675-686, 1963.

[10] MARTINS, T. S.; ISOLANI, P. C. Rare earths: industrial and biological applications. Quím. Nova, São Paulo, v. 28, n. 1, 2005 . Disponível em: <http://www.scielo.br/ scielo.php?script=sci_arttext\&pid=S0100-40422005000100020\&lng=en\&nrm=iso $>$. Acesso em: 15 mar. 2008.

[11] ATHERTON, L. J.; PAYNE, S. A.; BRANDLE, C. D. Oxide and Fluoride Laser Crystals. Annual Review of Materials Science, v. 23, p. 453-502, 1993.

[12] PFISTNER, C.; WEBER, R.; WEBER, H. P.; MERAZZI, S.; GRUBER, R. Thermal beam distortions in end-pumped Nd:YAG, Nd:GSGG, and Nd:YLF rods. J. Quantum Electron., v. 30, p. 1605-1615, 1994.

[13] BERNARD, J. E.; ALCOCK, A. J. High-efficiency diode-pumped Nd:YVO 4 slab laser. Opt. Lett., v. 18, p. 968, 1993.

[14] MINASSIAN, A.; THOMPSON, B.; DAMZEN, M. J. Ultrahigh-efficiency TEM 00 diode-side-pumped Nd:YVO 4 laser. Appl. Phys. B, v. 76, p. 341-343, 2003. 
[15] XIONG, Z.; LI, Z. G.; MOORE, N.; HUANG, W. L.; LIM, G. C. Detailed investigation of thermal effects in longitudinally diode-pumped $\mathrm{Nd}: \mathrm{YVO}_{4}$ lasers. J. Quantum Electron., v. 39, n. 8, p. 979-986, 2003.

[16] HENGLI, Z.; LI, D.; SHI, P.; DIART, R.; SHELL, A.; HAAS, C. R.; DU, K. Efficient, high power, Q-switched Nd:YLF slab laser end-pumped by diode stack. Opt. Commun., v. 250 p. 157-162, 2005.

[17] LI, D.; MA, Z.; HAAS, R.; SCHELL, A.; SIMON, J.; DIART, R.; SHI, P.; HU, P.; LOOSEN P.; DU, K. Diode-pumped efficient slab laser with two Nd:YLF crystals and second-harmonic generation by slab LBO. Opt. Lett., v. 32, p. 1272-1274, 2007.

[18] LI, Y.; WANG, Q.; ZHANG, S.; ZHANG, X.; LIU, Z.; JIANG, Z.; LIU, Z.; LI, S. A novel $\mathrm{La}_{3} \mathrm{Ga}_{5} \mathrm{SiO}_{14}$ electro-optic Q-switched Nd:LiYF (Nd:YLF) laser with a Cassegrain unstable cavity. Opt. Commun., v. 244, p. 333-338, 2005.

[19] GEERLING, G.; ROIDER, J.; SCHMIDT-ERFURT, U.; NAHEN, K.; EL-HIFNAWI, El-S.; LAQUA, H.; VOGEL A. Initial clinical experience with the picosecond Nd:YLF laser for intraocular therapeutic applications. Br. J. Ophthalmol.; v. 82, p. 504-509, 1998.

[20] Disponível em: <http://www.coherent.com/Lasers/index.cfm?fuseaction=show.page\& $\mathrm{ID}=1512 \& l o c=765>$. Acesso em: 17 mar. 2008.

[21] SPINHIRNE, J. D. Micro pulse lidar. IEEE Transactions on Geoscience and Remote Sensing, v. 31, n. 1, p. 48 - 55, 1993.

[22] BARNES, N. P.; STORM, M. E.; CROSS, P. L.; SKOLAUT JR., M. W.; Efficiency of Nd laser materials with laser diode pumping. J. Quantum Electron., v. 26, n. 3 p. 558-569, 1990.

[23] KAMINSKI, A. A. Crystalline lasers: physical processes and operating schemes. Boca Raton, Flórida: CRC Press, 1996.

[24] ZUEGEL, J. D.; SEKA, Wolf. Direct Measurements of ${ }^{4} \mathrm{I} 11_{12}$ Terminal-Level Lifetime in Nd:YLF. J. Quantum Electron., v. 31, n. 10, p. 1742-1746, 1995.

[25] MORRISON, G. R.; EBRAHIMZADEH, M.; RAE, C. F.; DUNN, M. H. Diodepumped, Q-switched, $1.321 \mu \mathrm{m} \mathrm{Nd}$ :YLF laser and its frequency doubling. Opt. Commun., v. 118 , p. 55-60, 1995.

[26] FLUCK, R.; ZHANG, G.; KELLER, U.; WEINGARTEN, K. J.; MOSER, M. Diodepumped passively mode-locked $1.3-\mu \mathrm{m} \mathrm{Nd}: \mathrm{YVO}_{4}$ and Nd:YLF lasers by use of semiconductor saturable absorbers. Opt. Lett., v. 21, n. 17, 1996.

[27] FREI B.; BALMER, J. E. 1053-nm-wavelength selection in a diode-laser-pumped Nd:YLF laser. Appl. Opt., v. 33, n. 30. p. 6942-6946, 1994.

[28] MURRAY, J. E. Pulsed gain and thermal lensing of Nd:LiYF. J. Quantum Electron., v. 19, n. 4, p. 488-491, 1983. 
[29] POLLNAU, M.; HARDMAN, P. J.; KERN, M. A.; CLARKSON, W. A.; HANNA, D. C. Upconversion-induced heat generation and thermal lensing in Nd:YLF and Nd:YAG. Phys. Rev. B, v. 58, p. 16076-16092, 1998.

[30] POLLAK, T. M.; WING, W. F., GRASSO, R. J.; CHICKLIS, E. P.; JENSSEN, H. P.; CW Laser Operation of Nd:YLF. J. Quantum Electron., v. 18, n. 2, p. 159-163, 1982.

[31] WEBER, M. J. Handbook of laser science and technology. v. 1. Boca Raton, Flórida: CRC Press, 1982.

[32] Disponível em: <http://www.casix.com/product/prod_cry_ndyvo4.html>. Acesso em: 04 jun. 2008.

[33] Disponível em: < http://www.foctek.net/products/crystals/Nd_GdVO4.htm>. Acesso em: 04 jun. 2008.

[34] TIDWELL, S. C.; SEAMANS, J. F.; HAMILTON, C. E.; MULLER, C. H.; LOWENTHAL, D. D. Efficient, $15 \mathrm{~W}$ output power, diode-end-pumped Nd:YAG laser. Opt. Lett., v. 16, p. 584-586, 1991.

[35] CLARKSON, W. A.; HANNA, D. C. Efficient Nd:YAG laser end pumped by a 20-W diode-laser bar. Opt. Lett., v. 21, n. 12, p. 869-871, 1996.

[36] CERULLO, G.; SILVESTRI, S.; MAGNI, V. High efficiency, $40 \mathrm{~W}$ cw Nd:YLF laser with large TEMoo mode. Opt. Commun., v. 93, p. 77-81, 1992.

[37] YAMAGUTCHI, S.; KOBAYASHI, T.; SAITO, Y.; CHIBA, K. Collimation of emissions from a high power multistripe laser-diode bar with a multiprism array coupling and focusing to a small spot. Opt. Lett., v. 20, p. 898-900, 1995.

[38] GRAF, T. H.; BALMER, J. E. High-power Nd:YLF laser end-pumped by a diodelaser bar. Opt. Lett., v. 18 p. 1317-1319, 1993.

[39] LEGER, J. R.; GOLTSOS, W.C. Geometrical transformation of linear diode-laser arrays for longitudinal pumping of solid-state lasers. J. Quantum. Electron., v. 28, p. 1088-1100, 1992.

[40] WETTER, N. U. Three-fold effective brightness increase of laser diode bar emission by assessment and correction of diode array curvature. Optics \& Laser Technology, v. 33, p. 181-187, 2001.

[41] ZEHETNER, J. Highly efficient diode-pumped elliptical mode Nd:YLF laser. Opt. Commun., v. 117, p. 273-276, 1995.

[42] Efficient, End-Pumped, 1053-nm Nd:YLF Laser. v. 74, p. 120-124, 1998.

Laboratory for Laser Energetic Review - University of Rochester. 
[43] EGGLESTON, J. M.; KANE, T. J.; KUHN, K.; UNTERNAHRER, J.; BYER, R. L. The Slab Geometry Laser-Part I: Theory. J. Quantum Electron., v. 20, p. 289- 301, 1984.

[44] RICHARDS, J.; MCINNES, A. Versatile, efficient, diode-pumped miniature slab laser. Opt. Lett., v. 20, p. 371-373, 1995.

[45] PIERRE, R. J. ST; MORDAUNT, D. W.; INJEYAN, H.; BERG, J. G.; HILYARD, R. C.; WEBER, M. E.; WICKHAM, M. G.; HARPOLE, G. M.; SENN, R. Diode Array Pumped Kilowatt Laser. J. Selec. Top. Quant. Electron., v. 3, p. 53-58, 1997.

[46] BAER, T. M.; HEAD, D. F.; GOODING, P.; KINTZ, G. J.; HUTCHINSON, S. Performance of diode-pumped Nd:YAG and Nd:YLF lasers in a tightly folded resonator configuration. J. Quantum Electron., v. 28, p. 1131-1138, 1992.

[47] DERGACHEV, A.; MOULTON, P.F. Short-pulse, high-repetition rate, high-power Nd:YLF MOPA system. In: ADVANCED SOLID STATE PHOTONICS MEETING, 2004. Disponível em: <http://www.qpeak.com/Papers/ASSP04/ASSP-2004-MOPA.pdf>. Acesso em: 13 mar. 2008.

[48] DERGACHEV, A.; FLINT, J. H.; ISYANOVA, Y.; PATI, B.; SLOBODTCHIKOV, E. V.; WALL, K. F.; MOULTON, P. F. Review of Multipass Slab Laser Systems. J. Selec. Top. Quant. Electron., v. 13, p. 647-660, 2007.

[49] MINASSIAN, A.; THOMPSON, B.; DAMZEN, M. J. High-power TEM 00 grazingincidence $\mathrm{Nd}: \mathrm{YVO}_{4}$ oscillators in single and multiple bounce configurations. Opt. Commun., v. 245, p. 295-300, 2005.

[50] SOUSA, E. C.; WETTER, N. U. Preparação e caracterização de cristais de YLF como meio ativo em lasers bombeados por diodo. In: XI SEMINÁRIO ANUAL PIBIC / II SEMNÁRIO ANUAL PROBIC, 2005, São Paulo. Livro resumo, 2005. v. 1, p. 29-30.

[51] FYNN, G. W.; POWELL, W. J. A. Cutting and polishing optical and eletronic materials. 2.ed. Bristol: Adam Hilger, 1988.

[52] SOUSA, E. C.; CAMARGO, F. A.; RANIERI, I. M.; BALDOCHI, S. L.; WETTER, N. U. CW operation of diode side pumped Nd:YLF laser. In: XXX ENCONTRO NACIONAL DE FÍSICA DA MATERIA CONDENSADA, 07-11 maio, 2007, São Lorenço/MG. Optics Technical Digest. São Paulo: Sociedade Brasileira de Física, 2007. p. 166-169.

[53] FOWLES, G. R. Introduction to Modern Optics. 2.ed. Nova York: Holt, Rinehart and Winston, 1975.

[54] SOUSA, E. C.; RANIERI, I. M.; WETTER, N. U. Caracterização de filmes finos antirefletores em cristais de YLF. In: $7^{\circ}$ SIMPÓSIO DE INICIAÇÃO CIENTÍFICA E TECNOLÓGICA, 2005, São Paulo. Boletim Técnico da Faculdade de Tecnologia de São Paulo, 2005. v. 19, p. 14-15. 
[55] AUERBACH, J. M.; SCHMITT, R. L. Diode-laser-pumped monolithic Nd:YLF laser operating at 1.053 mm. Opt. Lett., v. 16, n. 15, p. 1171-1173, 1991.

[56] FINDLAY, D.; CLAY, R. A. The measurement of internal losses in 4-level lasers. Appl. Lett., v. 20, n. 3. p. 277-278, 1966.

[57] JORGE, K. C. Novo método de caracterização de feixes laser utilizando espalhamento Rayleigh. 2004. Dissertação (Mestrado) - Instituto Tecnológico de Aeronáutica, São José dos Campos.

[58] INTERNATIONAL ORGANIZATION FOR STANDARDIZATION. Lasers and laser-related equipment - Test methods for laser beam parameters: beam widths, divergence angle and beam propagation factor. ISO, 2005. (ISO/11146).

[59] SIEGMAN, A.E.; SASNETT, M.W.; JOHNSTON, T.F., JR. Choice of clip levels for beam width measurements using knife-edge techniques. J. Quantum Electron., v. 27, n. 4, p. 1098-1104, 1991.

[60] CAMARGO, F. A.; WETTER, N. U. High power, good beam quality Nd:YVO 4 laser using a resonator with high extinction ratio for higher-order mode thresholds. In: $6^{\text {th }}$ IBERO-AMERICAN CONFERENCE ON OPTICS (RIAO) AND THE $9^{\text {th }}$ LATINAMERICAN MEETING ON OPTICS, LASERS AND APPLICATIONS (OPTILAS), 21 26 outubro, 2007, Campinas. AIP Conference Proceedings. Melville, NY: American Institute of Physics, 2008. v. 992, p. 420-425.

[61] ARMSTRONG, M.; ZHU, X.; GRACEWSKI, S.; MILLER, R. J. D. Development of a 25 W TEM diode-pumped Nd:YLF laser. Opt. Commun., v. 169, p. 141-148, 1999.

[62] KOGELNIK, H.; LI, T. Laser beams and resonators. Appl. Opt., v. 5, p. 1550, 1966.

[63] SIEGMAN, A. E. Lasers. Mill Valley: Univ. Science Books, 1986. 